NOTE TO USERS

This reproduction is the best copy available.

(B)

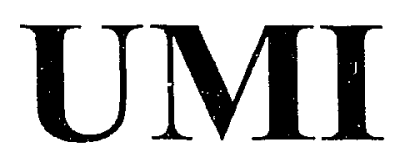

Reproduced with permission of the copyright owner. Further reproduction prohibited without permission. 
Reproduced with permission of the copyright owner. Further reproduction prohibited without permission. 


\title{
AN ASSESSMENT OF MUNICIPAL CAPACITY FOR Human-Wildlife Conflict Management in SELECTEd URBaN AREAS OF SOUTHERN ONTARIO
}

by

Stephanie Anne Kalt, BA (Hon., Bilingual)

University of Ottawa, Ontario. Canada, 2002

\author{
A thesis \\ presented to Ryerson University \\ in partial fulfillment of the \\ requirements for the degree of \\ Master of Applied Science \\ in the Program of \\ Environmental Applied Science and Management \\ $\therefore \quad$ Toronto, Ontario, Canada, 2004 \\ (C) Stephanie Kalt 2004
}

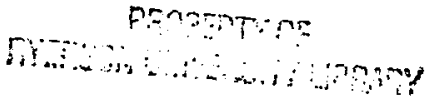

Reproduced with permission of the copyright owner. Further reproduction prohibited without permission. 
UMI Number: EC52954

\section{INFORMATION TO USERS}

The quality of this reproduction is dependent upon the quality of the copy submitted. Broken or indistinct print, colored or poor quality illustrations and photographs, print bleed-through, substandard margins, and improper alignment can adversely affect reproduction.

In the unlikely event that the author did not send a complete manuscript and there are missing pages, these will be noted. Also, if unauthorized copyright material had to be removed, a note will indicate the deletion.

(B)

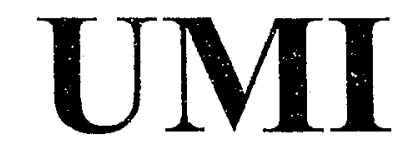

UMI Microform EC52954

Copyright 2008 by ProQuest LLC.

All rights reserved. This microform edition is protected against unauthorized copying under Title 17, United States Code.

ProQuest LLC

789 E. Eisenhower Parkway

PO Box 1346

Ann Arbor, MI 48106-1346 


\section{BORROWER'S PAGE:}

Ryerson University requires the signatures of all persons using or photocopying this thesis. Please sign below, and give address and date.

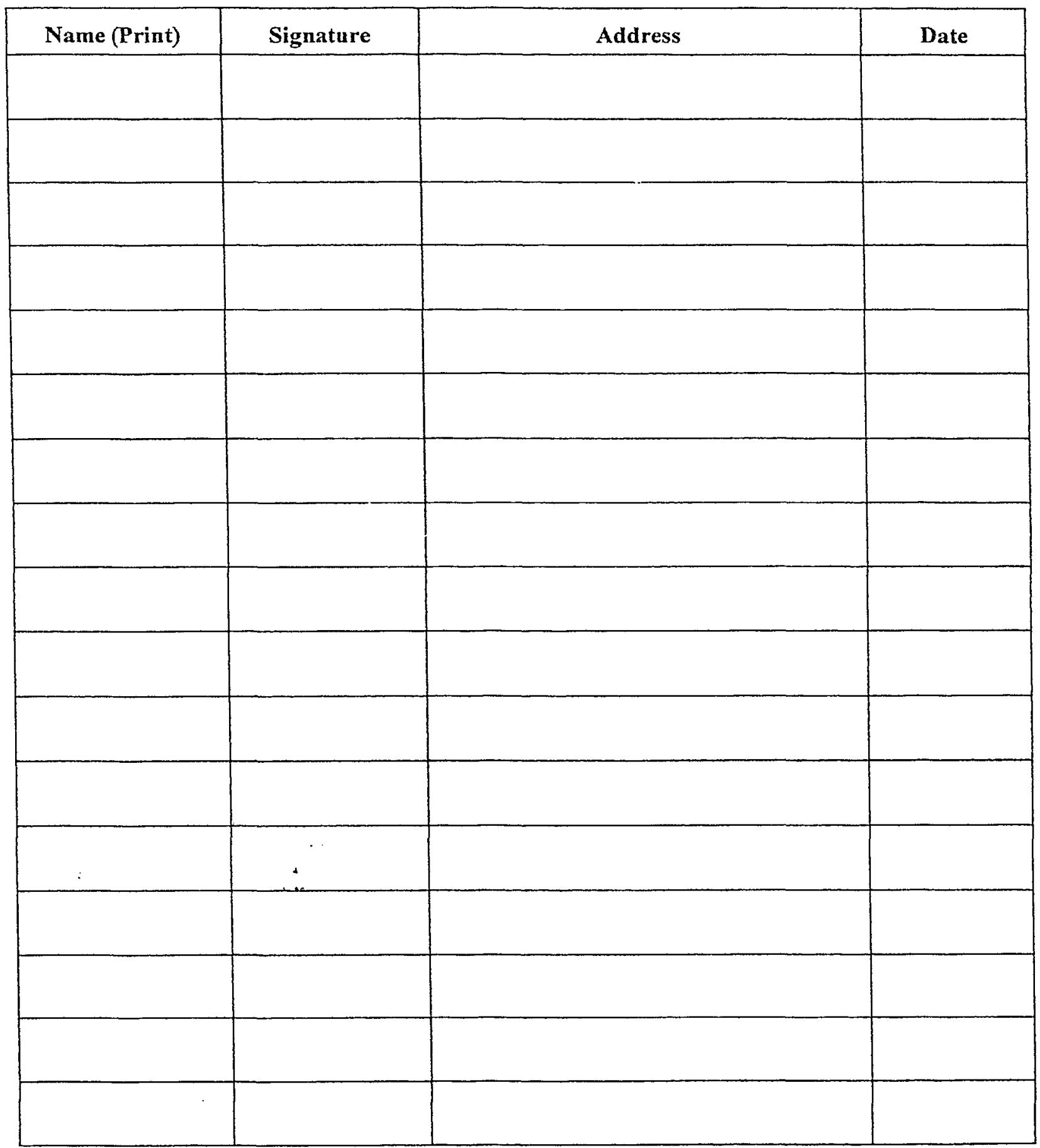

iii

Reproduced with permission of the copyright owner. Further reproduction prohibited without permission. 


\section{ABSTRACT \\ An Assessment of Municipal Capacity for Human-Wildlife Conflict Management in Selected Urban Areas of Southern Ontorio}

Stephanie Kalt, Master of Applied Science (2004)

in the program of Environmental Applied Science and Management

Ryerson University, Toronto

Recently, many Canadian municipalities have begun to experiment with urban raturalization programs. Consequently, many urban environments are now inhabited by a much larger wildlife population than they were several decades ago. The more species present in the city, the greater the potential for human-wildlife interaction and/or conflict. Current municipal capacity for human-wildlife conflict management is generally insufficient to deal with growing problems. New solutions for human-wildlife conflict are needed.

Using selected municipalities in southem Ontaric as an example, this thesis research explores the development and application of principles for human-wildlife conflict management in urban areas. A literature review, media analysis and interviews with key municipal stakeholders were used to identify best management practices. Recommendations for the development of integrated nuisance management (INM) systems are proposed based on study findings. 


\section{ACKNOWLEDGMENTS}

I would like to acknowledge the contribution of municipal staff from the City of Mississauga, City of Hamilton, City of London, City of Burlington, City of Guelph, City of Waterloo, and City of Ottawa as well as the contribution of staff from the Credit Valley Conservation Authority, the Hamilton Region Conservation Authority, the Upper Thames River Conservation Authority, Conservation Halton, and the Grand River Conservation Authority without whose assistance this thesis would not be possible.

I would also like to thank the staff at the Biodiversity Convention Office at Fnvironment Canada for their patience, support and valued use of resources.

Finally, I would like to express my gratitude to Dr. Beth Moore Milroy, for her supervision and respected guidance during the preparation of this thesis. 


\section{DEDICATION}

This thesis is dedicated to my family and friends for their love, support and debate skills. 


\section{TABLE OF CONTENTS}

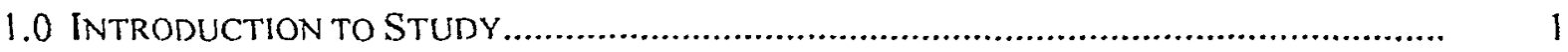

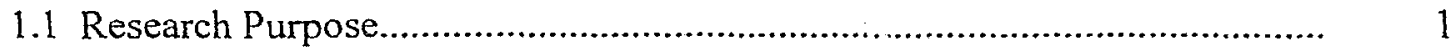

1.2 Study Background.............................................................................. 1

1.2.1 Why Study Urban Human-Wildlife Conflict Management?............ 1

1.2.2 Definition of Key Terms and Concepts..................................... 2

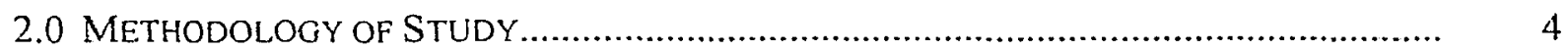

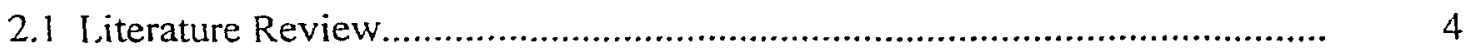

2.2 Media Monitoring............................................................................. 4

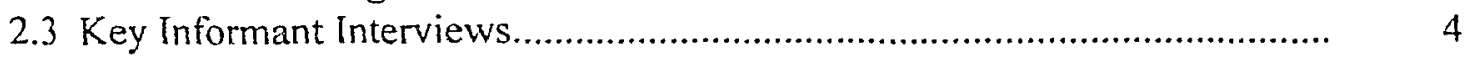

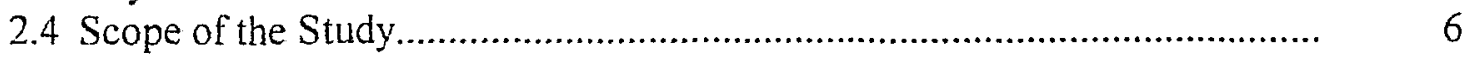

2.4.1 Gengraphic Scope................................................................ 6

2. +2 Selection of Municipalities for Study.................................... 7

2.4.3 Temporal Scope.................................................................. 9

3.0 Introduction to Naturalization \& Nuisance Management .......................... 10

3.1 Trends in Naturalization..................................................................... $\quad 10$

3.2 Nuisances and Naturalization............................................................ 11

3.3 Urban Human-Wildlife Conflict in the Media.......................................... 14

3.3.1 Methodology........................................................................ 14

3.3.2 Media Analysis.............................................................. 15

3.4 Municipal Human-Wildlife Conflict in Practice....................................... 19

3.4.1 .Jurisdictional Issues \& Legislation........................................... 19

3.4.2 Techniques for Wildlife Damage Management............................ 20

3.4 .3 The Need for a New Approach................................................. 23

4.0 Public Perceptions of Urban Human-Wildlife Conflicts ............................... 25

4.1 The Importance of Understanding Public Perceptions................................. 25

4.2 Public Perceptions of Wildlife Within Selected Municipalities..................... 25

4.3 Evaluating Public Perceptions of Wildlife............................................... 27

4.3.1 Tracking 'Nuisances' via Ecological Monitoring......................... 31

4.4 The Delivery and Impact of Public Education........................................... 32

4.4.1 Media. Print and On-line Resources.......................................... 33

t.t.2 Interpretive Programs.......................................................... 34

4. 4.3 Signage .......................................................................... $\quad 34$

t.t.t Suhdivision Agreements.................................................... 36

4.4.5 Public Education BMP: City of Mississauga............................ 37

4.5 Recommendations for Public Perceptions \& Education.............................. 40

Reproduced with permission of the copyright owner. Further reproduction prohibited without permission. 
5.0 MUNICIPAL CAPACITY FOR BIODIVERSITY SCIENCE \& INFORMATION........................ 41

5.1 The Need for Science and Information.................................................... 41

5.2 Science and Information in Selected Muricipalities..................................... 42

5.2.1 Watershed and Sub-watershed Studies........................................ 43

5.2 .2 Environmental Monitoring.................................................... 45

5.2.3 Biodiversity Science BMP: Community-Based Monitoring............ 47

5.2.4 Additional Monitoring Initiatives and the Need for Integration..... 49

5.2.5 Biodiversity \& Natural Area Inventories.................................... $\quad 50$

5.3 Recommendations for Biodiversity Science and Information....................... 56

6.0 PlanNING For NATURALIZATION AND CONFLICT MITIGation................................. 58

6.1 The Need for Enhanced Naturalization Planning.................................... 58

6.2 Naturalization Trends in Selected Municipalities...................................... 59

6.3 Criteria Used for Naturalization Planning .......................................... 61

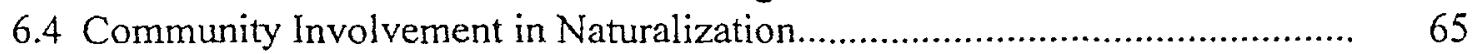

6.5 Proposed BMPs: Nuisances and Naturalization...................................... 68

6.5.1 Undertake a Strong Community Environmental Planning

Approach................................................................................ 68

6.5.2 Enhance Technical Considerations for Wildlife During

Naturalization.

6.5.3 Enhance Technical Considerations for Wildlife During

Development......................................................................... 71

6.5.4 Enhance Legislation and Encourage Environmental Compliance... $\quad 72$

6.5.5 Encourage Education on Naturalization.................................. $\quad 73$

6.6 Recommendations for Naturalization and Conflict Mitigation.................... 75

7.0 CONCIUSIONS AND RECOMMENDATIONS TO MUNICIPAI.ITIES................................. 76

7.1 Municipal Capacity for Human-Wildlife Conflict Management..................... 76

7.1.1 Public Perception of Nuisance Conflicts................................. 77

7.1.2 Biodiversity Science and Information...................................... 77

7.1.3 Nuisances and Naturalization........................................... $\quad 78$

7.2 Best Management Principles for Future Action......................................... 78

7.3 Recommendations for Integrated Management........................................ $\quad 80$

Recommendation 1: Create a Nuisance Management Working Group...... 80

Recommeñdation 2: Develop Integrated Nuisance Management (INM)

Plans.

Recommendation 3: Computerized maps of risk for human-wildlife

conflict.......................................................... 86

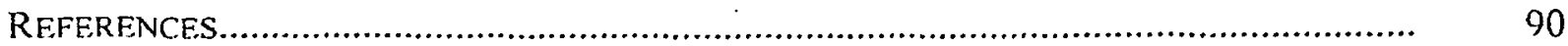

APPENDIX A - Urban Wildlife Management Study - Interview Questions........................ 99

A.PPENDIX B - Key Characteristics of the Six Municipalities Selected for Study................ 102

APPENDIX C - Annotated Bibliography of Articles Included in Media Analysis................. 107

viii 


\section{LIST OF TABLES}

Table 1: $\quad$ Criteria Selection of Municipalities for Further Study............................. 8

Table 2: $\quad$ Common Nuisance Species of Southwestern Ontario, Selected Examples.... 12

Table 3: $\quad$ Systems for Fvaluating Public Perceptions of Nuisances, Selected Municipalities............................................................................ 28

Table 4: $\quad$ Public Education Programs of Selected Municipalities, Focus on Wildlife.... 32

Table 5: Description of Municipal Interpretive Signage Programs, Selected Municipalities.

Table 6: Comparison of Education Material Distributed Under Subdivision Agreements, Selected Municipalities.................................................. 36

Table 7: Biodiversity Science Initiatives, Selected Municipalities......................... 43

Table 8: Examples of Terrestrial Monitoring Indicators, Selected Municipalities....... 45

Table 9: Characteristics of Biodiversity and Natural Areas Inventories (BNAI) Conducted by Selected Municipalities................................................. 53

Table 10: Naturalization and Regeneration Initiatives, City of Waterloo................... 60

Table 11: Naturalization Project Prioritization Methodology/Criteria, Selected Municipalities.

Table 12: Community Involvement in Naturalization per Project Phase, Selected Municipalities.

Table 13: Screening Criteria for Strategic INM Actions. 


\section{LIST OF FIGURES}

Figure : Geographical Scope of Study Area, Lake Erie Lowland............................ 6

Figure 2: $\quad$ Type of Nuisance Species Reported in the Media, Summer 2003.............. 16

Figure 3: $\quad$ Type of Nuisance Complaints Reported in the Media, Summer 2003......... 18

Figure 4: Spectrum of Public Perceptions of Wildlife........................................ 26

Figure 5: $\quad$ Trends in Wildlife Species Calls, Mississauga (1995-2002)...................... 29

Figure 6: Comparison of Urban Configurations for Wildlife Migration..................... 68

Figure 7: Human-Wildlife Conflict Management Spectrum, Options and Effects....... 79

Figure 8: Integrated Nuisance Management Programs, Design of Treatment

Strategies................................................................................... 85

Figure 9: GIS Configuration for Computerized Map of Risk for Human-Wildlife Conflict............................................................................... 88 


\section{LIST OF ACRONYMS}

$\begin{array}{ll}\text { ANSI - } & \text { Area of Natural and Scientific Interest } \\ \text { BMP - } & \text { Best Management Practice } \\ \text { BNAI - } & \text { Biodiversity and Natural Areas Inventory } \\ \text { CA - } & \text { Conservation Authority } \\ \text { CBI - } & \text { Canadian Biodiversity Institute } \\ \text { CBM - } & \text { Community-Based Monitoring } \\ \text { CFHS - } & \text { Canadian Federation of Humane Societies } \\ \text { CO - } & \text { Conservation Ontario } \\ \text { CVC - } & \text { Credit Valley Conservation } \\ \text { EC - } & \text { Environment Canada } \\ \text { EIS - } & \text { Environmental Impact Statement } \\ \text { ELC - } & \text { Ecological Land Classification } \\ \text { EMAN - } & \text { Ecological Monitoring and Assessment Network } \\ \text { ENGO - } & \text { Environmental Non-government Organization } \\ \text { FSA - } & \text { Environmentally Significant Area } \\ \text { ESP - } & \text { Environmental Strategic Plan } \\ \text { GIS - } & \text { Geographic Information System } \\ \text { GRCA - } & \text { Grand River Conservation Authority } \\ \text { HCA - } & \text { Hamilton Conservation Authority } \\ \text { HRCA - } & \text { Halton Region Conservation Authority } \\ \text { INM - } & \text { Integrated Nuisance Management } \\ \text { IPM - } & \text { Integrated Pest Management } \\ \text { KWS - } & \text { Kenya Wildlife Service } \\ \text { MDNR - } & \text { Maryland Department of Natural Resources } \\ \text { NAS - } & \text { Natural Area Survey } \\ \text { NGO - } & \text { Non-government Organization } \\ \text { OMAF - } & \text { Ontario Ministry of Agriculture and Food } \\ \text { OMNR - } & \text { Ontario Ministry of Natural Resources } \\ \text { OP - } & \text { Official Plan } \\ \text { OPIRG - } & \text { Ontario Public Interest Research Group } \\ \text { PEIL - } & \text { Planning \& Engineering Initiatives Ltd. } \\ \text { PHC - } & \text { Plant Health Care } \\ \text { TRCA - } & \text { Toronto Region Conservation Authority } \\ \text { UNAEES - } & \text { Urban Natural Area Environmental Evaluation Study } \\ \text { UTRCA - } & \text { Upper Thames River Conservation Authority } \\ \text { WHC - } & \text { Wildlife Habitat Canada } \\ \text { WNV - } & \text { West Nile Virus } \\ & \end{array}$

$\mathrm{xi}$ 


\subsection{INTRODUCTION}

\subsection{Research Purpose}

Using selected large municipalities in southern Ontario as an example, this research explores the development and application of principles for human-wildlife conflict management in urban ar:as in the face of expanded open space rehabilitation. The objective of the research is the development of principles for best management practices (BMP) through the identification of successes, failures and lessons learned by municipalities.

\subsection{BACKGROUND}

To enhance habitat opportunities for urban biodiversity, there has been a recent trend towards the integration of unused open space resources into the municipal land use system (Platt et al., 1994). However, the rehabilitation of urban open space resources has also created an inadvertent attractant and vector for the introduction of 'nuisance' species to urban areas that were previously uncolonized (Le Lay and Hubert-Moy, 2001; Pedroli et al., 2002).

As a result, human-wildife conflict management has recently emerged as a major concern for both urban planners and the sustainability of urban biodiversity. The complexity of the numerous socio-economic and ecological factors involved in these conflicts requires the development of a comprehensive tool for urban planners. "Unfortunately, there are [currently] no tools sufficiently adapted to the complexities of human-wildlife cohabitation in cities" (Le Lay and Hubert-Moy, 2001). Traditional techniques for nuisance species control that have been applied in rural areas are perceived as being less suitable to the urban environment (Messmer, 2000).

According to Messmer (2000), "[m]anagers must change their traditional emphasis from that of managing population to enhancing wildlife's societal values... Wildlife managers will also need to have a better understanding about how and why human-wildlife conflicts occur, the magnitude and public perceptions of the damage, and the strategies that can be implemented to address challenges posed by locally abundant wildlife populations". These are the important issues that are addressed by this thesis.

\subsubsection{Why study urban human-wildlife conflict management?}

While cities cover only about $0.2 \%$ of Canada's land area, it would be incorrect to argue that urban areas are irrelevant to the future of biodiversity in Canada. While the direct negative impact of urbanization on biodiversity requires no explanation, it is the indirect impact of urban areas as centres of economic and political power that may be of greater importance.

As cities encompass close to $80 \%$ of the Canadian population, most personal contacts with wild species occur in urban areas (Statcan, 2002). While more research is required to determine the linkage, if any, between exposure to wildlife in cities and decisions taken affecting biodiversity elsewhere in the country, some evidence suggests that personal exposure to nature in daily life is a 
major determinant of sensitivity to biodiversity issues (Middleton, 1994). Therefore, Canadian attitudes towards biodiversity and thus the future of biodiversity itself may be significantly affected by personal interactions with the wild species and ecosystems found in cities (Savard et al., 2000; WHC, 2001).

In addition, in certain cases, the success of urban biodiversity can be a significant factor in the survival of species in Canada (Middleton, 1994). For example, almost half of Canada's threatened and endangered species are located in Canada's most heavily urbanized region, the Quebec City - Windsor corridor (Bourdages and Labelle, 2000).

Therefore, if urban biodiversity is to be sustained, wildlife and people will need to learn how to successfully co-exist. The growing level of media attention being devoted to the issue suggests that this is not yet the case (see Section 3.3). Ironically, the positive increase in urban wildlife populations in response to protection has also adversely increased the level of human-wildlife conflict (Messmer, 2000; Fall and Jackson, 2002). In municipal open space rehabilitation projects, identifying urban nuisance species, where and why they are likely to occur are the first steps towards being able to predict, understand and resolve human-wildlife conflicts and ensure the success of urban biodiversity.

\subsubsection{Definition of Key Terms and Concepts}

The following definitions are considered to be essential to the development and understanding of this research.

\section{Urban Wildlife}

Urban wildlife includes all non-domesticated species within the urban area, whether native or nonnative, as well as both permanent and transient populations (Gibbs, 2001; WHC, 2001). While this definition includes both flora and fauna, the ability of fauna to actively interact with humans has made it the focus of the research.

\section{Nuisance Species}

There is no standard definition of 'nuisance' wildlife. The Ontario Ministry of Natural Resources only classifies wildlife as a nuisance "when an animal damages, or is about to damage, your property" (OMNR, 2003). However, this discounts the role of some wildlife species, for: example $e_{i}$ as a threat to human health and safety or as a source of biological noise pollution. Through the Federal Pest Control Products Act (2002), this definition of 'pest' is expanded to include any organism that poses a threat to resources, human health, and/or exists in an undesirable location.

For the purposes of this study, nuisance species are broadly defined as those that are involved in any real or perceived negative interactions between humans and urban wildlife (see Section 3.2 for specific examples). This is also the definition used to describe species in the field of humanwildlife conflict management (Messmer, 2000). 


\section{Conflict}

For the purposes of this study, a 'conflict' is defined as the result of negative interactions between humans and wildlife. Conflicts can be either real or perceived, and may lead to the need for action to reduce friction (Messmer, 2000). By contrast, wildlife contact involves all human-wildlife interactions, positive or negative. Thus, urban residents can have contact with nuisance species with or without the generation of conflict.

\section{Human-Wildlife Conflict Management}

According to Messmer (2000), "the phrase 'human-wildlife conflict management' has emerged to describe techniques and strategies that are being applied to manage all situations that involve any and all negative interactions between humans and wildlife". This can include a wide range of activities. For example, these techniques and strategies can be directed at wildlife management, involving both the direct and indirect management of species habitat and populations.

Conversely, these techniques and strategies can be directed at influencing human behaviour to help mitigate the frequency of conflicts and increase public tolerance of nuisance species.

Urban

A review of literature found that there is no single qualitative or quantitative definition of 'urban' that is used by either social or natural sciences (McIntyre et al., 2000). For the purposes of this study, an urban area is defined as a municipal-level political unit with a minimum total population of 100,000 people.

\section{Open Space}

An open space is defined as a "landscape unit (a) composed of plant and animal communities, water bodies, soil and rock, (b) largely devoid of man-made structures, (c) maintained and managed in such a way as to promote or enhance populations of wildlife" (Platt et al., 1994). This can include many types of urban habitat - managed parks, conservation areas, unused or abandoned developed lands, stream corridors, wetlands, forests and wildflower meadows are only a few examples.

Naturalization

Depending on an individual's professional background, the term 'naturalization' can have many different meanings. For the purposes of this study, naturalization will be broadly defined as the rehabilitation of natural areas, i.e. any active or passive procedure that targets the establishment, recovery or enhancement of ecological functions and processes of a natural area within the context of a disturbed landscape (Heaton et al,, 2002). In general, the goal of naturalization projects is to establish or re-establish an ecologically balanced landscape. 


\subsection{METHODOLOGY OF STUDY}

There are three research methods that have been applied to this Master's Degree Thesis -

1) literature review, 2) media monitoring, and 3) stakeholder interviews.

\subsection{LiteratURE REVIEW}

As with any research, a review of relevant literature formed the context for this study. The literature review focused on four key areas:

1. Nuisance species population identification, distribution, dynamics and behaviour;

2. Trends in urban open space rehabilitation, including the relationship between this practice and the (re)colonization of wildlife species;

3. Human-wildlife conflict management in urban areas, with a focus on understanding human perceptions and differing management philosophies and practices; and

4. The current practice of municipal open space planning and wildlife management in southern Ontario.

Academic texts, joumal articles, theses, and conference proceedings provided the information for the first three subject areas. However, the main focus of the literature review was a review of relevant documents produced by municipalities within the study area, identified through internet searches and during key informant interviews.

\subsection{MEdia MONITORING}

To supplement information collected during the literature review, a media monitoring exercise was conducted between May 1, 2003 and August 30, 2003. For this exercise, the identification of urban 'nuisance' species incidents that are reported by the media was used as a proxy for a public survey of the perception of urban wildlife conflicts in Canada. Media monitoring also assisted in the identification of majo: urban wildlife issues within the study area and possible models for human-wildlife management employed by municipalities across Canada.

The process undert 'en for the exercise as well as an analysis of the results of media monitoring are detailed further in Section 3.3.

\subsection{KEY INFORMANT INTERVIEWS}

Information collected during the literature review and media monitoring were used to form the basis for key informant interviews. Between January and April 2004, a total of 20 interviews were conducted with key staff from each selected municipality and Conservation Authority within the study area. This has allowed for a more in-depth examination of the current state of humanwildlife conflict management in southern Ontario, with insights into the perception and practice of wildlife conflict management as it varies among municipalities and among administrative divisions within municipalities. 
Open-ended interviews of relevant staff were conducted by telephone. Key informants to be interviewed were selected based on their professional connection to either municipal open space planning and/or wildlife management. For each municipality, this included at least one professional selected from the Planning Division and the Parks Division, as well as one as one relevant professional from the local Conservation Authority. Additional interview subjects were also contacted following the recommendation of interviewees.

Following the research protocol approved by the Ryerson University Human Ethics Review Board, initial contact with the subjects to be interviewed was made by standard mail. In addition to the study recruitment note, potential subjects were sent an information package that included a consent agreement and a copy of the questions that they would be asked to answer.

Subjects that agreed to participate were interviewed based on a set of pre-determined, openended questions (see Appendix A for complete set of questions). These interview questions were divided into four areas of interest:

A. Background Information - These questions related to the role that the interviewee and their department or division play in the municipality. The purpose of this section was to establish a context for the responses provided during the rest of the interview.

B. Public Perceptions of Nuisance Species - As detailed by Messmer (2000), one "approach that has been successfully used to manage human-wildlife conflicts involves changing the perceptions of people experiencing the damage by increasing their willingness to tolerate change". However, in order to effectively manage human-wildlife conflicts, the conflicts must first be understood. Questions in this section were designed to gauge how the residents and government of different municipalities view urban wildlife, and whether any programs are in place to evaluate and/or manage public perceptions of urban wildlife.

C. Biodiversity Science and Information - Planning for conservation is a process that uses scientific data. Experts have suggested that in order to preserve its biodiversity, at a minimum, a city must inventory its open spaces and ecological resources (Andrews and Cranmer-Byng, 1981; Inoguchi et al., 1999). For effective management, ecological data must be available to and be understood by not only decision-makers but also those who will be affected by the decisions being made (Theobald et al., 2000; EMAN, 2003). Questions in this section related to the type of biodiversity science and information that is maintained by each municipality, its uses and its accessibility.

D. Planning for Naturalization Projects - In recognition of its central importance to urban habitat conservation and diversification, there has been a recent trend towards the rehabilitation of rights-of-way, stream corridors, grass wastelands and many parks in urban areas across North America (Platt et al., 1994). However, significant planning is required to ensure that such projects result in sustainable improvements rather than further problems. In theory, many problems can be avoided if residents are informed of and/or are conferred a sense of local ownership and empowerment over rehabilitation projects (Caldecott, 1996; Beatley, 2000). Questions in this section relate to the nature of 
naturalization projects that have been undertaken in each municipality, including project design criteria and community response.

The exact order and precise wording of the open-ended questions was molded to suit the interview - the number and type of questions asked were directly related to the role that the interviewee played in their municipality. During the interview, the interviewees were also asked to identify and/or forward any relevant public documentation that they felt would be of use in furthering the study. This documentation has been used to supplement the literature review.

\subsection{SCOPE OF THE STUDY}

To add focus to the study, this research is delimited both geographically and temporally.

\subsubsection{Geographic Scope}

There are numerous cities in Canada that meet the definition of 'urban'. However, a comparison of municipal human-wildlife management capacity requires that an ecosystem-based approach be applied to ensure that the same general group of species is considered in each municipality. With approximately $10 \%$ of the Canadian population, the Lake Erie Lowland ecoregion is the most populated in Canada (EC, 1995). For this reason, it is the focus of this study.

The extent of the Lake Erie Lowland ecoregion, located within the Mixedwood Plains ecozone, is depicted in Figure 1.

Figure 1: Geographical Scope of Study Area, Lake Erie Lowland

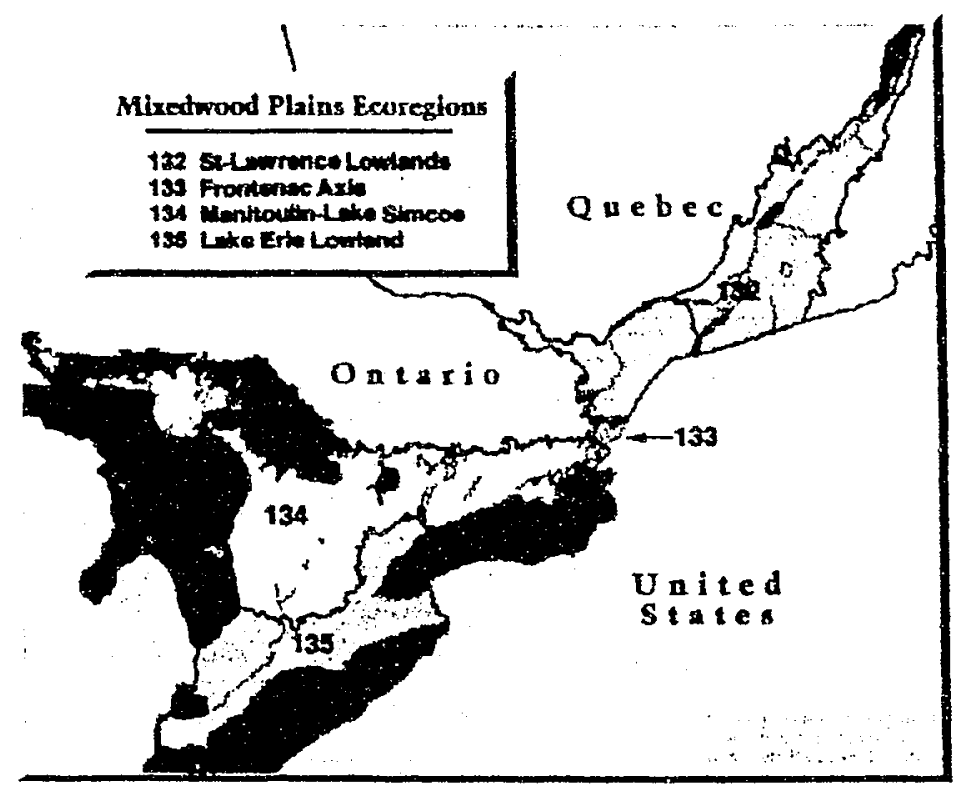

Source of Figure: EC, 1995 
An examination of census information produced by Statistics Canada found that there are currently 13 municipalities in the Lake Erie Lowland that meet the study definition of 'urban'. These are Toronto, Mississauga, Hamilton, London, Brampton, Markham, Windsor, Vaughan, Burlington, Oakville, Oshawa, Richmond Hill, and St. Catharines. Due to their proximity to the ecoregion and their relative importance as urban areas in southern Ontario, the municipalities of Kitchener, Waterloo and Guelph are also included in the study. ${ }^{1}$ This creates a total of 16 candidate urban study areas.

\subsubsection{Selection of Municipalities for Study}

From this list of candidate municipalities, a sample of six municipalities was selected for further study. This selection was performed for two reasons. First, the objective of the thesis is to document and assess the successes, failures and lessons learned on human-wildlife conflict management. As such, a strategic decision was made to narrow the scope in order to focus on those municipalities seen to be the most proactive in this area. In addition, it was determined that a narrowed scope would allow for a more accurate and meaningful analysis given the time allotted for the completion of the research.

Selection of the six cities to be studied began with a review of information and documents available through the municipal websites maintained by each of the 16 candidate municipalities, as well as those of their associated Conservation Authorities. Based on a preliminary review of online information, nine criteria were selected that would suggest proactive municipal action on the environment and/or urban wildlife management. These criteria are as follows:

1. Environmental Strategic Plan (ESP) - evidence of an ESP prepared or in development suggests proactive action on the environment. ESP may be general or issue-specific.

2. Environmental Advisory Committee (EAC) - evidence of the existence of such bodies suggests strong citizen involvement in the municipal decision-making process.

3. Greenspace and/or Biological Inventory (GBI) - evidence of biological studies suggests knowledge on biodiversity that may help plan land use within the municipality.

4. Naturalization Projects (NP) - evidence of successful or planned projects suggests creation of habitat and/or vectors for reintroduction of wildlife into urban areas.

5. Greenspace and/or wildlife considered in Official Plan (OP) - evidence of greenspace planning in the OP suggests proactive action on the environment. Note: for many urban areas, the text of the $\mathrm{OP}$ is often unavailable except by purchase from the municipality.

6. Nuisance Species (NS) - evidence that wildlife nuisances have been publicly identified suggests that the municipality has identified a problem which requires actiun.

\footnotetext{
'Though located in the Manitoulin-Lake Simcoe ecoregion, these cities share the same greater ecozone Mixedwood Plains - as the Lake Erie Lowlands and thus retain similar ecological characteristics.
} 
7. Reputation (Rep.) - evidence that the City has a reputation as an environmental leader suggests an extended history of proactive action on the environment. Reputation was assessed based on municipal claims and awards received.

8. Environmental Management Systems (EMS) - evidence of EMS adoption/creation, either general or issue-specific, suggests proactive environmental planning and management.

9. Public Awareness Campaigns (PAC) - evidence of PAC related to greenspaces and/or urban wildlife suggests proactive action on human-wildlife conflict management.

The results of this analysis are shown in Table 1. Based on intemet-based evidence, municipalities were assigned a score for each of the above criteria from 0 -1. A score of ' 1 ' indicates that there is definite evidence of significant effort on a particular criterion; a score of ' $0.5^{\prime}$ ' indicates that there is some evidence of efforts; and a score of ' 0 ' indicates that there is either no evidence of efforts or that the available evidence is inconclusive. The rank of each municipality was then calculated by the sum of the scores for each criterion, with each attribute given equal weight.

Table 1: Criteria Selection of Municipalities for Further Study

\begin{tabular}{|l|c|c|c|c|c|c|c|c|c|c|}
\hline \multirow{2}{*}{ City } & \multicolumn{9}{|c|}{ Criteria } \\
\cline { 2 - 11 } & ESP & EAC & GBI & NP & OP & NS & Rep. & EMS & PAC & SUM \\
\hline Toronto & - & - & -- & - & - & - & - & - & - & - \\
\hline Mississauga & 0.5 & 0.5 & 1 & 1 & 1 & 1 & 1 & 0 & 1 & 7.0 \\
\hline Hamilton & 0.5 & 0 & 1 & 1 & 1 & 0.5 & 1 & 0.5 & 1 & 6.5 \\
\hline London & 1 & 0.5 & 1 & 0.5 & 0.5 & 0.5 & 1 & 0 & 0.5 & 5.5 \\
\hline Brampton & 0 & 0 & 0 & 0 & 0.5 & 0.5 & 0 & 0 & 0.5 & 1.5 \\
\hline Markham & 0 & 1 & 0 & 0.5 & 0 & 0 & 0 & 0 & 0.5 & 2.0 \\
\hline Windsor & 0 & 1 & 0 & 0 & 0 & 0 & 0 & 0 & 0 & 1.0 \\
\hline Vaughan & 0 & 0 & 0.5 & 0.5 & 0.5 & 0 & 0 & 0 & 0.5 & 2.0 \\
\hline Burlington & 0.5 & 1 & 1 & 1 & 1 & 1 & 1 & 0 & 1 & 7.5 \\
\hline Oakville & 0.5 & 0 & 0.5 & 1 & 1 & 0.5 & 0.5 & 0 & 0 & 4.0 \\
\hline Oshawa & 0 & 0 & 0.5 & 1 & 0 & 0 & 0 & 0 & 0 & 1.5 \\
\hline Richmond Hill & 0.5 & 0 & 0 & 0.5 & 0.5 & 0.5 & 0 & 0 & 0.5 & 2.5 \\
\hline St. Catharines & 0.5 & 1 & 0 & 0.5 & 1 & 0.5 & 0.5 & 0 & 0.5 & 4.5 \\
\hline Kitchener & 1 & 1 & 0 & 0.5 & 0 & 0 & 0 & 0.5 & 0.5 & 3.5 \\
\hline Guelph & 1 & 1 & 0.5 & 1 & 1 & 0 & 1 & 0 & 1 & 6.5 \\
\hline Waterloo & 1 & 1 & 0.5 & 1 & 1 & 0.5 & 1 & 0.5 & 1 & 7.5 \\
\hline
\end{tabular}


There are several limitations to this method. First and foremost, this method is limited as the concept of providing information to stakeholders through the internet is relatively new at the municipal level and many municipal websites are still in the early phases of development. In addition, smaller municipalities often do not have the same level of resources available to devote to website maintenance as do larger municipalities. Therefore, a score of ' 0 ' in Table 1 does not necessarily indicate that no efforts exist to meet a given criterion, but rather that efforts in this area could not be substantiated based on the available internet resources. Consequently, the results of the website analysis may be skewed such that the six municipalities that received the highest total score may not in actuality be the most proactive. However, as reculting information is only being used for the purposes of scoping and sample selection, any limitations of the analysis are not expected to have a significant impact on the outcome of the overall study.

According to the analysis shown in Table 1, the following six municipalities are the most environmentally proactive major urban centres in southern Ontario: Burlington (7.5), Waterloo (7.5), Mississauga (7.0), Hamilton (6.5), Guelph (6.5), and London (5.5). The City of Toronto was eliminated from the analysis as it was assumed that, with more than twice the population of any other municipality in southern Ontario, the special management challenges that Toronto faces would not make it a suitable comparison given the purposes of this study.

To provide context to the analysis presented in this thesis, more detail on each of the six municipalities selected for study is found in Appendix B.

\subsubsection{Temporal Scope}

This study is only concerned with those municipal activities that have occurred in the past fifteen years, 1990-2004. During this period, there has been an increasing trend towards the rehabilitation of urban green space resources for the purposes of maximizing biodiversity (Platt et al., 1994; Sabloff, 2001). It is also during this period that urban human-wildlife conflict management began to emerge as an important area of knoviledge (Messmer, 2000).

While the recent amalgamation of several cities in southern Ontario may limit some results of the research, this limitation is considered to be unavoidable on a temporal scale. 


\subsection{INTRODUCTION TO NATURALIZATION \& NUISANCE MANAGEMENT}

The following section of this report is designed to provide more background on the issues that are important to a comprehensive understanding of the thesis topic. In general, this section will examine:

1. The recent trends in naturalization, i.e. why is it important and why now?;

2. The means by which naturalization and other urban developments encourage increased human-wildlife interactions, positive or negative; and

3. The results of the media analysis that explores Canadian perceptions of these urban wildlife interactions.

Following this review, this section will also provide a more specific overview of the current practice of urban human-wildlife conflict management in Ontario.

\subsection{TRENDS IN NATURALIZATION}

Cities are generally viewed as human-dominated landscapes that are detrimental to nature. However, within the past decade, there has been a broadening of public understanding of the value and functions of open spaces within urban areas (Kanter, 1990; Platt et al., 1994; Sabloff, 2001; WHC, 2001). Urban areas are now acquiring open spaces and, where possible, maintaining natural form in order to support a variety of initiatives that promote urban health and sustainability (Schauman and Salisbury, 1998).

Due to the rapid process of urbanization that has occurred in southern Ontario, many cities now need to be retrofit to include natural areas through a process of naturalization. Starting in the 1980 s, a number of municipalities in southern Ontario began to develop more formal naturalization policies and programs (Ingram et al., 2001). This makes not only sound ecological but also sound socio-economic sense. The following list, adapted from Hudson (2000), shows some of the benefits that municipalities can realize as a result of urban naturalization:

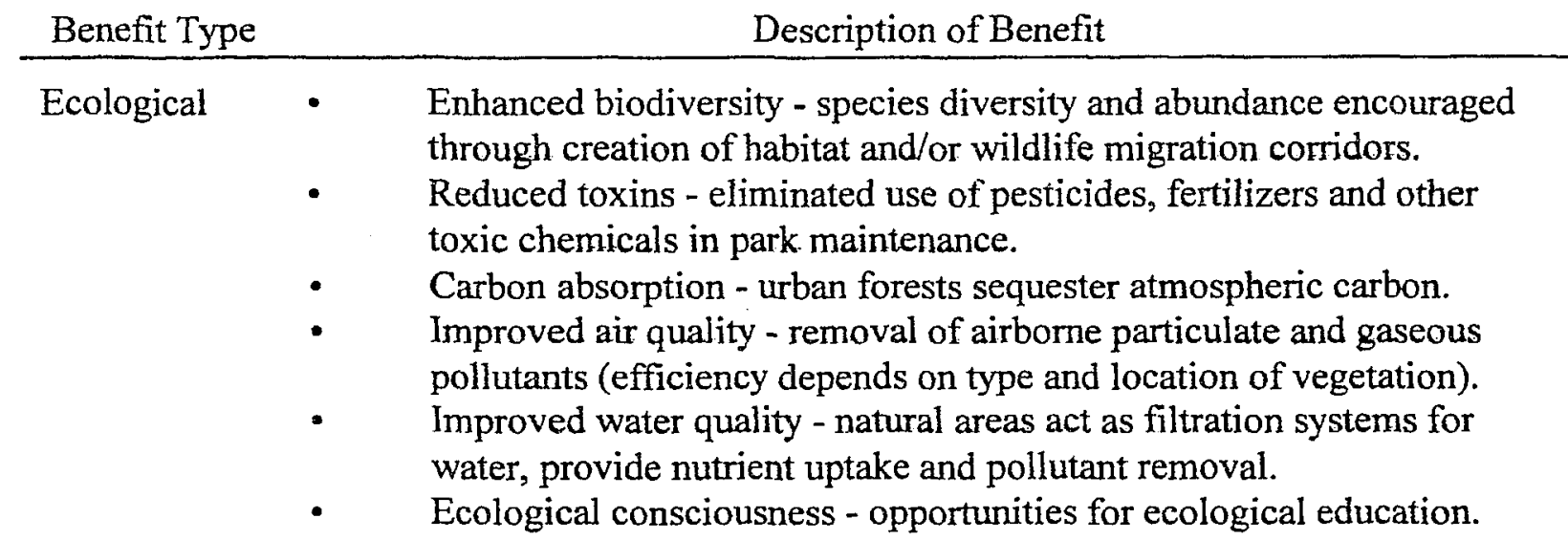




\begin{tabular}{|c|c|c|}
\hline Social/Human & • & $\begin{array}{l}\text { Community identity - anecdotal evidence suggests presence of nature } \\
\text { contributes to sense of community; source of community pride. } \\
\text { Community empowerment - naturalization projects act as focal points } \\
\text { for empowering local communities to enact social change. } \\
\text { Reduced crime - increased perception of safety; some studies have } \\
\text { shown lower levels of crime following urban naturalization. } \\
\text { Recreational opportunities - naturalized areas can meet both active and } \\
\text { passive recreational demands. } \\
\text { Physical health - improved air and water quality; health benefits of } \\
\text { exercise related to increased recreational opportunities. } \\
\text { Mental health - aesthetic value; research shows exposure to nature can } \\
\text { contribute to stress reduction. }\end{array}$ \\
\hline Economic & • & $\begin{array}{l}\text { Water management - porous natural surfaces absorb rainfall; reduced } \\
\text { volume of stormwater requiring municipal treatment. Also, vegetative } \\
\text { cover reduces magnitude of slope erosion and sedimentation problems. } \\
\text { Park maintenance - significant cost savings through reduced } \\
\text { maintenance; fewer chemical inputs and lower public water demands. } \\
\text { Property values - higher consumer willingness to pay for property in } \\
\text { proximity to the benefits of nature; results in strong municipal tax base. } \\
\text { Energy conservation - vegetation has moderating effect on } \\
\text { temperature; reduced need of energy for heating and cooling. }\end{array}$ \\
\hline
\end{tabular}

Most naturalization initiatives appear to be economically motivated, with municipal areas being naturalized when they become too costly to maintain or for the purposes of improved stormwater management (Flegel and Jacob, 1996; Platt et al., 1994). While the initial costs associated with a naturalization project may be high, once established, the low level of maintenance required to sustain the naturalized area can result in significant cost savings when compared to the alternative of continuing conventional horticultural practices (Guelph, 1993). Similarly, the water retention, filtration, erosion and sediment control services provided by natural areas can significantly defer the infrastructure costs associated with conventional stormwater treatment and flood control (Hudson, 2000). However, while economic benefits may be used as justification for undertaking a naturalization project, this does not undermine its clear ecological and social benefits.

The numerous applications of naturalization make it relevant to a wide range of municipal departments, including Planning, Parks and Recreation, Public Works, Environment, Public Health and Economic Development (Ingram et al., 2001). While municipalities support naturalization to lower maintenance costs and support community demands for passive recreation, developers have become interested in the ability of naturalization to increase local property values. The benefits of naturalization to stormwater management have also led Ontario's Conservation Authorities to be particularly active in this area.

\subsection{NUISANCES AND NATURALIzATION}

Throughout the past two decades, a major challenge for these municipal authorities has been determining how to integrate unused open space resources of the city into the land use system in 
order to maximize diversity (Platt et al., 1994). Despite the formal naturalization policies and programs that have been developed by municipalities, most naturalization projects remain relatively small in scale. While each individual land use change may result in a negligible impact, the accumulation of these changes over time within a landscape may be significant. Numerous small changes will eventually aggregate to enhance not only the environmental quality of a city but also the access and/or exposure to nature by its inhabitants (Schauman and Salisbury, 1998).

Through the improvement of habitat conditions and the creation of important migration corridors for wildlife, urban naturalization has indirectly had a positive impact on the abundance and overall health of urban wildlife populations (Fleury and Brown, 1997; Pedroli et al., 2002; Poole, 2003.06.14). Other species, such as the beaver and the coyote, are becoming increasingly well adapted to life in urban environments (Sabloff, 2001). Consequently, many urban environments are now inhabited by a much larger wildlife population than they were several decades ago (Messmer, 2000). However, despite attempts to create or enhance habitat, urban growth means that the space available to wildlife in the city is increasingly restricted (Poole, 2003.06.14). While most urban residents generally enjoy seeing wildlife, augmented exposure and negative experiences associated with locally overabundant wildlife populations are increasing public concern over these species.

Table 2 provides a list of species that are relatively common in urban and suburban areas of southern Ontario, their ecological or socio-economic benefits, and the theoretical nuisances they can create for city residents.

Table 2: Common Nuisance Species of Southern Ontario, Selected Examples

\begin{tabular}{|c|c|c|}
\hline Species & Benefits & 'Nuisances' \\
\hline $\begin{array}{l}\text { Bats } \\
\text { (various species) }\end{array}$ & Insect control; WNV & $\begin{array}{ll}\text { - } & \text { Roosting \& home invasion } \\
\text { - } & \text { Property damage } \\
\text { - } & \text { Rabies \& other diseases } \\
\end{array}$ \\
\hline $\begin{array}{l}\text { Beaver } \\
\text { (Castor canadensis) }\end{array}$ & $\begin{array}{ll}\text { - } & \text { Maintenance of water levels; } \\
\text { stabilized stream flow \& soil } \\
\text { erosion } \\
\text { - } \quad \text { Wetland habitat creation } \\
\text { - } \quad \text { National symbol } \\
\text { Furbearer }\end{array}$ & $\begin{array}{l}\text { Property damage - flooding } \\
\text { and urban tree destruction } \\
\text { Flood risk } \\
\text { - } \quad \text { Local overabundance }\end{array}$ \\
\hline $\begin{array}{l}\text { Chipmunk } \\
\text { (Tamias) }\end{array}$ & $\begin{array}{ll}- & \text { Seed dispersal } \\
- & \text { Entertainment }\end{array}$ & $\begin{array}{ll}- & \text { Property damage } \\
- & \text { Home invasion } \\
\text { - } & \text { Bird feeder competition }\end{array}$ \\
\hline $\begin{array}{l}\text { Coyote } \\
\text { (Canis latrans) }\end{array}$ & $\begin{array}{l}\text { Rodent \& small mammal } \\
\text { control } \\
\text { Symbol of ecological health }\end{array}$ & $\begin{array}{ll}\text { - } & \text { Physical threat - rare attacks } \\
\text { - } & \text { Rabies \& other diseases } \\
\text { Fear }\end{array}$ \\
\hline
\end{tabular}




\begin{tabular}{|c|c|c|}
\hline Species (con't.) & Benefits & 'Nuisances' \\
\hline $\begin{array}{l}\text { Eastern Grey Squirrel } \\
\text { (Sciurus carolinensis) }\end{array}$ & $\begin{array}{ll}- & \text { Seed dispersal } \\
\text { - } & \text { Entertainment }\end{array}$ & $\begin{array}{ll}- & \text { Property damage } \\
\text { - } & \text { Home invasion } \\
\text { Bird feeder competition }\end{array}$ \\
\hline $\begin{array}{l}\text { Raccoon } \\
\text { (Procyon lotor) }\end{array}$ & $\begin{array}{ll}- & \text { Rodent/insect control } \\
& \text { Furbearer }\end{array}$ & $\begin{array}{ll}- & \text { Property damage } \\
- & \text { Home invasion } \\
\text { - } & \text { Physical threat - rare attacks } \\
\text { - } & \text { Rabies \& other diseases } \\
\end{array}$ \\
\hline $\begin{array}{l}\text { Red Fox } \\
\text { (Vulpes vulpes) }\end{array}$ & $\begin{array}{ll}\text { - } & \text { Rodent/ small mammal control } \\
\text { - } & \text { Symbol of ecological health } \\
& \text { Furbearer }\end{array}$ & $\begin{array}{ll}\text { - } & \text { Rabies \& other diseases } \\
\text { - } & \text { Physical threat - rare attacks } \\
\text { Fear }\end{array}$ \\
\hline $\begin{array}{l}\text { Striped Skunk } \\
\text { (Mephitis mephitis) }\end{array}$ & $\begin{array}{ll}- & \text { Rodent \& insect control } \\
\text { - } & \text { Furbearer }\end{array}$ & $\begin{array}{ll}- & \text { Property damage } \\
- & \text { Home invasion } \\
- & \text { Rabies \& other diseases } \\
\text { - } & \text { Odour } \\
& \text { Vehicle collisions }\end{array}$ \\
\hline $\begin{array}{l}\text { White-tailed Deer } \\
\text { (Odocoileus virginianus) }\end{array}$ & $\begin{array}{l}\text { Symbol of ecological health } \\
\text { Meat/furbearer }\end{array}$ & $\begin{array}{ll}- & \text { Property damage } \\
- & \text { Vehicle collisions } \\
- & \text { Local overabundance } \\
- & \text { Lyme disease }\end{array}$ \\
\hline $\begin{array}{l}\text { Canada Goose } \\
\text { (Branta canadensis) }\end{array}$ & $\begin{array}{l}\text { National symbol } \\
\text { Migratory wetland species }\end{array}$ & $\begin{array}{ll}- & \text { Property damage } \\
- & \text { Physical threat - attacks } \\
\text { - } & \text { Disease \& water pollution } \\
- & \text { Local overabundance } \\
\text { - } & \text { Noise pollution } \\
& \text { Aircraft collisions }\end{array}$ \\
\hline $\begin{array}{l}\text { Herring Gull } \\
\text { (Larus argentatus) } \\
\& \\
\text { Ring-billed Gull } \\
\text { (Larus delowarensis) }\end{array}$ & $\begin{array}{l}\text { Migratory wetland species } \\
\text { Rodent control? }\end{array}$ & $\begin{array}{ll}\text { - } & \text { Roosting \& property damage } \\
\text { - } & \text { Physical threat - annoyance } \\
\text { - } & \text { Disease \& water pollution } \\
\text { - } & \text { Local overabundance } \\
\text { - } & \text { Noise pollution } \\
\end{array}$ \\
\hline $\begin{array}{l}\text { Other birds } \\
\text { (various species - } \\
\text { pigeon, starling, } \\
\text { crow, woodpecker, } \\
\text { etc.) }\end{array}$ & $\begin{array}{l}\text { Insect control } \\
\text { Some migratory species } \\
\text { Entertainment }\end{array}$ & $\begin{array}{l}\text { Roosting \& property damage } \\
\text { Disease - fecal droppings } \\
\text { Overabundance \& some alien } \\
\text { invasives } \\
\text { Noise pollution } \\
\end{array}$ \\
\hline $\begin{array}{l}\text { Other rodents } \\
\text { (various species - } \\
\text { mice, rats, voles, etc.) }\end{array}$ & Natural ecosystem functions & $\begin{array}{l}\text { Home invasion } \\
\text { Property damage } \\
\text { Disease vectors } \\
\text { Some alien invasive species }\end{array}$ \\
\hline $\begin{array}{l}\text { Other - general } \\
\text { (various species - } \\
\text { insects, weeds, etc.) }\end{array}$ & $\begin{array}{ll}- & \text { Natural ecosystem functions } \\
& \text { Pollination } \\
\text { - } & \text { Some 'weeds' = wildflowers }\end{array}$ & $\begin{array}{ll}- & \text { Allergies \& physical threat } \\
- & \text { Property damage } \\
\text { - } & \text { Home invasion }\end{array}$ \\
\hline
\end{tabular}

Sources: AAA, 2003; EC, 2003; CFHS, 2004 \& media monitor 
While, for example, skunks and raccoons are attracted to improperly stored waste, not all humanwildlife interactions that create nuisances are accidental. Recognizing the socio-economic benefits of urban wildlife, many residents of southern Ontario actively encourage wildlife interactions.

According to one study, urban residents spend an average of $\$ 60$ US and 22 hours each year trying to enhance neighbourhood wildlife populations (Messmer, 2000). The provision of backyard bird feeders and bath is draws not only a wide variety of birds, but also squirrels, chipmunks, mice, rats, and other species. However, as will be discussed in Section 4.2, residents often have a love-hate relationiship with these species. While people may encourage songbirds at feeders, they may not support the presence of larger birds (e.g. peregrine falcons) that would prey on the songbirds.

Naturalization projects have also been shown to directly and indirectly contribute to an increase in urban 'nuisances'. For example, despite the potential health, safety and even ecological concerns associated with coyotes in the city, naturalization managers in Toronto's Tommy Thompson Park have constructed den sites to make the park more attractive to coyotes (TRCA, 2000). This may be a benefit for the ecological balance of the park, but what about for city residents?

\subsection{Urban Human-Wildlife Conflict in the Media}

The previous section establishes a theoretical basis for concern over the increasing need for human-wildlife conflict management in urban areas. In order to justify the need for this study, one must also establish whether urban residents and/or municipal governments of southern Ontario perceive that there is a conflict between humans and wildlife that goes beyond the theoretical. However, the preliminary literature review revealed that no data are currently available to address this issue. In general, there is little research that has yet been done on human perception and appreciation of urban wildlife (Savard et al., 2000).

As a result, this thesis has used a daily media monitoring exercise as a proxy for a survey of public opinion on human-wildlife conflict. Studies have shown that, due to their wide audience, newspapers can act as a source of useful data on both urban wildlife and local attitudes towards it (Vuorisalo et al., 2001).

Conducted during the Summer 2003, this media monitoring exercise analyses the level of nuisance complaints through the identification of any urban 'nuisance' wildlife incidents that are reported by the media. Media monitoring has also assisted in the identification of possible human-wildlife management models and the perspectives on human-wildlife conflict of urban residents across Canada.

\subsubsection{Methodology}

Media monitoring was conducted using the 'Green in Sight' software available through the Environment Canada intranet, for the period of May 1, 2003 to August 30, 2003. This software provides access to a large number of large- and medium-sized newspapers from across Canada. The focus of the media monitoring exercise was the 'Wildlife' category of 'Green in Sight'.

The key words used to identify articles in the 'Wildlife' category of the media monitoring tool reflect the priorities of Environment Canada, and are therefore in constant flux. The following list 
outlines the major key words used during the Summer 2003, used both individually or in combination with another word (e.g. 'natural' and 'resources'). To help simplify the list, instances where several words can be derived from the same root are indicated by an asterisks (e.g., the root 'bio'”' could denote 'biodiversity', 'biological', 'biology', 'biologist', etc.).

Species:

$\begin{array}{ll}\text { - } & \text { Species } \\ \text { - } & \text { Animal(s) } \\ \text { - } & \text { Wild* } \\ \text { - } & \text { Bio* } \\ \text { - } & \text { Dird(s) } \\ \text { - } & \text { Coyote(s) } \\ \text { - } & \text { Snake(s) } \\ \text { - } & \text { Moose } \\ \text { - } & \text { Golf/wolves } \\ \text { - } & \text { Boose/Geese } \\ \text { - } & \text { Bearer(s) } \\ \text { - } & \text { Mosquito(s) } \\ \text { - } & \text { Bat(s) } \\ \text { - } & \text { Skunk(s) } \\ \text { - } & \text { Turtle(s) } \\ \text { - } & \text { Cougar(s) } \\ \text { - } & \text { Flora/fauna } \\ & \text { Plant(s) }\end{array}$

Environment: Issues:

-

Environment*
Habitat(s)
Wetland(s)
Forest*
Park(land)
Open Space
Green space
Vegetation
Wilderness
Ecosystem
Boreal

Carolinean

Migratory

Ecolog*

Water*

Natur*

$\begin{array}{lll}\text { - } & \text { Protect* } & \text { - } \\ \text { - } & \text { Threat* } & \text { Rare } \\ \text { - } & \text { Endanger* } & \text { - } \\ \text { - } & \text { Native } & \text { - } \\ \text { - } & \text { Alien/ } & \text { - } \\ & \text { invasive/ } & \text { exotic } \\ \text { - } & \text { Pesticide(s) } & \text { - } \\ \text { - } & \text { West Nile } & \text { - } \\ & \text { Virus } & \\ \text { - } & \text { Hunt* } \\ \text { - } & \text { Rabies } & \text { Disease(s) } \\ \text { - } & \text { Resource(s) } & \text { - } \\ \text { - } & \text { Animal Rights } & \text { - }\end{array}$

Administration:

In addition to the words found in the above list, the specific names of several government and non-government organizations are also included in the key word list of the media monitoring tool. This would include all federal departments and rnost provincial departments with an environinent or wildlife management role, as well as specific ENGOs.

\subsubsection{Media Analysis}

During the Summer 2003, there were approximately 148 articles reported by mid- to large-size newspapers across Canada that addressed the issue of 'nuisance' wildlife in urban areas. ${ }^{2}$ Close to $33 \%$ of these were published by newspapers within the study area of southern Ontario.

Figure 2 shows the distribution of the nuisance species which received the greatest number of media references in the Summer of 2003, with bears representing the greatest number of reports,

\footnotetext{
${ }^{2}$ Total does not include articles that were reported by more than one publication, i.e. no 'double-counting'. For reference, an annotated bibliography of all articles included in this analysis can be found in Appendix C.
} 
followed by white-tailed. d. $\quad$ rds, bats, coyotes, etc. Other species that received a passing mention in one or two articles are not integrated into Figure 2, but include: gophers, fox, squirrel, woodchuck, turtles, snakes, rabbit, ducks, wolf, ants and other bugs, rats, and feral cats.

Figure 2: Type of Nuisance Species Reported in the Media, Summer 2003

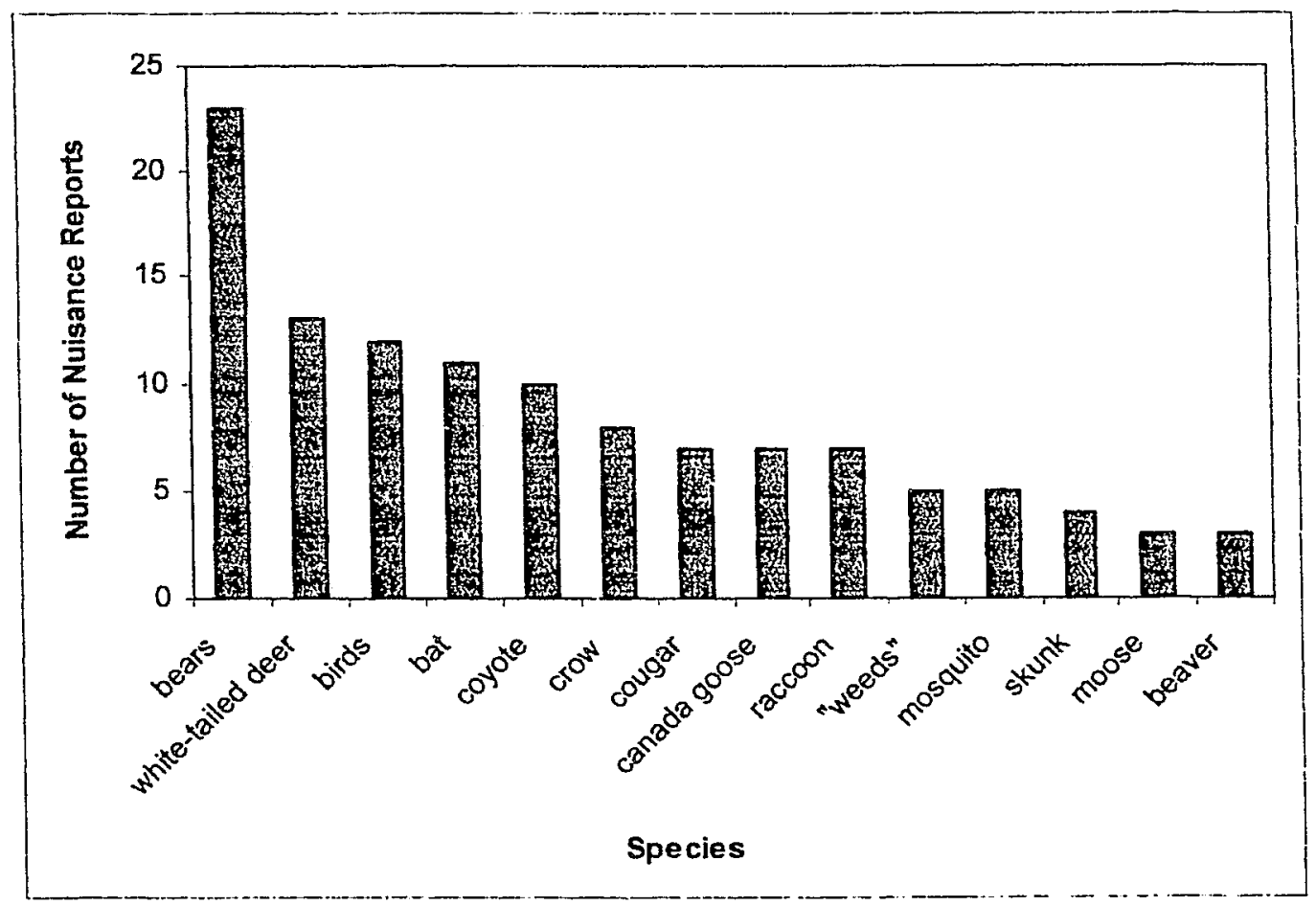

As can be seen, close: to $70 \%$ of all reports related to species commonly found within the study area. Notable exceptions are bears (black and grizzly), cougar, and moose. Unfortunately, it is not possible to compare this distribution to a Canada-wide or even Ontario-wide listing, as no such inventory exists. The Ontario Ministry of Natural Resources does not actively monitor urban wildlife unless species pose a significant economic or public safety concern (MacLeod, 2003.08.09). As discovered during key informant interviews, even on a City-wide level, most minicipalities have either no information or have only anecdotal information related to the distribution of nuisance species problems.

However, the types of species listed in fact sheets and other information materials intended as public education resources do suggest which species might be of greatest public concern and interest. Examples of species lists produced by organizations that operate in southern Ontario include:

- Canadian Federation of Humane Societies - lists raccoons, squirrels, pigeons, skunks, mice and rats as common urban wildlife problems (CFHS, 2004).

- Ontario Ministry Natural Resources - specific fact sheets on red foxes and bats, but also lists white-tailed deer, bears, raccoons and skunks as potential nuisances (OMNR, 2003). 
- Hamilton Conservation Authority - deer, raccoons, rabbits, woodpeckers, squirrels, skunks, rats and mice identified as some of the most common species to be encountered by those living in proximity to a natural area (HCA, 2002).

- City of Waterloo - raccoons, squirrel, skunks, rats, mice, groundhogs, muskrats, birds, bees, rabbits, foxes and deer identified as some of the most common urban species (Waterioo, 1998b).

- $\quad$ City of Mississauga - skunks, pigeons, waterfowl, coyotes, foxes, raccoons, squirrels and other rodents, and snakes identified as common urban species (Mississauga, 2003a).

- AAA Wildlife Control - provides educational fact sheets on raccoons, squirrels, skunk, and brown bats (AAA, 2003).

Clearly, there is some agreement between these lists and the species identified in Figure 2. However, the list of nuisances that has been created as a result of the media monitoring is void of any economic or ecological data, and thus does not necessarily reflect the true distribution of nuisances in Canada. This is because there are some problem species - such as mice - that are so common that they are generally no longer reported on as nuisances.

The species prominent in Figure 2 received more media attention as a result of some particular issues that arose during the Summer 2003. For example, bears (black and grizzly) have made the news as habitat change and the cancellation of the spring bear hunt in Ontario have resulted in increased conflicts with bears in semi-urban areas across Ontario and Canada. The large number of deer reports published during the Summer 2003 can mainly be attributed to a debate over management options for the overabundant deer population in the Sifton Bog of London, Ontario.

An increased public awareness related to West Nile Virus (WNV) also caused a probable spike in nuisance reports related to a number of species. Naturalization projects (especially those that involve wetlands or watersheds) have recently been the subject of increased media scrutiny related to their potential to attract mosquitos. Several municipalities across Canada also began to consider or to conduct a cull of the crow population, using their recugnized status as an indicator species for the spread of WNV as an excuse to reduce unrelated noise and other nuisance conflicts generated by crows. From these reports, it is clear that Canadians need more education regarding WNV and possible vectors for the spread of the disease.

Rabies is another disease which captured the attention of the media in 2003. Instances of raccoon rabies have increased dramatically since 1999, with the border regions of Ottawa, Oshawa and Niagara recognized as the prime 'danger zones'. As a result, Ontario launched a new $\$ 2 \mathrm{M}$ campaign to halt the spread of raccoon rabies in Ontario with a prime objective of stopping the spread of the disease into urban areas (Reguly, 2003.05.25). Similarly, while coyotes make up only a very small percent of Ontario's reported rabies cases, reports in Summer 2003 related to coyotes increased after a series of coyote attacks in Toronto parks. Reports related to bats increased at the end of the Summer 2003 when several bats tested positive for rabies near Hamilton and London. However, as bats are also closely tied to WNV via mosquito control, some attention has also been given to the concept of reestablishing native urban bat populations (e.g. through the adoption of urban 'bat houses') as a potential mosquito control measure. 
Yet other species - for example, birds and skunks - continue to receive media attention not related to any significant issue such as public health or safety, but rather due to an ongoing pubiic perception of them as 'muisances'. Figure 3 demonstrates the nature of nuisance complaints that were reported by the media in the Summer of 2003, and their distribution.

Figure 3: Type of Nuisance Complaints Reported in the Media, Summer 2003

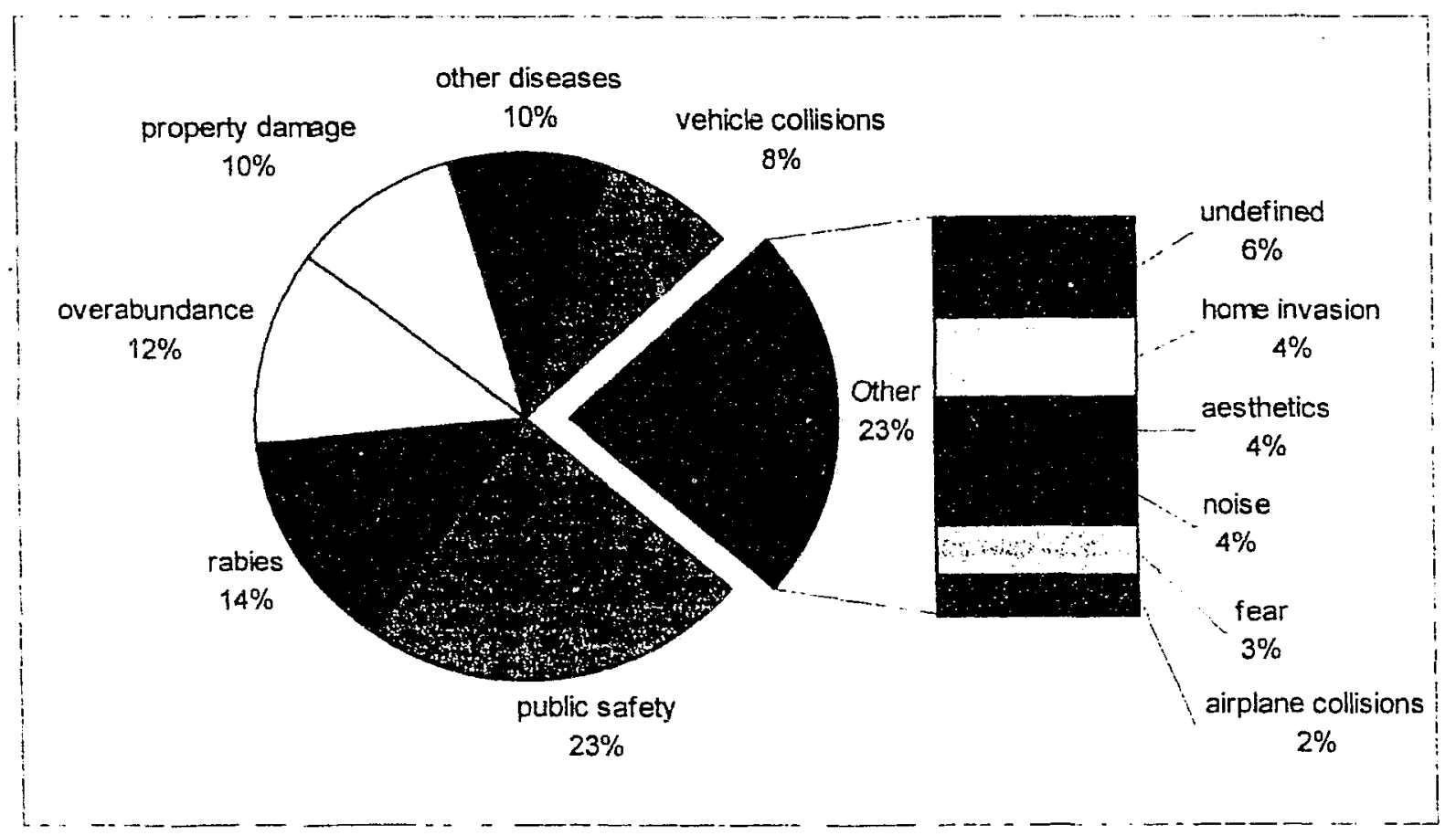

As can be seen, close to $60 \%$ of nuisance reports reference concerns for public health and safety. Most public safety concerns relate to the presence of large predators and other aggressive species (e.g. bears, coyotes, or even Canada geese), or to the potential for severe collisions. Important public health concerns include rabies, as well as emerging diseases (e.g. WNV) or those associated with overabundant animals and their feces.

Research performed in the United States suggests that the consequences of such wildlife incidents in urban areas can be significant. It is estimated that, on an annual basis, approximately 75,000 people are injured or taken ill and 415 people die because of wildlife related incidents in the United States. These figures include 28,000 people injured in vehicle collisions, 35,000 bitten by wildlife, and 12,000 who become ill because of other wildlife related diseases (Conover et al., 1998).

Apart from obvious threats to public health and safety, additional studies based on survey evidence also demonstrate the wide distribution of other real consequences that urban humanwildlife conflicts may present. As stated by Messmer (2000):

"[o]ver $60 \%$ of urban and suburban households in the US annually experience problems with wildlife... Urban households reported a mean loss of $\$ 63$ per household or a total loss of $\$ 1.9$ billion because of wildlife damage. Urban residents also reported spending over 260 million hours trying to solve or prevent these problems". 
The findings of studies such as these are also reflected in the results of the media monitoring exercise. Mentioned in approximately $22 \%$ of reports, concerns for property or other economic damage as a result of contact with wildlife received the second greatest number of references during the Summer 2003. Common complaints in this area include vehicle collisions, lawn and gardening conflicts, home "invasions" (i.e. presence/nesting of species in human structures), as well as a myriad of other problems. Canada geese may be the classic example of this in southern Ontario; having benefitted from the feeding opportunities they find in urban parks, beaches and golf courses and the relative lack of natural or human predators, urban populations of Canada geese have exploded. Managing problems associated with the overabundant geese - including. damage to lawns and beaches as a result of foraging and droppings, drinking water source fecal contamination, and collisions with vehicles and aircraft - can place a major economic strain on municipalities (EC, 2003; Oliviera, 2003.07.10).

Despite this potential for serious consequences, close to $17 \%$ of reports still identified species as a nuisance based on a perceived rather than a real conflict. Complaints in this category include noise, fear, aesthetics, and many other undefined reasons. While most urban residents derive numerous benefits from wildlife in the city, the mere presence of certain species (for example, skunks and snakes) is considered sufficient for them to be classified as a wildlife nuisance.

Although not shown in Figure 3, a small number of reports did emerge to highlight the positive aspects of and the need to co-exist with urban wildlife. In many cases, complaints regarding species overabundance include the threat of ecological damage amongst potential nuisances. This is also seen in the debate over the overabundant population of deer in the Sifton Bog, the Ontario bear hunt, and attempts to monitor and reduce the number of roadkills in urban areas.

\subsection{Municipal Human-Wildlife Conflict in Practice}

From the media analysis presented above, it is clear that there are several real and perceived human-wildlife conflicts that exist in the urbanized areas of southern Ontario. This is a fact that has been recognized not only by the public, but also by various levels of government. The following section provides a more specific overview of the current practice of urban humanwildlife conflict management in Ontario.

\subsubsection{Jurisdictional Issues and Legislation}

In Ontario, most wildlife matters are referred to the Ontario Ministry of Natural Resources (OMNR). The OMNR enforces the Fish and Wildlife Conservation Act (1997) which sets out the legal actions property owners can take, when they can take those actions, and the species of animal to which those actions apply. As outlined by the OMNR (2003), in general:

"Landowners, or an agent of the landowners may capiure, kill, or harass wildlife to stop it from damaging the landowner's property. There are some exceptions:

- Moose, caribou, elk or endangered species cannot be captured, killed or harassed in protection of property; 
- White-tailed deer cannot be captured, killed, or harassed unless you possess a Deer Removal Permit issued by the [OMNR];

- Unnecessary suffering cannot be caused to any wildlife;

- Bears killed in defence of property must be immediately reported to the local MNR office.

As well, specially protected raptors and furbearing mammals ${ }^{[3]}$ killed in defence of property and that an individual wishes to keep must be reported to the MNR within two working days."

Agents employed by the landowner to deal with nuisance wildlife must have authorization from the OMNR. In addition, a live-captured nuisance animal must, within 24 hours, be released in close proximity to where it was caught (up to a maximum of one kilometre), be turned over to an authorized wildlife custodian, or be humanely euthanized. However, the OMNR does not condone the killing of wildlife where other options might be available (OMNR, 2003).

Other federal and provincial legislation may also apply to the management of nuisance species in urban areas. In Ontario, where actions related to particular species are governed by both the Ontario Endangered Species Act (1990) and the Fish and Wildlife Conservation Act, the provision that affords the most protection prevails. Similarly, specific federal legislation gives Environment Canada jurisdiction over migratory birds, certain wetland species, and designated species at risk. For example, under the federal Migratory Birds Convention Act (1994), efforts to control locally overabundant Canada goose populations will require federal permits.

More than the legislation itself, of interest to this study is how the above noted legal requirements are applied on a local basis as well as the policies, procedures and municipal guidance that go beyond these legal requirements to create the overall urban wildlife management regime.

In most cases, the involvement of the OMNR is restricted to an advisory role. The OMNR will help landowners by providing information on animal biology and behaviour, animal control services and recommended best practices, appropriate animal control agency referrals, and information required to obtain permits where required. However, it is commonly understood that "landowners are responsible for managing nuisance animals on their properties including any costs" (OMNR, 2003). For urban residents, this means that the management of problems related to urban wildlife in southern Ontario is largely the responsibility of the individual or the municipality, most often in agreement with the local Conservation Authority. As will be seen, the techniques by which this is accomplished vary greatly both within and among municipalities. These techniques are likely to evolve as the science that supports human-wildlife management improves.

\subsubsection{Techniques for Wildlife Damage Management}

While the concept of managing wildlife damage is not new, "[ $[$ ]he continued growth of human populations and their expansion into new areas has increased the interface between humans and wildlife and added new dimensions to the... problem of human-wildlife conflict" (Fall and Jackson,

\footnotetext{
${ }^{3}$ Under the $A c t$, "furbearing mammals" include beaver, coyote, fox, raccoon, skunk, squirrel, etc. that have some economic value.
} 
2002). Wildlife damage has traditionally been thought of as a rural or agricultural problem, with damage control measures focused on reducing the economic losses caused by wildlife to crops and livestock (Messmer, 2000). However, as the nature and location of the conflict changes, so must the management techniques. Studies have shown that urban residents do not respond to wildlife problems and animal damage control in the same manner as rural residents ( $O$ 'Donnell and VanDruff, 1983). For example, concerns for public safety and property damage make traditional wildlife management techniques such as hunting and trapping unacceptable in urban areas. Additionally, there is a declining public tolerance of lethal methods of wildlife management (Fall and Jackson, 2002).

As urban decisions to control a particular wildlife species tend to depend more on public attitudes towards that species than actual damage, public perceptions will also limit the control measures employed (O'Donnell and VanDruff, 1983). Consequently, comprehensive solutions to urban and suburban human-wildlife conflicts are difficult as the control measures used must often be as specific as the actual problem.

Fortunately, there is a wide range of wildlife damage management techniques that exist and can be used in different situations with varying effectiveness. The general characteristics of the most frequently cited techniques are outlined below.

1. Habitat Management - Technique involves the modification of habitat through architectural or landscape design to make it less attractive to species causing nuisances. For example, increasing grass height will help deter nuisance geese and gulls that prefer large open areas with good visibility (Belant, 1997). Conversely, maintaining a mowed strip of grass around a property will deter the immigration of many rodents and snakes that prefer a large amount of cover (CFHS, 2004). Habitat management has a good success rate, but may not be feasible in naturalized areas.

2. Food Source Management - Technique involves the removal or containment of a food or water source that is attracting species causing nuisances. For example, the secure (i.e. animal-proot, disposal of residential garbage will significantly reduce conflicts with urban species looking for a free meal (CFHS, 2004). Again, this technique has a good success rate, but may not be feasible in naturalized areas.

3. Averse Conditioning - Technique involves the use of frightening devices to disperse resident nuisances and discourage species immigration. Common frightening devices that have been used with varying success include whistles, sirens, water sprays, predator decoys, dogs, falcons, lighting, flags, etc. However, the success of rate of this technique is limited as it is impractical in the long-term and as species can become habituated to the negative stimuli (Belant, 1997).

4. Exclusion - Technique involves the use of fencing and other devices to physically prevent or discourage the entry of species into specific areas. For example, overhead lines and netting are proven effective in excluding gulls and other birds from urban beaches (Belant, 1997). Wildlife-proofing of buildings involves little effort and is effective in discouraging home invasions. However, for large-scale nuisances, fencing programs are expensive to maintain and have been generally unsuccessful (London, 2003c). 
5. Repellents - Technique involves the use of tactile or other sensory repellants to deter wildlife. Planting garden species that are unappealing to or inedible by deer may help abate vegetation damage (London, 2003c). A wide variety of pesticides, insecticides and rodenticides are also available to repel wildlife. Besides being inhumane and/or environmentally hazardous, control by toxicants is limited in urban areas as it is illegal under the Criminal Code of Canada to place poison where it can be accessed by domestic animals (CFHS, 2004).

6. Capture, Removal and Relocation - Technique involves the live trapping, removal and relocation of individual nuisances. Live trapping, used most often to remove wildlife from buildings when an animal cannot be convinced to leave on their own, is best done by credible wildlife control operators to ensure that the animal is not injured in the process (AAA, 2003; CFHS, 2004). However, if not combined with other techniques, capture and removal is an ineffective solution as species tend to recolonize. Due to the poor success rate of relocated species and potential for the spread of disease, provincial regulations in Ontario prohibit the long-range (i.e. $>1 \mathrm{~km}$ ) relocation of most species of captured wildlife without a permit (OMNR, 2003).

7. Nest/Egg Disturbance - Technique involves the active management of the density of bird populations through the disturbance, removal or destruction of nests and/or eggs to suppress reproduction. Under the Migratory Birds Convention Act (1994), the use of this technique on migratory species such as Canada geese, ducks and gulls will require a federal permit.

8. Anti-Fertility Programs - Technique involves the active control of the density of certain large-scale nuisances through the suppression of reproduction by physical sterilization or birth control. Chemosterilization was one of the management options considered by the Sifton Bog White-tailed deer Steering Committee (London, 2003c). As this technique is still largely experimental, its effectiveness has not yet been proven.

9. Introduction of Natural Predators - Technique involves the passive control of the density of nuisances through the reintroduction of natural predators. The application of this option is limited as urban habitat is often insufficient to support many species of predator. The presence of predators in the city also creates concerns for the safety of the public and other non-target species (Belant, 1997; London, 2003c).

10. Lethal Methods - Technique involves all methods of active wildlife management that result in the death of wildlife species. This option includes many of the traditional wildlife management strategies, such as hunting, trapping and the use of lethal toxicants. Though in certain respects more humane, some of the other management options mentioned above (e.g. natural predation and nest disturbance) could also be considered lethal.

Amongst a wide variety of other less common and more experimental measures, the above mentioned techniques are aiso supplemented by the option to either do nothing or to manage the damage caused by the wildlife rather than the wildlife itself. For example, while the City of Calgary has not ruled out lethal measures to control a growing beaver population that threatens 
the City's urban forest, Toronto's beavers are being welcomed as part of the natural urban environment (Calgary, 1998; Toronto, 2001). Rather than attempt to control the density or location of its beaver population, the City of Toronto focuses its management efforts on the protection of urban forest resources by planting tree species that do not appeal to beavers and deterring harm to those that do (Toronto, 2001). However, it should be noted that the 'do nothing' approach is not the equivalent of ignoring a problem that creates real conflicts or risks.

\subsubsection{The Need for a New Approach}

Using urban beaver problems as one example, it is clear that municipalities are largely divided not only on how to manage, but also on what to manage. This is often because what is perceived as a nuisance to one person is a benefit to another. As a result, issues surrounding choice of methods often remain controversial and politically charged (Fall and Jackson, 2002). Furthermore, as naturalization and urban wildlife management is in many ways still in the experimental phase ${ }_{y}$ there is no guarantee that the methods selected will have wide-scale effectiveness.

While a variety of methods exist to deter nuisance wildlife, the basic method of eliminating food, shelter and water is proven effective for all species on a site-specific basis. However, the migratory and opportunistic nature of nuisance wildlife populations means that control activities that are effective at one site will rarely solve a nuisance problem across a larger management area. Uncoordinated management efforts may cause the relocation of the problem to surrounding areas (Bhat et al., 1996; Belant, 1997). Ironically, uncoordinated wildlife management may also encourage new nuisance species to immigrate into the controlled area to take advantage of reduced resource competition (Bhat et al., 1996). This is further aggravated by an ongoing trend toward the creation of continuity and linkages between natural areas that has been encouraged in southern Ontario, which - while ecologically beneficial - provides enhanced opportunities for wildlife migration (Kanter, 1990; Middleton, 1994).

Given this, studies have shown that the optimal management scenario for wildlife nuisances would be to have the control responsibility for human-wildlife conflict management of the entire problem area delegated to a single, centralized manager (Bhat et al., 1996; Belant, 1997). The utility of a centralized landscape approach, "integrating biodiversity issues into mainstream planning, is increasingly appreciated by municipalities... Unfortunately, the link from theory to practice is still very weak" (Middleton, 1994). There is also a growing public interest and participation in resource management decision-making that must be accounted for (Fall and Jackson, 2002). Without a recognized need for coordinated management, decisions regarding human-wildlife conflicts are taken at crisis points rather than at early stages when mitigative intervention and public participation are most effective, resulting in actions that are often extreme and confrontational (EMAN, 2003).

Unfortunately, even if management could be coordinated, current wildlife management techniques are not sufficiently adapted to the complexities of human-wildlife interactions in cities (Le Lay and Hubert-Moy, 2001). Some authors have suggested that a cartographic (i.e. GIS) approach is needed to integrate all the different components of human-wildlife interactions. This would allow urban wildlife managers to analyze the spatial distribution of and connections among humanwildlife interactions in the city, and to identify courses of action (Le Lay and Hubert-Moy, 2001). 
However, before any map layers can be drawn or decisions made, managers must have sufficient data on the various human and wildlife components of the conflicts. As will be shown, this type of information is currently lacking in many municipalities.

Due to the complexities of managing wildlife to control human-wildlife conflicts in urban areas, other authors suggest that urban wildlife managers "must change their traditional emphasis from that of managing population to enhancing wildlife's societal values" (Messmer, 2000). There is also an increased recognition that many human-wildlife conflicts can be resolved by managing the behaviour of individuals (e.g. encouraging residents to wildlife-proof their home and garbage) rather than the wildlife population itself (Savard, 2000; Fall and Jackson, 2002). Similarly, several studies have found that increased tolerance to urban wildlife is often directly related to the level of understanding that an individual has of the ecological role that particular species play in the urban environment (Hadidian, 1991; Gibbs, 2001). Understanding the public's perception, interest, values and knowledge of urban wildlife is key not only to effective public education programs but also to the selection of viable damage control options.

Based on the above discussion, there appears to be three basic things that any municipality can do to better manage human-wildlife conflicts:

1. Increase their knowledge of the magnitude and public perception of the conflicts;

2. Increase their knowledge of urban biodiversity, to address the ecology of conflicts; and

3. Use the information gained to better plan the location and landscape of urban natural areas and to enhance residents' willingness to tolerate damage.

The extent to which selected municipalities in southern Ontario have recognized the need for and/or have begun to implement these activities has been the focus of this study. The sections that follow assess the relative effectiveness of the current human-wildlife management regime established by the selected municipalities based on successes, failures and lessons learned. 


\subsection{PUBLIC PERCEPTIONS OF URBAN HUMAN-WILDLIFE CONFLICTS}

Based on testimony provided during interviews and municipal documentation, this section will explore public perceptions of wildlife in the six selected municipalities, how they are assessed by the municipality and what measures are being taken to positively influence residents tolerance for wildlife - i.e. public education.

\subsection{The Importance of Understanding Public Perceptions}

In 2001, WHC found that "[t]he extent to which urban areas act as wildlife habitats is a reflection of the human desire to be close to nature, as long as nature does not threaten or inconvenience them". While urbanites have a generally positive attitude towards wildlife, the tension between urban residents and urban wildlife is increasing. During the Summer 2003, barely a day passed without the reporting of a wildlife conflict incident in the media. This finding has also been supported by several other studies (Fall and Jackson, 2002).

An enhanced appreciation of the origin and dynamic nature of conflicts may provide valuable insights into potential management strategies that could be designed to increase wildlife's perceived societal value. The success of such solutions "will largely rest on the ability of the decision makers and managers to recognize, embrace, and incorporate different stakeholder values, attitudes and beliefs in the policy making process" (Messmer, 2000). However, this cannot be accomplished if public perceptions are not first assessed and understood.

\subsection{Public Perceptions of Wildlife Within Selected Municipalities}

Municipal staff from each of the selected municipalities were asked their professional opinion on how wildlife is perceived by residents within their jurisdiction (see Appendix A). According to those interviewed, urban residents in each of the selected municipalities would appear to apply similar terms in developing their perception of urban wildlife. As shown in Figure 4, most respondents described the relationship between people and wildlife as falling somewhere along a spectrum of benefits and nuisances. While perceptions generally tend toward the 'benefit' end of the spectrum, individual views range from complete tolerance to complete intolerance.

In most cases, the location of an individual along the spectrum will largely depend on (1) the nature and extent of their personal interactions with urban species; and (2) the degree to which the individual understands the role of native species in urban ecosystems. As a result, wildife managers in the selected municipalities have found that negative perceptions held by individuals being adversely impacted by wildlife can frequently be improved through the provision of basic information on the ecological value of that species in the urban environment. These findings reflect the results of previous survey-based research conducted in the United States and Canada (O'Donnell and VanDruff, 1983; Hadidian, 1991; Messmer, 2000). For example, Gibbs (2001) and Gommper (2002) have shown how residential concern regarding the presence of coyotes can be partially diffused by shifting community focus to the important role coyotes play in the control of other nuisances, such as small rodents. 


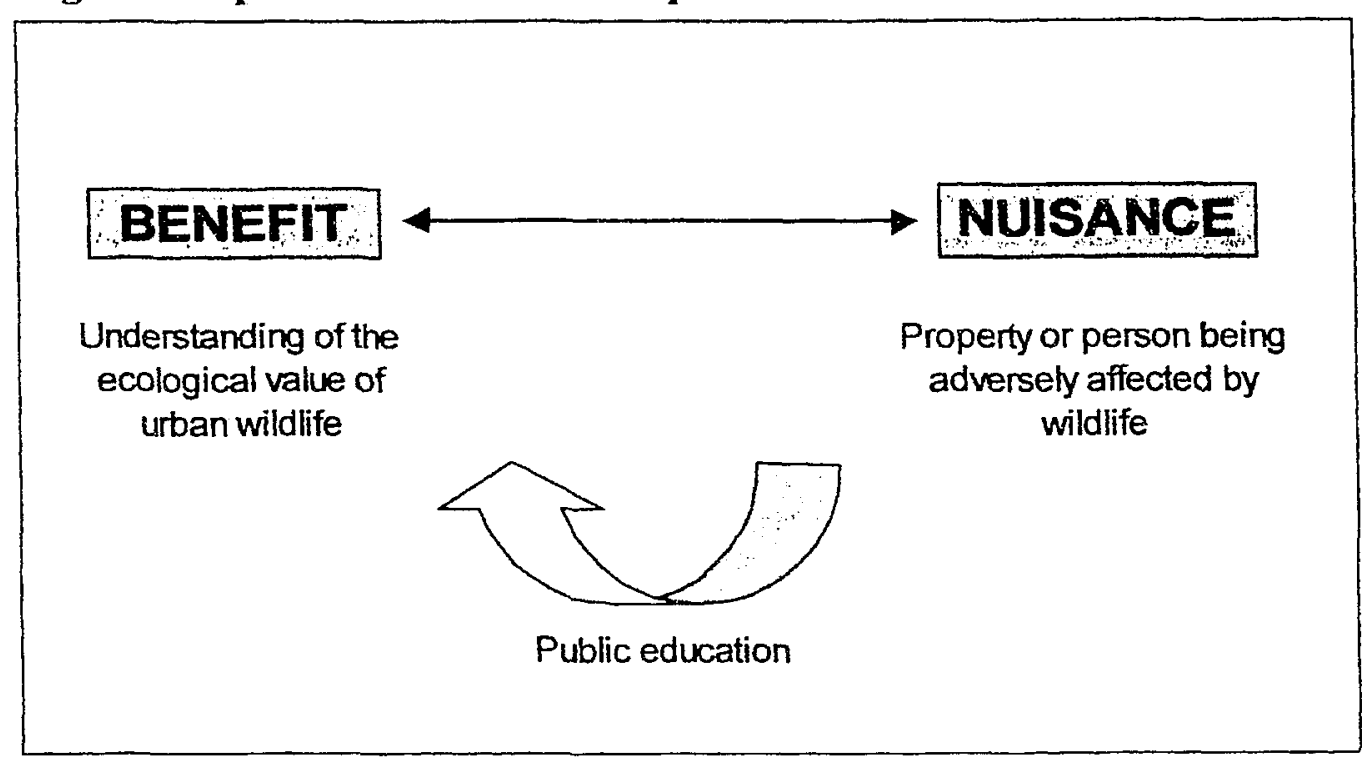

In addition to ecological education, respondents identified a need to raise awareness among residents about how human behaviour can create human-wildlife conflicts or aggravate existing problems. Simple actions such as leaving food outside for pets, improper use of a composter, or the improper storage of garbage may attract a whole host of nuisance species. Fortunately, these actions are also easily avoided. Larger conflicts arise when - due to differences in general perceptions or ecological understanding - residents disagree as to what constitutes a 'nuisance'. For instance, despite major conflicts with Canada geese on shorelines across southern Ontario, many individuals continue to inadvertently encourage nesting by feeding the resident goose population. Similarly, while excessive browsing by deer has been identified as a major concern in both the City of Hamilton and the City of London, many residents with property adjacent to natural areas continue to supply White-tailed deer with supplemental feed during the winter.

It is interesting to note that disagreement as to the nature and extent of nuisance problems is also common among municipal staff. While the ability of staff to identify areas of nuisance concern depends in part on their level of professional or personal exposure to community members that experience human-wildlife conflicts, inability to do so may suggest an important lack of intermunicipal communication. At a minimum, municipal staff whose decision-making has a direct influence on human-wildlife interactions should be aware of nuisance species in their City. This is particularly true in the case of open space planners, as the decisions that they make regarding the size, shape, location and landscape of natural habitats can have a large effect on both the immigration of urban species and the exposure of people to wildlife (Middleton, 1994; Johnson, 1995; Le Lay and Hubert-Moy, 2001; Fall and Jackson, 2002).

During interviews, it was found that most staff were generally aware of the major human-wildlife conflicts that exist in their municipality. Regardless, most municipal wildlife managers and open space planners disliked the use of the term 'nuisance' to describe urban wildlife, preferring to consider any native wildlife as a benefit to urban ecology. It is commonly held that "[ $t]$ he creatures with which we share our outdoor living space are not intruders, but co-inhabitants" 
(Pearman, 2004). However, most also conceded that in certain cases wildlife can create adverse situations. Unfortunately, compared to ecologists and other wildlife managers, open space planners tended to have a more peripheral knowledge of the issue. At one extreme, Park and Environmental Planners in Guelph asserted that human-wildlife conflict is not perceived as an issue in their municipality. This is in stark contrast to testimony provided by the staff of the Grand River Conservation Authority with responsibility for that area. ${ }^{4}$

Effective urban planning for wildlife co-existence may be further confounded by the actions of developers. Respondents noted that the perceptions of wildlife held by urban developers are often appreciably different than those of the individual resident. There is a strong potential for wildlife to create conflict for developers when it is identified as a significant landscape feature during the pre-development environmental assessment process. Despite this, developers are motivated to build in proximity to natural areas as this proximity to nature increases the value of residential lots. Municipalities tend to support this practice as (1) there are frequently few remaining alternatives for urban expansion and (2) increased property values translate into a stronger tax base (Hudson, 2000).

However, while living in proximity to nature will increase the frequency of positive interactions with wildlife, there is also the possibility that it will increase the frequency of negative interactions. For example, a community survey of deer browsing habits in an established residential area of London found that two-thirds of residents who experience conflicts with the deer had lots that backed directly onto a natural area (London, 2003c). Despite this, not all municipalities have yet recognized the importance of mitigating the negative wildlife interactions that may result from expanded residential development. Municipalities that have taken mitigative action commonly rely on two approaches - public education to increase residential tolerance for co-existence with nature and the creation of landscape buffers between the natural areas and development. These options will be discussed further in Section 4.4 and 6.5 respectively.

\subsection{Evaluating Public Perceptions of Wildlife}

From responses received as a result of inquiry under Section 4.2 , it is clear that wildlife and open space managers believe that they have a sound understanding of the public perceptions of wildlife in their municipality. However, as seen in Table 3 , there have been few actual attempts to assess these perceptions. Of the six municipalities examined, only the City of Mississauga was found to have a formalized system for monitoring residents' concerns regarding wildlife.

\footnotetext{
${ }^{4}$ Potential reasons for this discrepancy will be discussed further in Section 6.5.1.
} 
Table 3: Systems for Evaluating Public Perceptions of Nuisances, Selected Municipalities

\begin{tabular}{|c|c|c|c|c|}
\hline \multirow{2}{*}{ City } & \multicolumn{4}{|c|}{ Type of Evaluation } \\
\hline & $\begin{array}{c}\text { Informal } \\
\text { (Log of Calis) }\end{array}$ & $\begin{array}{l}\text { Ecological } \\
\text { Monitoring }\end{array}$ & $\begin{array}{l}\text { Nuisance } \\
\text { Specific }\end{array}$ & $\begin{array}{l}\text { Formal } \\
\text { System }\end{array}$ \\
\hline Hamilton & $\vartheta$ & $\checkmark$ & & \\
\hline Guelph & $\mathscr{O}$ & & & $\mathscr{O}$ \\
\hline Burlington & $\mathscr{O}$ & & & \\
\hline Mississauga & $\checkmark$ & $\checkmark$ & $\checkmark$ & $\checkmark$ \\
\hline Waterioo & & $\theta$ & & $\leadsto$ \\
\hline London & $\mathscr{O}$ & $\checkmark$ & $\checkmark$ & $\mathscr{\theta}$ \\
\hline
\end{tabular}

According to those interviewed, information on public perceptions of wildlife is derived from a. wide variety of sources. However, the actual evaluation of these perceptions was based primarily on anecdotal evidence or was extrapolated from other general environmental policy initiatives. For example, respondents that were the direct recipients of residential complaints stated that they keep an informal log of the number and nature of calls received related both to wildlife and the general management of open spaces. However, this information is of limited use as it is generally neither aggregated by the individual for monitoring purposes nor shared among City staff.

The exception to this is the City of Mississauga Animal Services Department where, since 1996, there has been a full-time staff member dedicated to the monitoring of residential nuisance species complaints received via telephone or e-mail. This enhanced coordination allows staff to aggregate data on an annual basis and generate statistics, effectively allowing the municipality to respond to questions concerning not only which species are involved in human-wildlife conflicts, but also where and when conflicts occur, and the nature of the problems that these species create. Access to aggregate information not only improves the ability of the municipality to react to residents' concerns on a timely basis but, as seen in Figure 5, this data is also useful for monitoring longterm trends in the effectiveness of nuisance management programs.

Mississauga currently maintains year-end statistics for the twelve most common urban nuisance species in the City, with all bird species combined into one general category. All other species are included in the data as 'miscellaneous'. Numerical data are also supported by detailed notes that help to explain possible causes behind fluctuations in the overall trends, such as weather patterns, instances of wildlife disease (i.e. rabies, mange, distemper, etc.), or media interest in an issue. 
Figure 5: Trends in Wildlife Species Calls, Mississauga (1995-2002)

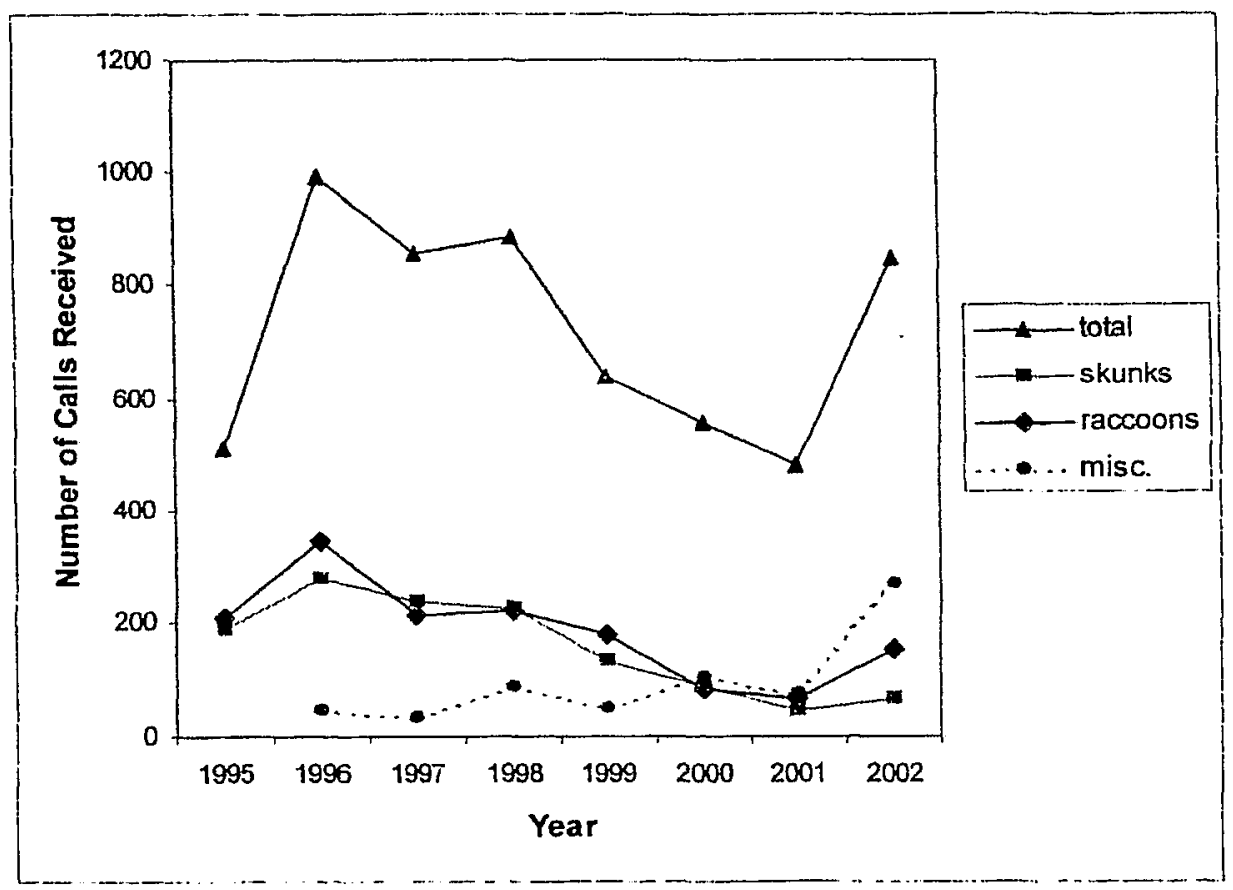

Source: Adapted from Mississauga, 2004

Figure 5 displays the overall trend in wildlife species calls reccived by Animal Services in Mississauga between 1995 and 2002, as well ais thid for the two most commonly reported species and the 'miscellaneous' grouping of species. As can be seen, there has been an overall decline in the total number of calls received. This decline is attributed by staff to an important shift in program delivery that was implemented in 1994 (see Section 4.4.5). Among all species being tracked, only the 'miscellaneous' category continues to show an upward trend in the number of calls received." This trend may suggest a need for Animal Services to amend its new system of program delivery in order to increase its effectiveness in addressing general nuisances. Conversely, it may be an indicator of the effectiveness of Animal Services recent initiatives to raise awareness of nuisance species management among residents.

Provided that decision-makers are aware of and have easy access to the resulting data, a formalized system for the collection, aggregation and analysis of nuisance complaints received by municipal staff via telephone or e-mail may represent a municipal best management practice. ${ }^{6}$

${ }^{5} \mathrm{An}$ exception to the overall trend is also observed for the year 2002 . In part, this can be attributed to a heightened concern over West Nile Virus and a year of particularly severe weather conditions that resulted in a large number of unusual calls. Data coordination was also improved as this was the first year that one full-time education officer was the sole respondent to residents' concerns.

${ }^{6}$ In Mississauga, data exist and are shared upon request but is no: readily accessible for City-wide use. Staff of the Credit Valley Conservation Authority and municipal staff outside of Animal Services were unaware of the existence of the data. 
With a bit of enhanced coordination, it allows the municipality to use readily available information to understand public perceptions and react to community concerns before they can evolve into crisis situations. However, even if demands for access to information can be met, this system is still subject to other shortcomings as an evaluation tool for public perceptions as the information collected does not represent a random sample of the population. A system that only monitors complaints will capture the opinion of those most adversely affected by nuisances while effectively ignoring the views of any residents with more positive perceptions of wildlife.

Ass a more representative alternative, public surveys are often used by municipalities as a means of evaluating general public perceptions towards various issues affecting the City. For example, recent surveys were conducted in conjunction with the development of:

- $\quad$ City of London Parks and Recreation Strategic Master Plan (2003-2007);

- Imagine! Waterloo 2020 Community Vision (2001);

- City of Hamilton Parks, Culture and Recreation Master Plan (2002); and

- $\quad$ City of Guelph Terrestrial Inventory of Open Spaces (upcoming).

Community survey processes and broad community consultations are also common as part of the master planning process and the development of municipal strategic directions.

Drawing off these formal studies, several respondents stated that their evaluation of public perceptions of wildlife was extrapolated from public surveys conducted in conjunction with other municipal community consultation processes. In most cases, the surveys found that residents had a high affinity for wildlife and the protection of natural open spaces and/or would like to see these resources increased within the City. However, none of these studies included any questions specifically related to human-wildlife conflict.

The City of London is a notable exception. During the summer of 2000, the Upper Thames River Conservation Authority (UTRCA) and the City of London began to receive a number of calls from residents of the Sifton Bog community regarding frequent sightings of and conflicts with White-tailed deer. In 2001, the Sifton Bog White-tailed Deer Community Steering Committee initiated a survey of residents living in close proximity to the Bog as a means of determining the extent of deer damage to private landowners. Of close to 800 surveys mailed, 255 were returned. ${ }^{7}$ In addition to identifying the type, extent and location of private property damage, the survey found that:

- The majority of residents (approx. 69\%) felt that the deer presented a problem for the community, even though only a small proportion (28\%) were currently being directly affected. While about half of those not currently impacted had never seen the deer in their yards at all, $41 \%$ feared that the deer would be a problem for them in the future.

- Deer activity appeared to be related to human behaviour and landscaping choice; inhibited. by dogs and fenced yards and encouraged by the presence of fruit trees and bird feeders. However, only about 1 in 5 households had made some attempt at deer proofing. These

${ }^{7}$ Similar to the monitoring of nuisance complaints, this type of survey does not represent a random sample. People with strong points of view are more likely to respond. 
measures were typically reactive rather than proactive, and were not seen to be highly effective.

- The health of the Bog and the health of the deer were cited as the greatest concerns for the community, followed by human health and safety. Damage to vegetation was only a major concern for those that had already been directly impacted.

As can be seen, the results of this survey have provided decision-makers with valuable information as to the real nature of the problem and how this is perceived by residents. Combined with the conclusions of a management options review, this information allowed the Community Steering Committee to prepare recommendations for the resolution of the problem that reflected not only scientific and economic feasibility but also community values. Whether the recommendations will be accepted by the community as a whole remains to be seen (London, 2003c).

However, perhaps of greater importance than the findings themselves is the possible precedent that this survey and the broader community consultation process set for future wildlife management discussions in the City. In its Final Report (2003), the Community Steering Committee notes that "conclusions reached... may influence how problems of a similar nature would be handled at other natural areas within the City of London". According to one respondent, a similar Community Steering Committee is already being formed for the development of informed management decisions regarding Canada geese.

\subsubsection{Tracking 'Nuisances' via Ecological Monitoring}

Human-wildlife conflicts that occur in urban areas are frequently the result of locally overabundant wildlife populations, such as is the case with the White-tailed deer in London and Canada geese throughout most of southern Ontario. These species can not only create public nuisances, but may also be a concern for the ecological health of the area in which they are found. As a result, among the actual studies of urban nuisance species that do take place, it would appear that the majority are performed for the purpose of ecological monitoring rather than to evaluate public perceptions. For example, studies have been initiated to evaluate the ecological impact of overabundant gull, goose and cormorant populations in the Hamilton Harbour area and the success of various control measures to mitigate these impacts. As a result, any complaints regarding these species are referred to a committee that has been set up in the Hamilton Region for the purpose of nuisance bird control.

There are also several occasions where nuisance wildlife tracking is performed as a result of legislation. In these instances, tracking is generally performed by agencies outside the municipal government. For example, the Ontario Ministry of Natural Resources maintains statistics on both the number of deer removal permits issued and the number of deer-vehicle collisions sustained in a given area. Staff of Conservation Authorities record instances of beaver or beaver dam removal and removal requests for tracking by the OMNR. Similarly, the Canadian Wildlife Service maintains statistics on the number of egg oiling permits issued for migratory bird species. Transport Canada maintains annual statistics on the number and severity of aircraft collisions that involve wildlife (Blackwell, 2003.07.16).

Again, while these studies do not include information that would help improve municipal understanding of public perceptions, they may provide other valuable information that is critical to 
effective municipal management (e.g. data on the location and extent of specific nuisance problems). Some of this information is also used by higher levels of government to develop and distribute nuisance management education to municipalities faced with particular problems - e.g. The Beaver Handbook: $A$ Guide to Understanding and Coping with Beaver Activity (D'eon et al., 1995). Despite this, it was generally found that municipalities lack the information needed to take proactive action on diffusing nuisance situations. In most cases, monitoring of either the ecological or public impact of nuisance species occurs only after tiey have reached a crisis level. This limits the number of options available to the municipality to reactive measures, many of which are often extreme, non-adaptive and lead to public confrontation (EMAN, 2003).

\subsection{The Delivery and Impact OF Public Education}

There are many means of mitigating public concern over nuisance species before problems reach crisis level. Information and education are important for the development of an appreciation of nature among Canada's expanding urban population, many of whom have never lived close to nature (WHC, 2001). As many urban wildlife problems are often either directly or indirectly created by humans, human behaviour modification and enhancing tolerance for urban wildlife are considered prime strategies for dealing with present and future conflicts (Messmer, 2000; Fall and Jackson, 2002). As stated by Hadidian (1991), "[p]erhaps the most demanding task facing us is educating the urban populace, not only in regard to the cause and resolution of urban wildlife problems, but also in regard to the ecological basis of these". Targeted education and awareness programs, combined with improved access to relevant urban biodiversity information, will allow individuals to make more informed decisions about nuisance species control and management on their own land and in the municipality as a whole (WHC, 2001).

Table 4 outlines some of the most common public education initiatives delivered by the selected municipalities. As can be seen in the Table, most municipalities actively conduct some form of public education aimed at improving general environmental awareness. However, a much smaller proportion of these municipal or Conservation Authority programs are directly targeted at issues related to human-wildlife conflict mitigation or resolution.

Table 4: Public Education Programs of Selected Municipalities, Focus on Wildlife

\begin{tabular}{|c|c|c|c|c|c|c|}
\hline \multirow[b]{2}{*}{ City } & \multicolumn{6}{|c|}{ Initiative Type } \\
\hline & $\begin{array}{c}\text { Print } \\
\text { Resources }\end{array}$ & $\begin{array}{c}\text { On-line } \\
\text { Resources }\end{array}$ & $\begin{array}{c}\text { Media/ } \\
\text { Newsletters }\end{array}$ & $\begin{array}{l}\text { Interpretive } \\
\text { Programs }\end{array}$ & Signage & $\begin{array}{l}\text { Subdivision } \\
\text { Agreements }\end{array}$ \\
\hline Hamilton & $\mathscr{q}$ & $\checkmark$ & & $\mathscr{G}$ & $\mathscr{G}$ & \\
\hline Guelph & $\mathscr{S}$ & $\mathscr{A}$ & $\mathscr{9}$ & $\mathscr{A}$ & $\checkmark$ & $\mathscr{G}$ \\
\hline Burlington & $\checkmark$ & $\checkmark$ & $\mathscr{G}$ & $\mathscr{\theta}$ & $\theta$ & $\mathscr{\theta}$ \\
\hline Mississauga & $d$ & $\checkmark$ & $\checkmark$ & $\checkmark$ & $\checkmark$ & $\mathscr{O}$ \\
\hline Waterloo & $\checkmark$ & $\checkmark$ & & $\mathscr{O}$ & $\mathscr{S}$ & $\mathscr{A}$ \\
\hline London & $\checkmark$ & $\checkmark$ & $\checkmark$ & $\checkmark$ & $\mathscr{O}$ & $\mathscr{A}$ \\
\hline
\end{tabular}

$\checkmark$ - Wildlife-specific initiatives; $\mathscr{\emptyset}$ - General environment initiatives 
As will be discussed, while each of the selected municipalities may use a similar set of tools for the delivery of public environmental education, the nature and substance of the programs delivered varies substantially.

\subsubsection{Media, Print and On-line Resources}

As demonstrated in Section 3.3, issues of biodiversity and urban wildlife now receive a reasonable share of attention in the media. Reporting on events of interest to Canadians, media reports are more frequent when urban wildlife has created a problem that affects a large section of the population. This is true of the Sifton Bog White-tailed deer problem and the more general problem of overabundant Canada geese in southern Ontario. Upon request, most municipalities will provide the media with the information they require to accurately report on these issues. As such, the media can be used as a resource to distribute municipal information regarding wildlife issues to the public at virtually no cost to the municipality.

Unfortunately, by focusing on the high profile issues, media reports do not reflect the true distribution of nuisance problems within a municipality or region. This is because there are some nuisances - such as mice or raccoons - that are so common that they are generally no longer reported on as nuisances. However, due to their wide audience, it has been found that media reports not only reflect attitudes toward urban wildlife but can also be used to help to develop these perceptions (Vuorisalo et al., 2001). For example, the City of Mississauga Animal Services takes advantage of the local newspaper to publish a regular editorial on wildlife in the city, providing tips to residents on nuisance species control. Despite this opportunity for information sharing, most municipalities do not yet have ready access to use of the media for these purposes. For municipalities such as the City of London and the City of Burlington, media coverage is limited to updates on issues of importance - for example, progress on naturalization projects or the management of specific nuisance species - in newsletters produced by the municipality.

By contrast, the majority of municipalities now have either print and/or on-line resources available to inform residents about wildlife in the city. These publications are perhaps more effective as they are directly targeted at addressing the nuisance problems of greatest importance to the local municipality, but are also limited by a somewhat weaker distribution than media reports. Print materials being distributed by the municipal government and/or the Conservation Authority range from basic one-page educational fact sheets to more detailed brochures, up to approximately thirty pages in length. The most common themes for these materials include health and safety concerns (e.g. rabies and WNV), naturalization, by-law and provincial law enforcement, identification of wildlife in the city, and human-wildlife conflict management techniques. For the latter, emphasis is given to those species responsible for the highest proportion of nuisance complaints - coyotes, waterfowl, pigeons, foxes, deer, raccoons, skunks, squirrels, rodents, flocking birds and weeds. A typical information brochure will include biological information on the species of concern to help residents identify the nuisance, will identify normal versus abnormal behaviour for the species (i.e. identify when health risks may be present or real conflict a potential), and will provide suggestions as to how to legally and humanely prevent or resolve conflicts. Other information packages will focus more generally on measures for home and community wild-proofing, such as proper waste disposal and the importance of not feeding wildlife. 
In the case of print and electronic materials, there is also strong evidence of resource sharing among municipalities. The Animal Services Division of the City of Toronto Public Health Department is cited on several occasions as the original source of information. The City of Hamilton collaborates with the City of Burlington's Animal Control for resource access, except for issues related to public health (e.g. WNV) or by-law enforcement. This practice of resource sharing should be encouraged where common problems exist in order to make the best use of scarce municipal resources. Resource sharing could also help provide residents with enhanced electronic access to information by alleviating the limitations in bandwidth size of municipal websites. However, municipalities are still encouraged to develop their own information materials to fill resource gaps.

\subsubsection{Interpretive Programs}

In southern Ontario, Conservation Authorities appear to be key in the provision of general environmental education through interpretive programming. Created by the Ontario Conservation Authorities Act in 1946, part of the mandate of these watershed-based agencies is to develop and deliver education and information programs to the public with a goal to establish a higher standard of co-existence between the community and the local environment. To accomplish this, the designated Conservation Areas present in each of the selected municipalities are treated as "outdoor schoolrooms" where the public can learn the ecological, social and economic value of their natural environment (CO, 2000a). On an annual basis, close to one million students participate in either on- or off-site environmental education programs delivered by Conservation Authorities across Ontario (CO, 2000b). Similar educational opportunities are available to adults who visit Conservation Areas or participate in community events with an environmental component. As is the case with the City of Mississauga, some interpretive programs are also delivered by the municipal government either independent of or in conjunction with the local Conservation Authority.

While this is an impressive accomplishment, the delivery of these interpretive programs limits their use as educational tools due to a weak distribution of information among the general population exposure is limited to a select number of individuals (or their parents). Other than the relatively fixed school-age audience, it is difficult to target educational programs to where they are needed most. ${ }^{8}$ Among adults, the information provided primarily reaches those who already have a relatively high affinity for nature, as demonstrated by their presence at the Conservation Area or community event. In addition, while learning respect for urban wildlife may be a component of the general environmental education program, the interpretive programming generally does not specifically target the issue of nuisance wildlife or human-wildlife conflict management.

\subsubsection{Signage}

Another, more passive but still practical approach towards the distribution of general environmental education in natural areas is the erection of signs. As seen in Table 5, municipal

\footnotetext{
${ }^{8}$ While formal education (i.e. school curriculum) is an important component of community awareness, it has been excluded from this analysis as it is an issue of provincial jurisdiction. Most municipalities have now recognized the need to enhance local environmental education in schools.
} 
signage programs exist at various scales and stages of implementation. ${ }^{9}$ These can also be either interpretive and/or instructive in nature.

Table 5: Description of Municipal Interpretive Signage Programs, Selected Municipalities

\begin{tabular}{|c|c|c|c|}
\hline City & $\begin{array}{c}\text { Stage of } \\
\text { Implementation }\end{array}$ & $\begin{array}{c}\text { Area of } \\
\text { Implementation }\end{array}$ & Nature of Information Provided \\
\hline Hamilton & in developrnent & restricted to shorelines & $\begin{array}{l}\text { Signage planned to advise residents not to feed } \\
\text { waterfowl; will include ecological basis for } \\
\text { warning - currently at sample wording stage. }\end{array}$ \\
\hline Guelph & implemented & $\begin{array}{l}\text { naturalization projects/ } \\
\text { new developments }\end{array}$ & $\begin{array}{l}\text { Signage discourages encroachment by identifying } \\
\text { natural areas adjacent to new developments } \\
\text { (mandatory) and increases tolerance through the } \\
\text { identification of naturalization projects. }\end{array}$ \\
\hline Burlington & $\begin{array}{l}\text { implemented/ } \\
\text { in development }\end{array}$ & $\begin{array}{l}\text { restricted to } \\
\text { 'unusual' projects }\end{array}$ & $\begin{array}{l}\text { Signage program will educate public if unusual } \\
\text { techniques are being applied to a natural area - } \\
\text { e.g. herbicides being used on invasive } \\
\text { wildflowers. Interpretive signage being planned } \\
\text { for natural areas adjacent to new developrnents, } \\
\text { but delayed due to budgetary constraints - no } \\
\text { formal sign design yet exists. }\end{array}$ \\
\hline Mississauga & implemented & $\begin{array}{l}\text { natural areas/ } \\
\text { naturalization projects/ } \\
\text { waterways }\end{array}$ & $\begin{array}{l}\text { Signage discourages residents from negative } \\
\text { interactions with natural areas (e.g. } \\
\text { encroachment) and/or dispel negative perceptions } \\
\text { of naturalization projects as municipal } \\
\text { negligence. }\end{array}$ \\
\hline Waterloo & $\begin{array}{l}\text { implemented/ } \\
\text { in development }\end{array}$ & trails \& natural areas & $\begin{array}{l}\text { Signage used to identify trails through natural } \\
\text { areas and keep residents on track, but do not } \\
\text { provide interpretive information - part of } \\
\text { Waterloo Trails Master Plan. Planned installation } \\
\text { of interpretive signs along some trails to explain } \\
\text { natural features. }\end{array}$ \\
\hline London & discontinued & $\begin{array}{l}\text { restricted to } \\
\text { by-law enforcement }\end{array}$ & $\begin{array}{l}\text { Signage in natural areas restricted to by-law } \\
\text { enforcement (e.g. no dumping, no encroachment, } \\
\text { etc.). Interpretive signage discontinued due to } \\
\text { vandalism concerns. }\end{array}$ \\
\hline
\end{tabular}

As an education technique, signs placed in natural areas or on naturalization projects gain effectiveness by targeting residents who use or live in proximity to specific sites. The information they provide may be highly valuable in raising public perceptions of naturalization projects, particularly during the juvenile stage when they appear the most unkept. Signs are also useful reminders to residents that certain human behaviours (such as wildlife feeding) may encourage nuisances.

${ }^{9}$ This table excludes signage maintained by Conservation Authorities in designated Conservation Areas as part of their mandate for environmental education. 
However, there are also several factors that limit the feasibility and effectiveness of this educational technique. Though reaching a target population, signs are limited in the amount of information they can provide. In addition, signs are not only costly to introduce but may also be costly to maintain. The City of London found such programs to be unsustainable following several incidences of vandalism and has now discontinued any signage in natural areas that is not specifically required for by-law enforcement. Similarly, other municipalities have limited the number of signs erected due to cost restraints.

\subsubsection{Subdivision Agreements}

As discussed in Section 4.2, there is a current trend towards the construction of new residential developments in proximity to natural areas. Having recognized this, the majority of municipalities examined now require that developers distribute educational material to all new residents as part of subdivision agreements. While this material is focused on the environment as a whole, most packages will refer to specific urban wildlife issues (see Table 6). The majority of materials encourage close interactions with urban wildlife through landscaping or other stewardship practices (e.g. prevention of encroachment), though many also address the potential for humanwildlife conflicts on residential property.

Table 6: Comparison of Educational Material Distributed Under Subdivision Agreencents

\begin{tabular}{|c|c|}
\hline City & Description of Residents' Environrnental Edncation Manua! \\
\hline Hamilton & Not available; no evidence of initiative. \\
\hline Guelph & $\begin{array}{l}\text { Guelph Residents' Environmental Handbook (2000): } \\
\text { Purpose - to identify concrete ways for individuais and groups tc become stewerds of } \\
\text { the natural environment; document suggests projects. } \\
\text { References to wildlife include - description of Naturalization in City Parks Strategy } \\
\text { (1991); information on natural landscaping and 'lasidscaping for wildlife'; } \\
\text { recommendations for use of natural areas such as to minimize disturbances to wildlife. } \\
\text { Document available on-line: } \\
\text { www.city.guelph.on.ca/uploaddocuments/d3018+2003_handbook.poff }\end{array}$ \\
\hline Burlington & Not available; data not publicly accessible. \\
\hline Mississauga & $\begin{array}{l}\text { Neighbours of Mississauga's Natural Areas (2003a): } \\
\text { Purpose - to encourage the residential awareness, understanding and cooperation } \\
\text { necessary for the preservation of natural areas. } \\
\text { References to wildlife include - description of natural areas as wildlife habitats; } \\
\text { information on natural landscaping; recommendations for use of natural areas such as } \\
\text { to minimize disturbances to wildlife; recommendations for use of property such as to } \\
\text { avoid attracting wildlife out of natural areas, with specific emphasis on key nuisance } \\
\text { species. } \\
\text { Document available on-line: } \\
\text { www.mississauga.ca/ecity/download/?repositoryKey=Ecity\&itemDesc=file\&dataName- } \\
\text { data\&mimeTypeName-mimeType\&id=5900091 }\end{array}$ \\
\hline
\end{tabular}

${ }^{10}$ Companion document to Mississauga's Natural Areas (2002). Document describes type of natural areas present in City, their benefits, and Mississauga's protection efforts. The Credit Valley Conservation Authority has also produced a similar document for the entire watershed area - Be A Good Neighbour (CVCA, n.d.). 


\begin{tabular}{|c|c|}
\hline (Con't) & Description of Residents' Environmental Education Manual \\
\hline Waterloo & $\begin{array}{l}\text { Living with Nature in West Side Waterloo (1998a): } \\
\text { Purpose - to present information on local nature conservation efforts and provide tips } \\
\text { on being good stewards and living in harmony with nature; West Side of Waterloo is an } \\
\text { area that was designed such that nature could be preserved. } \\
\text { References to wildlife include - description of the function of naturalized buffer areas } \\
\text { (e.g. as wildlife habitat, migration corridors, etc.), 'living fences', woodlands and creek } \\
\text { valleylands, and recommendations for their protection; information on natural } \\
\text { landscaping; awareness raising of both the positive and negative human-wildlife } \\
\text { interactions associated with living in proximity to nature with recommendations for use } \\
\text { of property such as to minimize disturbances and avoid attracting wildlife out of natural } \\
\text { areas. } \\
\text { Document not available on-line, but can be accessed by public by calling City of } \\
\text { Waterloo Environmental Services (519-886-2310). }\end{array}$ \\
\hline London & $\begin{array}{l}\text { Living with Natural Areas (UTRCA, n.d.): } \\
\text { Purpose - to provide guidelines as to what a property owner or other user of natural } \\
\text { areas can do to minimize their impact. } \\
\text { References to wildlife include - awareness raising of both the positive and negative } \\
\text { human-wildlife interactions associated with living in proximity to nature with } \\
\text { recommendations for use of property and natural areas such as to minimize } \\
\text { disturbances and tips for increasing tolerance to pests; encourages 'landscaping for } \\
\text { wildlife'. } \\
\text { Document available on-line: } \\
\text { www.thamesriver.org/Wetlands_\&_Natural_Areas/living_with_natura!_areas l.htm }\end{array}$ \\
\hline
\end{tabular}

The fact that the majority of these educational materials emphasize the positive aspects of humanwildlife interactions should not be considered as a negative feature of such programs. Positive perceptions of wildlife and an improved understanding of its ecological value have been demonstrated to increase tolerance for conflicts and the capacity to co-exist.

At present, this may represent a municipal best management practice. However, as suggested by one respondent, the long-term effectiveness of this practice is still in question. While the initial purchaser will receive valuable information as to how to co-exist and mitigate conflicts with the abutting natural area, this resident likely already has a high affinity for nature as demonstrated by their selection of lot location. By contrast, it is subsequent purchasers (with a potentially less-well developed affinity for nature) who do not receive the information package that may pose the greatest risk to the adjacent natural area. In part, this risk can be mitigated by the additional online availability of the majority of these resources. However, as will be discussed in Section 6.5.3, the establishment of municipal guidelines that encourage developers to take urban wildlife into consideration during residential building design may be a more effective solution.

\subsubsection{Public Education BMP: City of Mississauga}

In 1994, the City of Mississauga Animal Services Department made an innovative shift in program delivery that has had a significant positive impact on nuisance species management. Rather than the traditional form of direct, on-ground management, Animal Services now relies almost exclusively on public education as the primary human-wildlife conflict resolution tool. 
As a result, the City of Mississauga was found to be the only selected municipality to have a comprehensive program for public education devoted to wildlife in the City. This program is composed of a number of elements, including but not limited to:

1. Staff Education - Staff education and the development of comprehensive in-house information resources are considered critical components in ensuring municipal capacity to respond to resident inquiries and complaints in a timely manner. A review of municipal experiences and research into best management practices for the effective resolution and prevention of conflicts have allowed the City to improve service delivery

2. Telephone Counseling - Municipal experience has shown that many questions can be answered over the telephone. The Mississauga Animal Control Wildlife Trouble Shooting Guide (1995) was developed to assist dispatchers and other staff members in responding to public concerns regarding wildlife. The guide presents information on more than a dozen common urban wildlife species and provides advice on the basis of the many situations in which the wildlife may be encountered or create conflict. As would be expected, the type and level of advice required differs significantly for general sightings than it would for, for example, home invasions. More unusual wildlife concerns are to be directed to an on-staff wildlife representative for advice.

3. Residential Visits - Telephone counseling and the provision of education materials are now considered by the City to be the first course of action when contacted regarding wildlife conflicts. The decreased reliance on residential visits has significantly reduced the onground costs to the municipality associated with nuisance management. However, in the case of an emergency where an animal is in immediate danger or causing a dangerous situation, an Animal Control Officer will still be dispatched. Property visits allow Animal Control Officers to better estimate the severity of the problem, and advise or educate the resident accordingly. While other municipalities may still lend or rent out traps as part of their community support, Animal Control does not provide wildlife removal services and no longer supports trapping approaches. " Where necessary, residents may be referred to credible wildlife removal companies in order to deal with specific problems. Many private wildlife removal companies have been established in the City to help fill the gap left by Animal Services.

4. Distribution of Print Resources - A wide variety of print resources are now available for hand-out or mail-out distribution, as required. Some of these resources have been developed in-house (based on community need and best available information) while others are collected for distribution from respected external agencies with an interest in urban wildlife management, such as the Canadian Federation of Humane Societies. Print resources include information on issues such as wildlife proofing, choosing a wildlife removal company and understanding legislation, as well as specific information on the identification and control of common urban nuisance wildlife species.

\footnotetext{
${ }^{11}$ Trapping and relocation of wildlife was found to not only be ineffective, but also inhumane and an increased risk factor for of the spread of disease. The practice of lending traps was discontinued by the City of Mississauga by 1994.
} 
5. Distribution of Internet Resources - Access to information resources has recently been simplified and expedited through the use of the internet. Resources provided on-line by Animal Services are a reflection of the print resources that have been developed and feature similar information. This service has been positively received by residents of Mississauga, and the number of dispatch calls has declined as more people access the information they need on-line. In order to improve service delivery, Animal Services is now designing an internet poll of their site to get a better sense of their ability to meet the demand for information that can be delivered via the internet.

6. Media Coverage - Animal Services publishes a regular editorial article in The Mississauga News (a local community newspaper), to provide residents with information on City wildlife and wildlife management techniques. This is in addition to newsletter update contributions and the response to specific media requests for information on wildlife issues of wide-scale public importance or general public interest.

7. Response to Community Requests - At the request of schools and other community groups, Animal Services will occasionally prepare and present information on urban wildlife issues and the role of the City. Information provided during these sessions is tailored to the needs of the group making the request and will often include information on the other functions of Animal Services, such as domestic pet control.

8. Targeted Information Delivery - The statistics that are collected by Animal Services in connection with its call complaints monitoring system (see Section 4.3) allow staff to assess species and spaces of particular concern within the City. Once identified, local situations can often be diffused through a targeted mail-out of educational material and/or door-to-door visits by Animal Control Officers. Information delivery is usually completed at the request of or with assistance from the office of the City Councillor with jurisdiction over that section of the City. Similarly, major issues perceived to be of wide-spread concern may be addressed by targeted information sessions open to the general public. For example, when the residents' concern regarding urban coyotes escalated in 19951996, a series of public information sessions were conducted to educate the public and raise awareness about municipal initiatives to monitor and control coyote activity. Organized and delivered in conjunction with other municipalities from across the Greater Toronto Area, the large community turn-out to these sessions helped to diffuse the situation.

Have the City of Mississauga's public education efforts been successful? As was seen in Figure 5, the first year of the public education program was the most difficult due to the need for adjustment by both staff and the community to the new service delivery approach. However, despite an increase in the urban population of both humans and wildlife, the number of wildliferelated calls received by Animal Services have been almost steadily in decline. According to Mississauga, credit for this decline can be attributed to the ability of their public education program to increase wildlife tolerance and positively modify human behaviour that creates potential conflicts. Unfortunately, while it is supported by anecdotal evidence no formal study of program effectiveness has yet been conducted to test this theory. 


\subsection{Recommendations for Public Perceptions and Education}

As even the most comprehensive public education program has yet to conduct an assessment for effectiveness, it is difficult to develop specific recommendations for best management practices in human-wildlife conflict management from this review of municipal practices. Stakeholders from each of the selected municipalities cited a lack of human and financial resources as the major impediment to program review, with program development and implementation considered as more critical expenditures of scarce resources. There is some indication that "[p]ublic education in the form of signs, pamphlets and public announcements has varying degrees of success" (Henshaw, 1997). As stated by Henshaw (1997), program success is tied to the presence/absence of language barriers, the amount of enforcement, and the extent of pre-existing public understanding of the link between human behaviour and ecology. These factors are particularly important in the multicultural environment that is southern Ontario, where not only language but also cultural perspectives may significantly alter an individuals' view of urban wildlife (O'Donell and VanDruff, 1983; Gobster, 2001; WHC, 2001).

As a result, in order to develop effective public education programs, it is clear that municipalities must first understand how residents perceive urban wildlife and have a basic understanding of the issues that they face related to human-wildlife conflicts. Currently, while wildlife and open space managers believe that they have a sound understanding of the public perceptions of wildlife in their municipality, there have been few actual attempts to assess these perceptions. The City of Mississauga's complaint monitoring system may be viewed as a model for understanding and reacting to community wildlife concerns before they reach crisis level. Knowing where conflicts arise and which species are likely involved also allows the City to target public education efforts to where they are needed most, both mitigating conflicts before they become major problems and making the best use of scarce resources.

Public education programs that are developed should incorporate both ecological and human behaviour components. This is needed to not only increase tolerance towards wildlife but ensure that a level of more harmonious co-existence can be reached. The information provided should also be easily accessible, understandable and relevant to local conditions. Such as is done with the Subdivision Agreements, proactive measures to reduce the frequency of conflicts should be promoted whenever possible. More than identifying problems or providing general tips, information should also be available to residents that suggests a course of action when reactive measures are required. Resources should be shared among municipalities facing similar problems so that more municipalities can develop a multi-faceted approach to public education delivery, such as that which is applied by the City of Mississauga.

If effectively delivered, public education and awareness programs will enable urban residents to make more informed decisions about their interactions with wildlife. In turn, these positive perceptions of urban wildlife and urban wildlife habitat may have spin-off implications - both in terms of economic and political decisions - for the conservation of nature in other landscapes (Middleton, 1994; WHC, 2001). 


\subsection{MUNICIPAL CAPACITY FOR BIODIVERSITY SCIENCE \& INFORMATION}

In order to effectively manage human-wildlife conflicts, the conflicts must first be understood. In addition to public input and awareness, planning for human-wildlife conflicts is a process that uses scientific, socioeconomic and technical data. For effective management, ecological data and analysis must be available to and be understood by those who will be affected by the decisions being made (EMAN, 2003).

Unfortunately, Canadian cities continue to suffer from a relative lack of urban biological data and predictive ability (Middleton, 1994, WHC, 2001). Included in this is a deficiency of data necessary for making decisions on most human-wildlife conflicts (Messmer, 2000; Le Lay and Hubert-Moy, 2001). Currently, "[f]ew public stakeholders understand how human-wildlife conflicts are created, let alone the most environmentally correct way to manage the problem" (Messmer, 2000). To develop effective urban solutions, there is now a critical need for information on the location, behaviour and abundance of particular nuisance species and environmental settings where damage or conflicts are known to occur (Fall and Jackson, 2002).

Based on testimony provided during interviews and municipal documentation, this section will explore the development and use of biodiversity science and information in the six selected municipalities, what initiatives are currently taking place, and their effectiveness for humanwildlife conflicts.

\subsection{THE NEED FOR SCIENCE AND INFORMATION}

What is the nature of the information needed to make decisions? How can we develop and use biodiversity information to better guide local growth and development decisions? These are the questions that communities need to ask in order to make sustainable choices for development and in the day-to-day lives of residents.

Basic research on the social and economic values associated with wildlife can help determine what kinds of habitats urban residents desire within their urban area, with a view to integrating those values into the planning process (WHC, 2001). This issue was addressed in Section 4. However, studies have also found that there is a need for basic scientific research associated with biodiversity in urban habitats (Middleton, 1994; WHC, 2001). "On the scientific side, developing a better quantitative understanding of the interactions between species and their homes will help bring better information to land use decision-making" (WHC, 2001).

Currently, when human-wildlife conflicts arise in an urban area, a lack of good information results in a lack of consensus on how to deal with the problem (MDNR, 2002). In many cases, this leads communities to spend excessive time collecting information which, coupled with the lack of an advanced warning system, means that data are provided too late to avoid or mitigate major problems (EMAN, 2003). Options are limited when decisions are taken at crisis points, and this results in reactionary measures that are extreme, confrontational and not designed for adaptive management. 
According to EMAN (2003), environmental information required for community-based decision making should be: targeted and relevant to local problems; accessible and understandable to the audience; integrated; usable in both form and context; and timely. This means that knowledge needs to be driven by what information is needed, and not just what is easily accessible. As will be seen, this is not the case in the majority of selected municipalities.

However, simply finding better ways to provide scientific information will not result in better decisions. This is due to the fundamental difference between the generation of information and the creation of knowledge. To be useful, the information gathered must also be organized in such a way that it will actually allow the user to make knowledgeable decisions, i.e. it suggests a course of action and/or allows decision makers to weigh possible outcomes and feel that they are in control of the problem (EMAN, 2003).

While this Section will focus on municipal capacity for basic research into urban biodiversity, it should be recalled that there are a broad range of other issues for which knowledge deficiencies exist. Some examples include:

- the impacts of overabundant species on other natural resources and the environment;

- the extent of urban forestry losses associated with species (e.g. beavers);

- the ability of species to newly adapt to human-altered environments (e.g. coyotes);

- the incidence of human disease for which wildlife may play a role in transmission;

- the magnitude and consequences of deer-vehicle collisions;

- the prevalence and consequence of bird-aircraft or bird-structure collisions; and

- the general ecology of nuisance species and their dynamics in urban areas (e.g. roosting, feeding, nesting, colonization patterns, times of year when present, etc.)

Fnhanced knowledge in any or all of these areas could move national, provincial and particularly local governments towards the development of a system to efficiently allocate resources and effectively manage human-wildlife conflicts (Messmer, 2000).

\subsection{SCIENCE AND INFORMATION IN SELECTED MUNICIPALITIES}

Before we can analyse the effectiveness of municipal biodiversity information for human-wildlife conflict, we must first examine the type of science and monitoring that is currently taking place. During interviews, each of the relevant stakeholders was asked what type of information on open spaces and wildlife is currently available for use by the municipality in planning and operations. The results of this inquiry are found summarized in Table 7. 
Table 7: Biodiversity Science Initiatives, Selected Municipalities

\begin{tabular}{|c|c|c|c|c|}
\hline City & $\begin{array}{c}\text { Watershed } \\
\text { Study }\end{array}$ & $\begin{array}{c}\text { Subwatershed } \\
\text { Study }\end{array}$ & $\begin{array}{c}\text { Additional Study } f \\
\text { Monitoring }\end{array}$ & $\begin{array}{l}\text { Biodiversity } \\
\text { Inventory }\end{array}$ \\
\hline Hamilton & $\checkmark$ & 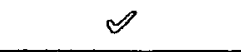 & $\checkmark$ & $\mathscr{\sigma}$ \\
\hline Guelph & $\checkmark$ & 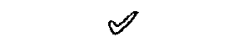 & $\checkmark$ & $\mathscr{O}$ \\
\hline Burlington & $\checkmark$ & $\mathscr{O}$ & $\checkmark$ & $\infty$ \\
\hline Mississauga & $\checkmark$ & $\mathscr{P}$ & $\checkmark$ & $\checkmark$ \\
\hline Waterloo & $\checkmark$ & $\cong$ & $\checkmark$ & \\
\hline London & $\checkmark$ & $\mathscr{\theta}$ & $\checkmark$ & \\
\hline
\end{tabular}

$\checkmark$ - Initiated completed; $\mathscr{}$ - Initiative in progress/partial completion

As can be seen from Table 7, each of the six selected municipalities is currently involved in some amount of biodiversity science and biodiversity science-related initiatives. Even so, is this science and monitoring data being turned into useful information for biodiversity and/or human-wildlife conflict management? Answers to this question will be outlined in the following sections.

\subsubsection{Watershed and Sub-watershed Studies}

Under the Conservation Authorities Act (1946), Ontario's Conservation Authorities share a mandate for the protection, management and restoration of watershed resources. This includes not only aquatic but also terrestrial resources - woodlands, wetlands and other natural habitat. However, "[s]uccessful management strategies can only be developed if accurate and representative information on the watershed characteristics and dynamics are available" (PEIL, 2003). Watershed studies contribute to this goal by gathering information on the watershed that is required for environmentally sound policy development.

While each Conservation Authority may gear its methods to its own particular conditions, there are essentially three phases to any watershed study (GRCA, 1993; CVC, 2003):

1. Phase I involves the characterization of the watershed and its existing environmental and water resource processes (e.g. hydrology, water quality, stream morphology, aquatic and terrestrial resources, land use, etc.). This phase may also include public input to set the community's vision and goals for the study and/or watershed.

2. Phase II assesses the potential impacts of future changes in land use. This phase can also be used to develop and assess alternatives to help protect the environment.

3. Phase III results in the development of a management strategy for the watershed. This is frequently the result of the selection of a preferred alternative future (identified during Phase II). A series of actions will then be recommended to achieve the future watershed goal. The management strategy will consist of a schedule for the completion of these actions, including the assignment of responsibilities, suggestion of implementation costs, and measures that can be used to monitor progress. 
Most important to this thesis research is Phase I. This phase includes activities such as the collection of primary and secondary data, modeling, and the analysis of data. Based on an ecosystem approach, analysis for watershed studies includes an examination of individual components as well as the interrelationship among elements. Terrestrial resource components of these studies include elements such as a categorization of vegetation communities, delineation of wetland boundaries, identification of significant wildlife habitat, and the identification of significant or rare wildlife communities (GRCA, 1993; PEIL, 2003). This information can also be mapped against or used to identify Environmentally Sensitive Areas (ESAs) or other components of an existing and/or proposed greenspace system.

As a result of provincial guidelines, the Conservation Authorities for all six of the selected municipalities have now completed a watershed study for their management area. These highly comprehensive documents are used extensively by both Conservation Authorities and municipal government for the purposes of land use planning. Some municipalities, such as the City of Waterloo, currently rely almost exclusively on these studies (and their associated monitoring programs) as a source of planning information.

However, the Gredit River watershed drains an area of approximately $1,000 \mathrm{~km}^{2}$, with $1,500 \mathrm{~km}$ of tributaries (CVC, 2003). Even this expanse is dwarfed by the Grand River watershed, which includes an area greater than $7,000 \mathrm{~km}^{2}$ (GRCA, 1993). The size of each watershed means that the watershed studies can only really offer municipal planners a generalized, landscape level assessment of the local environment. This leaves obvious gaps in information required to answer questions about small, site specific wildlife issues.

To help address these information gaps, the Conservation Authorities have subdivided each watershed into sub-watershed components based on important tributaries. For example, the Credit Valley Conservation Authority has identified the need to break down the study area of the Credit River watershed into 20 subwatersheds (CVC, 2003). Though smaller than the watershed, these subwatersheds can still cover a significant area. Important to planning in Waterloo, the Laurel Creek subwatershed includes an area of approximately $74 \mathrm{~km}^{2}$ (GRCA, 1993).

Subwatershed studies are similar in methodology and content to watershed studies, but provide a finer resolution of information that is more useful for local planning. Subwatershed studies also outline the monitoring requirements necessary to allow for development to occur. Conducted in conjunction with the local Conservation Authority, these studies are more often the responsibility of both the development industry and the municipality.

Table 7 lists the subwatershed studies for each of the selected municipalities as being in progress or partially complete. This is because while some subwatersheds have been thoroughly studied, cthers have not. As of 2003 , the Credit Valley Conservation Authority had only completed 17 of the 20 required studies (CVC, 2003). There are larger gaps in areas where subwatershed studies do not follow such a systematic approach but are completed on more of an as needed basis, often subject to the will of Council. For example, in Waterloo, there are no subwatershed studies that have been conducted in areas not scheduled for development. Lastly, several other watershed and subwatershed studies are now in need of an update, with data being up to 20 years old. 


\subsubsection{Environmental Monitoring}

As stated in Section 5.2.1, monitoring programs associated with watershed studies and subwatershed studies are currently a major source of planning information for municipalities in the study area. However, the relative utility of monitoring information means that these programs are also conducted in conjunction with a much wider variety of activities.

"The role of monitoring is to measure the success at which resource managers can, in this case, conserve the biological integrity of terrestrial ecosystems" (Morris, 2002). While monitoring initiatives differ from jurisdiction to jurisdiction, there are several key characteristics that are common to all effective programs. The process begins with the identification of program objectives, the selection of relevant scientific indicators and collection of baseline data based on these parameters. As an assessment of progress towards a particular target, a good indicator should be easily measured. Examples of indicators used in terrestrial monitoring programs of selected municipalities are shown in Table 8.

\section{Table 8: Examples of Terrestrial Monitoring Indicators, Selected Municipalities}

\begin{tabular}{|c|c|}
\hline City & Terrestrial Monitoring Indicator(s) \\
\hline Hamilton & $\begin{array}{l}\text { - Presence/absence of selected biota (Dwyer et al., 2002) } \\
\text { - Cumulative area of significant natural areas protected (Hamilton, 2001) }\end{array}$ \\
\hline Guelph & $\begin{array}{l}\text { - Presence/absence of common or rare wildlife species (PEIL, 2003) } \\
\text { - Percent of land in natural open space and park open space (Guelph, 2003b) } \\
\text { - Number of bird species identified during Christmas Bird Count (Guelph, 2003b) }\end{array}$ \\
\hline Burlington & $\begin{array}{l}\text { - Number, type and area of Parks, ESAs and ANSls (Burlington, 1998) } \\
\text { - Number of trees (Burlington, 1998) }\end{array}$ \\
\hline Mississauga & $\begin{array}{l}\text { - Percent of City land use by natural community - forest, wetland, etc. (Morris et al., 2002) } \\
\text { - Number and mean, median, min. and max. size of natural area patches (Morris et al., 2002) } \\
\text { - Percent of urban land use within } 2 \mathrm{~km} \text { radius of natural area patch (Morris et al., 2002) } \\
\text { - Presence/absence of significant wildlife species (Mississauga, 2001) } \\
\text { - Number and diversity of forest bird species (CVC, 2002) } \\
\text { - Number and diversity of wetland frog species (CVC, 2002) }\end{array}$ \\
\hline Waterloo & $\begin{array}{l}\text { - Landbird abundance and diversity - identified by bird calls/sightings (Waterloo, 2001) } \\
\text { - Amphibian abundance and diversity during breeding season (Waterloo, 2001) } \\
\text { - Changes in size of woodlands, wetlands, riparian areas (Waterloo, 2001) } \\
\text { - Movement of herpifauna (i.e. reptiles and amphibians) at RIM Park (Waterloo, n.d.) }\end{array}$ \\
\hline London & $\begin{array}{l}\text { - Percent forest cover, forest density and forest interior (UTRCA, 2001) } \\
\text { - Presence/absence of White-tailed deer in Sifton Bog - visual count of pop. (London, 2003r) }\end{array}$ \\
\hline
\end{tabular}

As it would be impossible to continuously monitor every environmental aspect within the urban ecosystem, indicators must be used. However, careful consideration must be given to the selection of meaningful indicators. In particular, "[e]nvironmental indicators have to be based on the delivery of the information needed, not the data that is [sic] easily collected" (EMAN, 2003). While information provided by the Christmas Bird Count is easily accessible (see Table 8), it is likely not the most meaningful nor accurate measure of ecological sensitivity and habitat protection. 
As part of an ongoing process, these indicators are then measured at regular intervals, such as on a daily, monthly, seasonal or annual basis. This periodic measurement allows for the identification of trends which would indicate positive and negative changes in the ecosystem. Similar to the selection of indicators, the measurement interval must be logically connected to the monitoring objectives. For example, data collected on urban wildlife must take into consideration seasonal variations in species breeding and migration patterns. Bird counts taken only in the summer months or during the day may not capture important bird roosting behaviour observed during the spring and fall migrations or at night (Burlington, 2002).

Once collected, monitoring data are then documented and analysed to determine trends, areas of management success and areas requiring improvement or corrective action. Assessment of environmental conditions based on these data are integral to the process of making effective management decisions. First and foremost, monitoring allows for a municipality to effectively implement adaptive planning and management. Adaptive planning is an approach to management that is characterized by a continuous cycle of flexible planning, implementation, monitoring, evaluation and adjustment according to lessons learned (PEIL, 2003). Monitoring assists in this cycle by assessing and integrating this scientific knowledge into revised planning strategies.

However, terrestrial wildlife monitoring can also have numerous other benefits for planning and management within a municipality. It can be used to locate sensitive areas and to develop an understanding of wildlife patterns and natural corridor use. This knowledge is then applied to the development and implementation of future resource management policy. Monitoring can also be used as an early waming detection system, making problem detection possible before serious damage occurs.

Despite the known benefits, a review of the six selected municipalities found that terrestrial monitoring tends to be far less extensive than aquatic or riparian monitoring. Systematic wildlife surveys are viewed as being extremely time consuming and costly, as the mobility of most terrestrial species makes it difficult to obtain a clear picture of their distribution. This is further complicated by the general suggestion that, as most open space decisions are based on habitat distribution rather than wildlife distribution, there is no real need to know the location or population density of each species. Reasons for which this may be a fallacious assumption will be discussed in Section 5.2.1.

In addition, it was found that the majority of terrestrial monitoring activities are undertaken by the local Conservation Authorities. As a result, in most cases, it would appear that terrestrial conditions are only of interest for monitoring in so far as they are an important determining factor for water quality and quantity. As such, terrestrial species monitoring is often limited to habitat density, vegetation, land birds, amphibians and rare species. Indicators tend to relate to the presence/absence of species based on inexact site observations. More meaningful quantitative data is rare. The biomonitoring that does occur is infrequent, often conducted less than twice per year. This is an insufficient interval given species movement and temporal behaviour variations.

One of the greatest impediments to the monitoring of biodiversity is cost. The easy-to-quantify costs but often difficult-to-quantify benefits of environmental programs and scientific studies mean that these initiatives are often negatively impacted during times of budgetary constraint. 
However, the experience of agencies involved in monitoring has revealed its inherent value. According to Waterloo (n.d.), this inherent value includes benefits in the form of environmental and human health, quality of life for residents, relationships and partnerships with various agencies, and project efficiencies. Data generated through monitoring allow a municipality to identify areas under stress and set priorities such that efforts can be focused on areas that will benefit most from interventions. Cost savings are also realized if problems can be identified and remedied before serious damage occurs.

For example, to be effective in human-wildlife conflict management, monitoring information should be used to influence land use decisions in a way that proactively mitigates future potential wildlife conflicts. In the City of London's Sifton Bog, a deer monitoring program was established only after the deer-resident conflict had reached a crisis level. This reactive measure has severely limited the number of feasible deer management options (UTRCA, 2003). By contrast, results of on-going White-tailed deer monitoring in the City of Waterloo RIM Park area have acted as an early warning system, having already been used to identify deer concentration areas, as well as to modify landscape planting species and locations (Waterloo, n.d.).

In point of fact, the City of Waterloo has been both nationally and internationally renowned for its watershed monitoring programs (Waterloo, n.d.). According to one respondent from the City of Waterloo, this success can be attributed to two main factors - (1) capacity for fieldwork that is supported by a strong economy, and (2) strong citizen support. Can these two factors be effectively encouraged in other municipalities to increase the amount of terrestrial biomonitoring?

\subsubsection{Biodiversity Science BMP: Community-Based Monitoring}

One solution that has been proposed to help overcome municipal resource shortages for the collection of biodiversity science and information is the concept of community-based monitoring (CBM). This is also being increasingly recognized by municipalities. For example, the City of Guelph State of Sustainability Report (2003) included a recommendation that the City improve its performance on habitat protection through the development of a protocol for community-based monitoring.

More than just the support of volunteers, community-based monitoring is "a process where concerned citizens, government agencies, industry, academia, community groups and local institutions collaborate to monitor, track, and respond to issues of common community concern" (EMAN, 2003). For instance, the City of Waterloo depends on cooperative partnerships with other agencies, universities and the development industry to carry out the Laurel Creek Watershed Monitoring Program (Waterloo, 2002). Other notable examples of successful CBM programs include the Nature Watch Programs administered by the Ecological Monitoring and Assessment Network (EMAN) of Environment Canada and the national bird count efforts supported by Bird Studies Canada (Whitelaw et al., 2003). ${ }^{12}$ Each is a volunteer monitoring

12 EMAN monitoring initiatives include FrogWatch, PlantWatch and WormWatch. National programs supported by Bird Studies Canada include include FeederWatch, NestWatch and the Christmas Bird Count. These programs encourage individuals or groups to engage in monitoring of aspects of environmental quality and provide the resources (e.g. observation kits, instructions and training) to ensure that citizens submit meaningful results. 
program that has demonstrated how citizen-science, with a bit of expert guidance, can collect valuable data for decision-making. The results of Bird Studies Canada surveys are now being utilized by various municipalities as indicators of ecosystem health (Guelph, 2003b).

Even at a local scale, the increasingly recognized benefits of community-based monitoring activities have resulted in an abundance of smaller, less coordinated programs. One example of this is the development and delivery of a Bio-blitz. A Bio-blitz is a community-based volunteer initiative with the objective of surveying an area to identify and record as many species as possible, from as many taxonomic groups as possible, within a 24-hour period (CBI, 2001). As an initiative that links science, education and public participation, a Bio-blitz is best described as being part science, part publicity stunt (Johnson, 2003.06.28). However, in many areas these events also represent the first ever attempt to inventory local species. The involvement of both amateur and expert biodiversity specialists with members of the general public helps to ensure the scientific integrity of the data collected as a result of the blitz (CBI, 2001; Johnson, 2003.06.28). If conducted on an annual basis, Bio-blitzes can become the biodiversity benchmark against which ecosystem changes are measured. In Ontario, recent Bio-blitzes have not only attracted high-level media attention but have also contributed valuable information for future municipal planning decisions (CBI, 2001).

Whitelaw et al. (2003) have developed the following list of CBM benefits to include, but not be limited to:

1. extension of government or academic monitoring networks;

2. cost savings due to in-kind contributions of volunteers;

3. flexibility to carry out fieldwork during non-office hours;

4. provision of information for early (if uncertain) detection of ecosystem changes that may merit further expert investigation or long-term monitoring;

5. exposure of people to the environment and development of stewardship ethic;

6. contributions to government planning through enhanced public participation; and

7. potential to inform public debate, influence local government and promote adaptive management.

Most important to municipalities, CBM can be used to fill the gaps in existing government capacity to monitor ecosystems that have been left as the result of cutbacks to environmental programs and activities (Whitelaw et al., 2003). However, volunteer monitoring programs should be carefully designed to complement, not replace existing programs for scientific monitoring.

In 2003, EMAN published the results of a pilot project aimed at determining the best approaches for engaging communities in monitoring activities that contribute to local sustainability. This pilot project resulted in the development of a model to be used as a reference for other communities interested in starting up a CBM program. According to EMAN (2003), a successful CBM involves four key interrelated and cyclical phases:

1. Community Mapping - Gathering information about the community to understand the local context. This phase must answer questions related to local information needs, existing monitoring initiatives, community governance and community interest in monitoring. 
2. Participation Assessment - Citizen engagement and understanding the groups and people involved in the CBM. This helps find the best approaches for building capacity by developing an understanding of participants motivations, expectations, skills, expertise and training requirements. This stage will often include a community visioning process.

3. Capacity Building - Enhancing the community's ability to carry out monitoring requires capacity in the form of resources and skills, both technical and social. This phase requires the development of good coordination, training and information delivery mechanisms.

4. Information Gathering \& Delivery - Collection of monitoring data and conversion of data into useful information for decision making. To be useful, data to be collected should be defined and driven by the needs of the community. Effective communication mechanisms are required to ensure that information can be used to influence meaningful action.

Since all communities are unique, the above model must only be considered as a guide and applied in a manner appropriate to the local context (EMAN, 2003). Each community must also review best management practices in order to address particular problems or constraints that may jeopardize the success of their CBM process. Such problems may include a loss of interest by volunteers, lack of participant objectivity, questionable accuracy of data collection, and inconsistent funding that causes data fragmentation (Whitelaw et al., 2003). To attain meaningful results, it is critical that adequate funding and a commitment to the CBM process be secured prior to the initiation of monitoring activities.

\subsubsection{Additional Monitoring Initiatives and the Need for Integration}

While watershed studies and subwatershed studies provide most of the information currently used for planning, they leave considerable information gaps. A subwatershed study that looks only at areas scheduled for development may miss important biodiversity features within other natural areas. In addition, the broad scope and limited resources available for watershed studies or associated monitoring programs does not allow for a detailed examination of every environmental aspect within the urban ecosystem. These information gaps are often filled by numerous smallscale, ad hoc studies.

When asked what sources of information on open spaces or wildlife are used for planning and operations, respondents from each of the selected municipalities listed on average 5 additional sources. ${ }^{13}$ Examples of additional monitoring or other studies that are common to most municipalities include:

- Environmental impact statements (EISs) prepared by the City or development industry;

- Ecological Land Classification (of vegetative communities);

- Inventories on ESAs included in the Official Plan or other Master Plans;

- Inventories of City woodlots to be included in Master Plans;

- Regional, landscape-level natural heritage studies or species databases;

- $\quad$ Provincial data on rare species from the Natural Heritage Information Centre;

\footnotetext{
${ }^{13}$ List of 'additional' studies does not include the BNAI (see Section 5.2.5). Those municipalities that had completed a BNAI relied more heavily on this study for planning and operations than any other study.
} 
- Street tree or other public tree inventories;

- Informal studies of areas scheduled for restoration or purchase by the City; and

- Consultant reports prepared for specific sites (e.g. Sifton Bog).

On an individual basis, each of the above studies is useful in the sense that it contributes to the specific management need for which the original research was designed. In some cases, these management needs include human-wildlife conflict management. One notable example is the City of Mississauga's Credit Valley Wildlife Study (2001), designed to identify significant wildlife issues in the Credit Valley. This study is unique among those conducted in the six selected municipalities as, in addition to identifying priority habitat and significant species, it sought to track common mammals and the conflicts that they create with people.

As a collective, this information can also be a useful supplement for the purposes of planning. For example, the Greenway Plan for the City of Guelph was developed before the development of a detailed resource inventory or analysis of the existing corridors. Instead it stated that "[t]his information is, or will become available in the numerous watershed and sub-watershed studies, : zcondary plan studies and reports that have been or are in preparation" (Guelph, 1997).

However, according to at least one respondent, the main challenge is integrating these many sources of information to ensure that the public and decision-makers have sufficient access to make informed decisions. Research for this thesis found no central repository in any municipality for the information that was generated as a result of these many studies, nor evidence of a system to coordinate and track their progress. With information distributed among several departments and agencies, there is a risk that the data required for management decisions could easily be overlooked. There is also a risk of project inefficiencies, such as a duplication of effort or missed opportunities for partnerships.

\subsubsection{Biodiversity \& Natural Area Inventories}

In North America, municipalities have begun to respond to the need for more highly integrated biodiversity data by developing Biodiversity and Natural Areas Inventories (BNAI). Many municipalities consider Biodiversity and Natural Areas Inventories as another form of monitoring (Waterloo, 2002). However, BNAI differ from other monitoring programs in that they are not part of a continuous assessment process. As outlined in Table 9, these studies are typically used to create a one-time, detailed database of facts about the location, size, shape, quantity and quality of natural features, uses and health of natural areas within a municipality. This comprehensive information creates a baseline that assists the municipality in responsible planning; assessing the relative environmental significance of natural areas to set priorities for management, predicting the impacts of land use decisions, and setting targets for future conservation and/or use (Ottawa, 1999; Mississauga, 2000; Dwyer et al., 2002).

The importance of Biodiversity and Natural Areas Inventories has been well recognized by experts as a critical step towards the best management of municipal biodiversity resources. It is now recommended that, at a minimum, each municipality conduct a BNAI to identify existing natural and open spaces, regardless of ownership, and to inventory the resources of which they 
are comprised (Andrews and Cranmer-Byng, 1981; Platt et al., 1994; Inoguchi, 1999; Savard et al., 2000; WHC, 2001).

This recommendation has also been recognized by several Canadian municipalities, including many of those in southern Ontario. Four of the six selected municipalities have either completed or are in the process of completing such initiatives (see Table 7). ${ }^{14}$ The City of Guelph

Environmental Action Plan (2003b) placed a particular importance on the need to address gaps in resource inventories, making data collection for an inventory of selected natural features and the development of a strategy for routine data collection among its first priority environmental actions. This recommendation is also reflected in other City of Guelph planning documents, such as the City of Guelph State of Sustainability Report (2003) and the Official Plan (1995). The Official Plan (1997) for the City of Burlington also includes a commitment to periodically prepare and update an inventory of significant natural areas within the urban planning area. While the City of Waterloo Environmental Strategic Plan (2002) recommended that an inventory of the size and health of municipal greenspaces be prepared, there is no evidence that this sort of initiative is yet taking place.

Why should a Biodiversity and Natural Areas Inventory be so important to these municipalities? According to one respondent from the City of Guelph, a BNAI is urgently needed as municipal planners in Guelph currently do not have the knowledge that is required to effectively implement the recommendations that have been made in the watershed studies. Natural areas have not been ranked according to priorities for protection, restoration and management because the City does not know for certain what natural features they contain. A large amount of the information contained in subwatershed studies has been researched by consultants for the development industry, but little of this has yet been verified by the municipality. As such, the municipality is lacking a crucial base of knowledge that is needed to support or challenge data presented by developers in environmental impact statements (EIS). The City of Guelph is thus concerned that, due to factual or technical errors in EIS, urban natural features are in decline. This situation is likely to be reflected in other municipalities that have yet to conduct a BNAI.

Similarly, respondents from municipalities that have completed a BNAI spoke to its multiple benefits for both the agencies responsible and the community. In the City of Hamilton, a computer model is now being developed based on information generated during the BNAI to assess and predict the impact of land use changes within the municipality. This is one of many otherwise impossible planning initiatives that has been made practicable by a BNAI. Overall, municipal experience has shown how a BNAI can be used to:

- $\quad$ Provide information to decision makers, developers and the public;

- Monitor the status of species, with particular emphasis on rare species;

\footnotetext{
${ }^{14}$ The City of Guelph is not included in Table 7 as Guelph had not yet begun its inventory study. In February 2004, Phase I of the study was in progress. This included background research, identification of areas for field work, contact with landowners, and a public process to define the concept of 'local significance'. Phase II inventory fieldwork - was expected to officially begin in the Summer of 2004. Phase III - development of an integrated municipal stewardship program - will be completed at the end of the study. In February 2004, project budget was limited $(\$ 60,000-\$ 90,000)$ but is expected to be enhanced by external partnership funding.
} 
- Monitor the status of plant communities, with particular emphasis on rare communities;

- Identify and heighten awareness of Environmentally Significant Areas (ESAs) and other natural areas;

- Provide information to rank priorities for conservation or restoration of natural areas;

- Generate a municipal base of data that can be used to verify, support or challenge data presented by developers in environmental impact statements; and

- Collect baseline data such that it is possible to monitor the impact of land use change and to develop models to more accurately predict future impacts.

As discussed in Section 5.2.4, some information is already available for significant natural areas (e.g. ESAs, wetlands, woodlots, etc.) that have been previously studied for provincial and/or municipal conservation designations. The success of BNAI is dependent in part on the extent to which they build upon these previous studies, effectively integrating existing data and generating new data. However, while these tend to focus on public land resources, there is also a need to know what exists in municipality as a whole - both public and private land. 
Table 9: Characteristics of Biodiversity and Natural Areas Inventories (BNAI) Conducted by Selected Municipalities

\begin{tabular}{|c|c|c|c|}
\hline $\begin{array}{l}\text { Study } \\
\text { Characteristic }\end{array}$ & Hamilton & Burlington & Mississanga \\
\hline Study Title & Nature Counts! (2001-2002) & $\begin{array}{l}\text { Halton Natural Areas Inventory } \\
\text { (2003-present) }\end{array}$ & Natural Areas Survey (2000) \\
\hline $\begin{array}{l}\text { Purpose/ } \\
\text { Objectives }\end{array}$ & $\begin{array}{l}\text { - To re-examine existing and candidate } \\
\text { ESAs to see if conditions have changed } \\
\text { within them (from 1990-1991 NAI) } \\
\text { - To find out whether the rare species } \\
\text { reported in 1990-1991 were still present, } \\
\text { and to check for the presence of } \\
\text { additional rare species } \\
\text { - To obtain plant community information } \\
\text { using the OMNR Ecological Land } \\
\text { Classification systems } \\
\text { - To incorporate all data into a geographic } \\
\text { information system (GIS). } \\
\text { - Input into new City of Hamilton's first } \\
\text { Official Plan and 30-year growth strategy. }\end{array}$ & $\begin{array}{l}\text { - Conduct a comprehensive and current } \\
\text { biological inventory of all significant } \\
\text { habitats in Halton Region } \\
\text { - Provide information to the general public } \\
\text { and agencies making decisions concerning } \\
\text { the environment } \\
\text { - Provide supporting documentation for the } \\
\text { protection of natural areas through their } \\
\text { inclusion in local and regional official } \\
\text { plans. }\end{array}$ & $\begin{array}{l}\text { - Identify and inventory natural areas } \\
\text { - Recommend strategies and guidelines for } \\
\text { the future protection of natural areas }\end{array}$ \\
\hline Methods & $\begin{array}{l}\text { - Site selection process systematically } \\
\text { identified new or priority areas for study } \\
\text { - Flora \& fauna inventories (plant } \\
\text { communities, vascular plants, butterflies, } \\
\text { breeding birds, herpotofauna and } \\
\text { mammals) } \\
\text { - Database management and GIS used to } \\
\text { digitally store data and produce maps } \\
\text { - Ecological Land Classification (ELC) to } \\
\text { classify areas at a landscape level }\end{array}$ & $\begin{array}{l}\text { - Flora and fauna inventories to develop } \\
\text { comprehensive list of species for each area } \\
\text { (birds, butterflies, mammals, vascular } \\
\text { plants, reptiles and amphibians) with a } \\
\text { main focus on rare species } \\
\text { - Database management and GIS used to } \\
\text { digitally store data and produce maps } \\
\text { - Ecological Land Classification (ELC) to } \\
\text { classify areas at a landscape level }\end{array}$ & $\begin{array}{l}\text { Conducted in four phases over three years: } \\
\text { - review of existing reports and databases; } \\
\text { - survey of public opinion on environmental } \\
\text { issues; } \\
\text { - site visits to } 144 \text { remnant natural areas; and } \\
\text { - development of databases for the natural } \\
\text { areas. } \\
\text { One quadrant of the City is updated each } \\
\text { year. }\end{array}$ \\
\hline Study Area & $\begin{array}{l}\text { - Most study sites included natural areas } \\
\text { from } 1991 \text { NAI, but also added/extended } \\
\text { sites; } 108 \text { sites (up from } 80 \text { in } 1991 \text { NAI) } \\
\text { - Focus on existing and proposed ESAs } \\
\text { - Public and private lands }\end{array}$ & $\begin{array}{l}\text { - All mid- to large-size natural areas in } \\
\text { Halton Region (includes Hamilton) with a } \\
\text { focus on existing and proposed new ESAs } \\
\text { - Public and private lands }\end{array}$ & $\begin{array}{l}\text { - } 144 \text { natural areas within the City of } \\
\text { Mississauga; woodlands, wetlands, creeks } \\
\text { and streams. } \\
\text { - Public and private lands }\end{array}$ \\
\hline
\end{tabular}




\begin{tabular}{|c|c|c|c|}
\hline (con't) & Hamilton & Burlington & Mississauga \\
\hline Study Costs & $\begin{array}{l}\text { - Total Project Budget: } \$ 427,900 \\
\text { - Financial Contribution: } \$ 382,000 \\
\text { - In-kind Contribution: } \$ 45,900 \\
\text { - Total \# Project Funders: } 12\end{array}$ & $\begin{array}{l}\text { - Total Project Budget: } \$ 500,000 \\
\text { (includes both financial and in-kind) } \\
\text { - Total \# Project Funders: } 14\end{array}$ & No data. \\
\hline $\begin{array}{l}\text { Project } \\
\text { Manager }\end{array}$ & $\begin{array}{l}\text { - Overall project manager: Hamilton } \\
\text { Naturalists' Club (HNC) } \\
\text { - Total \# Contributing Partners: }+8 \\
\text { - Partners include City of Hamilton and } \\
\text { Hamilton Conservation Authority }\end{array}$ & $\begin{array}{l}\text { - Project being managed by } 3 \text { Naturalists' } \\
\text { Clubs: Hamilton NC, South Peel NC, } \\
\text { Halton/North Peel NC } \\
\text { - Total \# Contributing Partners: } 11 \\
\text { - Partners include City of Burlington and } \\
\text { Conservation Halton }\end{array}$ & $\begin{array}{l}\text { - Project manager: City of Mississauga } \\
\text { - No data on contributing partners. }\end{array}$ \\
\hline Main Outputs & $\begin{array}{l}\text { - Updated Access and GIS natural areas } \\
\text { databases } \\
\text { - Two-volume final report document } \\
\text { - Site evaluations and recommendations } \\
\text { - Mammal Atlas }\end{array}$ & $\begin{array}{l}\text { - Final report expected in Spring } 2005 \text {; } \\
\text { available for purchase by public } \\
\text { - HNAI database made available to } \\
\text { partners } \\
\text { - Site evaluations and recommendations }\end{array}$ & $\begin{array}{l}\text { - Final report \& updates available to public } \\
\text { for purchase } \\
\text { - Detailed NAS Maps and Fact Sheets } \\
\text { available to the public (on-line) } \\
\text { - Site evaluations and recommendations }\end{array}$ \\
\hline $\begin{array}{l}\text { Expected } \\
\text { End-users }\end{array}$ & $\begin{array}{l}\text { - Planners in the City of Hamilton } \\
\text { - Scientists, planners and resource } \\
\text { managers in various branches of the } \\
\text { provincial government, esp. OMNR } \\
\text { - biologists, planners and consultants } \\
\text { working for the Conservation Authorities } \\
\text { - public and private landowners, } \\
\text { managers and developers } \\
\text { - environmental consultants } \\
\text { - members of the HNC and other ENGOs }\end{array}$ & $\begin{array}{l}\text { - Collaborative agencies; includes three } \\
\text { levels of government and local/regional } \\
\text { ENGOs } \\
\text { - General public (for purchase) } \\
\text { - Landowners with areas included in the } \\
\text { study. } \\
\text { - Creates baseline for follow-up in future } \\
\text { studies }\end{array}$ & $\begin{array}{l}\text { - Incorporation of management needs } \\
\text { recommendations into Official Plan } \\
\text { - Use of data by City staff when making } \\
\text { decisions regarding proper use of natural } \\
\text { areas } \\
\text { - General public and private landowners }\end{array}$ \\
\hline $\begin{array}{l}\text { Project } \\
\text { Template }\end{array}$ & $\begin{array}{l}\text { - Update to Hamilton-Wentworth Natural } \\
\text { Areas Inventory (1990-1991); relied on } \\
\text { design of } 1991 \mathrm{NAI} \text { as template. }\end{array}$ & $\begin{array}{l}\text { - HNAI template based on Hamilton } \\
\text { experience and methodology in Nature } \\
\text { Counts! }\end{array}$ & $\begin{array}{l}\text { - NAS }(2000) \text { is an update to NAS 1996; uses } \\
\text { NAS } 1996 \text { as a template }\end{array}$ \\
\hline
\end{tabular}

Sources: Dwyer et al., 2002; HRCA, 2003a; HRCA, 2003b; Mississauga, 2000 
Each of the studies presented in Table 9 is an example of a successful BNAI. The City of Hamilton and City of Mississauga have both tested their methodology and, following a few minor adjustments, have now completed a second update to the original study. The BNAI completed by the City of Hamilton has become a key planning document for both the Planning Department in the City of Hamilton and the Hamilton Region Conservation Authority. ${ }^{15}$ Capitalizing on the experience of other municipalities, the BNAI for the Halton Region (including Burlington) is now being modeled after the Hamilton inventory study. These two projects even share the same project coordinator. This sharing of successes and lessons learned among municipalities can create significant savings in terms of both time and resources, particularly as it contributes to good study design and helps to overcome common constraints.

Similar to monitoring, cost can be one of the main impediments to the completion of a BNAI. As seen in Table 9, a well-managed BNAl can be expected to cost upwards of $\$ 500,000$. However, municipal experiences have shown how human and financial resource availability can be easily expanded by the development of partnerships. While the Hamilton Conservation Authority provided for the day-to-day management of the inventory, the Hamilton Naturalists' Club maintained the role of overall project manager because its "charitable non-profit status meant that funds unavailable to government agencies could be obtained" (Dwyer et al., 2002).

As demonstrated by the experience of the City of Ottawa, there is also a strong role for community-based monitoring in the development of a biodiversity or a natural areas inventory. The City of Ottawa is currently in the process of completing a Urban Natural Areas Environmental Evaluation Study (UNAEES). This BNAI study is designed to gather factual information about spaces with measurable natural values within the urban planning area. For the purposes of the UNAEES, residents were considered a valuable source of information on the characteristics, value and use of natural spaces within the community (Ottawa, 2003a). As such, during the planning phase for the study, members of the public were consulted to (a) provide information on the ecology and use of sites selected for study, and (b) suggest additional candidate sites for study based on their knowledge of spaces in the local community (Ottawa, 2003b). Community input resulted in eight new study sites being added to the study, as well as the further expansion of the study area of six existing sites (Ottawa, 2004). Ecological and land use information collected during the field work phase is now being used to rank Ottawa's natural areas and prioritize courses of action for management, protection and naturalization.

Another major obstacle to the completion of a BNAI is landowner consent. As seen in Table 9, an accurate image of urban biodiversity depends on an assessment of the resources of both public and private lands. However, as the inventory is being conducted in an urban area, the majority of land within the study area is privately owned. While permission to conduct non-invasive investigations on private property can be assumed (e.g. as it was in Hamilton's 1991 NAI), methods that seek explicit permission are considered to be more desirable. Permission to access a

\footnotetext{
${ }^{15}$ Despite being well developed, there is some suggestion that the Hamilton BNAI may not be in wide use as a tool across other departments in the City. Interviews with staff from the City of Hamilton Parks Department revealed no knowledge or use of the BNAI in operations.
} 
property not only demonstrates respect for the rights of the property owners but also raises their awareness to issues of local biodiversity. In the experience of municipalities, depending on the method of contact, landowner consent can be as low as $15 \% .^{16}$ Slightly higher participation rates are realized when landowners are contacted in person, but this can be very time consuming (Dwyer et al., 2002).

Though its integration may be a costly addition to the BNAI studies, the final study characteristic to highlight from Table 9 - the integration of data obtained into a spatial database - is not a study constraint, but an example of the value-added by such inventories. This recommended step is common to all effective BNAI as it provides several distinct advantages for urban planners (Platt et al., 1994; WHC, 2001). First, it allows the municipality to integrate and store all data from the BNAI with historical data from other studies in one centralized computer program. This helps to ensure that decisions taken are based on a complete set of the best possible information. Second, it allows the municipality to digitally map and visually present and analyse the study findings.

To date, Biodiversity and Natural Areas Inventories do not include special considerations for nuisance species. However, Section 7.3 outlines how such spatially referenced information may be useful for human-wildlife conflict management in the future.

\subsection{RECOMMENDATIONS FOR BIODIVERSITY SCIENCE AND INFORMATION}

This Section has demonstrated the wide range of environmental studies being undertaken by each of the six selected municipalities. However, the question remains - if there is so much data available, why is improved scientific information on urban biodiversity still necessary?

The first major challenge now faced by municipalities relates to the data that are collected. This analysis supports the results of other studies which have found that, "[r]eporting on the quantity and quality of urban habitats is rarely done" (WHC, 2001). While the selected municipalities have mapped the more dominant natural areas and characterized broad vegetation types, they have spent less time evaluating their value as quality habitat or identifying the species therein. While the BNAI are a step in the right direction, the scope of these studies is frequently still isolated to ESAs. The information on species that would be required to implement spatially referenced solutions to human-wildlife conflicts (see Section 7.3) is still largely lacking. Studies that explore other areas of knowledge deficiency (e.g. the epidemiological risks associated with nuisance species as a vector for disease) are also still in need of development.

The second major challenge is the relative utility of the data that are collected. Municipalities do not just need to deliver environmental information, but they also need to increase community capacity to understand and use that information (EMAN, 2003). To be effective in humanwildlife conflict management, monitoring information should be used to influence land use decisions in a way that proactively mitigates future potential wildlife conflicts. To accomplish this, it is recommended that municipalities undertake a study that specifically relates to wildlife

\footnotetext{
${ }^{16}$ However, it should be noted that the low consent rate is linked more to a lack of landowner response than aversion to the BNAI study (Dwyer et al., 2002).
} 
issues is the urban area. This could be something similar to or even more in depth than the City of Mississauga's Credit Valley Wildlife Study (2001). However, in order for such a study to be effective, it must first ask the right questions. Therefore, this may also require more front-end research into the socioeconomic aspects of human-wildlife conflicts.

The question of access to information has also not yet been fully addressed. The public and other non-government stakeholders were found to have relatively open access to the results of the watershed studies, subwatershed studies and BNAI. The results are available for purchase in some municipalities (to assist in covering the cost of the research) while others provide them free of charge. Only sensitive data, such as the location of rare species, may be withheld. However, the real challenge is finding it. In many cases, the information that wildlife managers, open space planners and the public need to make decisions simply does not exist. However, where the data do exist, it is clear that the many sources must be integrated to ensure that the public and decision-makers have sufficient access to make informed decisions.

Therefore, it is recommended that municipalities and their related Consen ation Authorities work in partnership with other agencies to complete both a BNAI and a more detailed wildlife study. In doing so, municipalities should not only review the best management practices of other urban areas, but should also look for areas where data, expertise, resources or even staff can be shared to increase opportunities for project efficiencies. Finally, it is also recommended that municipalities increase their capacity for gathering data on urban biodiversity by implementing protocols for community-based monitoring. A review of the pilot-tested modei for CBM developed by EMAN is a good first step in this direction. ${ }^{17}$

${ }^{17}$ This model can be viewed on-line: www.ccmn.ca/english/library/ccmn.pdf. 


\subsection{PLANNING FOR NATURALIZATION AND CONI LICT MITIGATION}

Based on testimony provided during interviews and municipal documentation, this section will explore the development of naturalization projects in the six selected municipalities, what initiatives are currently taking place, how they are planned and implemented, and if these processes take into consideration community concerns for nuisance species. This section will also outline some of the best management practices that have been proposed to help reduce the frequency and/or severity of human-wildlife conflicts that might result from naturalization and urban development.

\subsection{The NeEd for Enhanced Naturalization Planning}

The ability for a given area to support any species is dependent on the availability of food and shelter (Belant, 1997). As a result, a wildlife population will generally increase in response to habitat protection measures that enhance the abundance of such resources (Messmer, 2000). In urban centres, this is often accomplished by closing areas to developr." nt to protect species and habitats or by reversing previous development impacts on habitat via naturalization. However, problems arise as these protection measures are undertaken "often without regard to the activity ranges of the animals to be protected or to in-holdings, where land use patterns conflict with the surrounding area" (Fall and Jackson, 2002). Such is the case with protected open spaces surrounding residential areas or urban airports, where public perceptions of lethal measures or concerns for public safety mean wildlife cannot be managed using traditional methods.

Naturalization has been defined as both an experimental science and an urban project, where each step must be subject to monitoring, review and debate (Middleton, 1994; Alario, 2000). However, while a great deal of research has been directed towards determining the ideal 'environmental aesthetic' for urban restoration projects, there has been less focus on research for the purpose of monitoring human-wildlife interactions (Johnson, 1995; Parsons, 1995; Schauman and Salisbury, 1998; Gobster, 2001).

In addition to applicable science, Schauman and Salisbury (1998) demonstrate how the "restoration of urban green areas requires two complementary efforts, (1) a plan or process to locate and rank potential restoration sites and (2) an understanding of how restoration designs will be accepted, and therefore, maintained by nearby residents". As will be discussed in the following sections, the capacity of $n$ unicipalities in southern Ontario to realize these efforts is currently ir need of significant improvement. 


\subsection{Naturalization TRENDS IN SELECTED MUNiCipalrties}

Naturalization is often seen as an evolution of the urban process. Many urbanized areas have now reached a level of development where highly valued natural areas have become scarce. Residents in many municipalities have shown support for an increase in the amount and quality of environment-oriented urban land. For example, a public survey associated with the City of Hamilton Parks, Culture and Recreation Master Plan (2002) found that approximately 36\% of residents surveyed support new and improved natural open spaces. As a result, municipalities are now acquiring open spaces and, where possible, maintaining and enhancing natural form (Schauman and Salisbury, 1998).

As noted in Section 3.1, starting in the 1980s, a number of municipalities in southern Ontario began to retrofit urbanized areas to include natural components through the process of naturalization (Ingram et al., 2001). This is true of each of the six municipalities selected for study, each of which has made significant progress in this area. For example, the City of Mississauga's naturalization program now includes more than 200 sites and over 303 ha of public land (Mississauga, 2002). In addition, each of the six select $x$ municipalities continue to relatively aggressively pursue additional environmental land acquisition and rehabilitation projects (Mississauga, 2002; Waterloo, 2002; Guelph, 2003a; HCA, 2003).

As a result, a continuing challenge for these municipalities is to determine how to best integrate the degraded and/or unused open space resources of the city into the land use system in order to maximize diversity (Platt et al., 1994). During research, only three of the selected municipalities London, Guelph and Mississauga - could present evidence of having developed a coordinated municipal policy or program that could be used to guide naturalization. ${ }^{18}$

However, a formal naturalization policy is not a prerequisite for the generation of naturalization initiatives within the urban area. The City of Waterloo is a prime example of how a more diffuse naturalization program, with numerous small changes in policy and practice, can aggregate over time to result in significant landscape modifications. Table 10 outlines some of the major naturalization-related initiatives that have been introduced in the City of Waterloo since the late 1970's.

\footnotetext{
${ }^{18}$ While the City of Waterloo's Environmental Lands Acquisition and Maintenance Strategy (1999) can be considered a naturalization policy, it is limited in scope. As a result, it has not been counted as such for the purposes of this analysis. As of the May 2004, a naturalization policy for the City of Burlington had been proposed but not yet approved.
} 
Table 10: Naturalization and Regeneration Initiatives, City of Waterloo.

\begin{tabular}{|c|c|c|}
\hline City Initiative/Policy & Start Year & Description of Naturalization Benefits \\
\hline Plant Health Care Program " & $1970 \mathrm{~s}$ & - Phased pesticide reduction on City-owned land \\
\hline Urban Forestry Practices ${ }^{a}$ & 1990 & $\begin{array}{l}\text { - Policy guiding developers outlining number and species } \\
\text { of trees, and } 5 \% \text { park designation per subdivision. } \\
\text { - Tree savings plan in place for new developments. } \\
\text { - Preservation of buffer areas around woodlands, wetlands, } \\
\text { and creeks. }\end{array}$ \\
\hline $\begin{array}{l}\text { Mowing of Parkland and City } \\
\text { Open Space Adjacent to } \\
\text { Watercourses Policy ab }\end{array}$ & 1990 & $\begin{array}{l}\text { - Areas along watercourses are continually allowed to } \\
\text { naturalize and left ummowed. Often achieved with help } \\
\text { of planting projects done by volunteers. }\end{array}$ \\
\hline $\begin{array}{l}\text { Mowing of Parks and Open Space } \\
\text { Policy }{ }^{\mathrm{b}}\end{array}$ & 1990 & $\begin{array}{l}\text { - Park and open space areas are continually allowed to } \\
\text { naturalize and left unmowed (where viable). }\end{array}$ \\
\hline Official Plan Policies ab & 1994 & $\begin{array}{l}\text { - Constraint levels designated to various areas in the City, } \\
\text { based on their natural features (restricts development). } \\
\text { - Designation of } 15-30 \text { m buffer areas along all streams, } \\
\text { wetlands and forests. }\end{array}$ \\
\hline $\begin{array}{l}\text { Woodland Acquisition and } \\
\text { Maintenance Policy }{ }^{b}\end{array}$ & 1996 & $\begin{array}{l}\text { - Acquisition of woodlands for their protection. } \\
\text { - Management plans implemented (may include } \\
\text { enhancement of area). }\end{array}$ \\
\hline Partners in Parks ${ }^{a}$ & 1996 & $\begin{array}{l}\text { - Promotes citizen involvement in greenspace management } \\
\text { - Projects include various forms naturalization and/or area } \\
\text { clean-up. }\end{array}$ \\
\hline $\begin{array}{l}\text { Environmental Lands Acquisition } \\
\text { and Maintenance Policy }{ }^{\text {a }}\end{array}$ & 1999 & $\begin{array}{l}\text { - Acquisition of environmental lands for their protection. } \\
\text { - Management plans implemented (may include } \\
\text { enhancement of area). }\end{array}$ \\
\hline
\end{tabular}

Source: (a) Waterloo, 2002; (b) Waterloo, 2003

While their implementation has been diffuse, the results of the various naturalization programs outlined in Table 10 have been significant. Since 1989, 161.53 ha of park and open space has been designated as 'no-mow' creek buffer area (Waterloo, 2003). As of 1990, all new subdivisions have had an "appropriate" number of trees planted - the equivalent of approximately 1400 new trees per year (Waterloo, 2003). In 1999, more than $46 \%$ of the 688 ha of woodlands in the City of Waterloo were under public ownership for protection and ecological management (Waterloo, 1999). By the year 2000, over $40 \mathrm{~km}$ of Waterloo's $91 \mathrm{~km}$ of total creek length had been naturalized or rehabilitated to some extent (Waterloo, 2003).

According to one respondent from the City of Guelph, these municipal achievements do not even begin to compare to what has been accomplished by the non-government community. Two volunteer naturalization initiatives have virtually changed the landscape of Guelph - (1) Trees for Guelph, a massive tree planting initiative on unused open lands, and (2) an Ontario Public Interest Research Group (OPIRG) managed initiative to transplant mature trees from areas to be 
developed to natural areas in need. ${ }^{19}$ Though frequently smaller in scale, similar volunteer-led naturalization initiatives can also be found in each of the five other selected municipalities (see Section 6.4).

Volunteer participation is attractive to mumicipalities and Conservation Authorities that undertake naturalization projects as it not only helps to secure the success of projects through the development of a sense of public ownership, but also helps to expand limited financial and human resources. The initial costs associated with a naturalization project may be high. According to one respondent from the Parks Department in the City of Mississauga, average annual costs of their city-wide naturalization program can be broken out as follows:

(Average) Budget Expense

$\begin{array}{cl}\$ 50,000 & \text { - plant materials and supplies } \\ \$ 50,000 & \text { - partnerships with the Conservation Authority } \\ +\$ 25,000 & \text { - community coordination and school initiatives } \\ & \end{array}$

Similarly, the current purchase price for environmental lands in the City of Waterloo is estimated at $\$ 2,650$ per acre (Waterloo, 1999). Assuming that the Capital Budget program provides for the purchase of 30 to 40 acres of environmental lands per year, the City of Waterloo estimates the additional maintenance/management costs of their acquisitions to be in the range of $\$ 2100-\$ 2900$ annually (Waterloo, 1999). However, once established, the low level of maintenance that is generally required to sustain a naturalized area can result in significant cost savings when compared to the alternative of continuing conventional horticultural practices (Guelph, 1993). This assumes that the projects are successful.

\subsection{Criteria Used for Naturalization PlanNing}

Given the commitment of resources, municipalities and other organizations involved in naturalization should look for means to ensure a positive return on investment. Though not required, formal naturalization policies and programs do benefit the municipality by providing direction in decision-making. Without this, decisions for naturalization projects are taken on a very opportunistic basis. According to respondents, municipal experiences have shown how opportunistic naturalization projects that are taken as a result of political will or visibility are more likely to fail than those that are well planned.

This theory is also supported by several authors (Schauman and Salisbury, 1998; Pedroli et al., 2002). Pedroli et al. (2002) emphasize that a relatively high level of impact assessment is required to ensure the success of restoration projects. Such assessments help to determine not only viable areas for naturalization, but also the goals, actions, resource requirements and possible constraints

${ }^{19}$ OPIRG is an incorporated, non-profit volunteer organization that focuses on social, political, economic and environmental issues of public concern in Ontario. 
on a project. Next to resource availability, other major constraints might include other societal demands on the natural area and a lack of community support.

Despite the importance of this step, only three of the six selected municipalities have developed some type of prioritization criteria for their naturalization projects - Mississauga, Waterloo, and London (see Table 11). These criteria are often associated with formal naturalization policies or programs, if limited in scope. 
Table 11: Naturalization Project Prioritization Methodology/Criteria, Selected Municipalities

\begin{tabular}{|c|c|}
\hline City & Description of Prioritization Methodology/Criteria \\
\hline Hamilton & $\begin{array}{l}\text { - The City of Hamilton does not yet have a formal system or formal criteria for the prioritization of naturalization projects. } \\
\text { Projects are currently undertaken based on opportunity for landowner or volunteer cooperation. However, the City is } \\
\text { working on setting up targets for the amount of natural cover to be achieved within the municipality. Based on a landscape- } \\
\text { level analysis of existing natural areas, priorities for naturalization will then be set per habitat type. } \\
\text { The Hamilton Conservation Authority currently uses needs identified in the Nature Counts! (2002) BNAI as the primary } \\
\text { criteria for the selection of naturalization sites. Other criteria include land ownership, funding, effort required and support } \\
\text { from the CA superintendent with responsibility for a particular area. These projects are highly opportunistic, looking to } \\
\text { maximize the amount of natural restoration that can be accomplished given resources for a particular year (i.e. the biggest } \\
\text { "bang-for-buck"). }\end{array}$ \\
\hline Guelph & $\begin{array}{l}\text { - The Naturalization in the Ciry of Guelph Parks Policy (1993) does not include criteria for prioritization of sites. Extension } \\
\text { of Policy to nearly all existing and new City parks is based on success of } 10 \text { pilot projects. } \\
\text { With review of watershed studies, decisions for naturalization are taken by the Grand River Conservation Authority (GRCA) } \\
\text { on an opportunistic basis. Projects with high visibility or political support tend to receive priority. }\end{array}$ \\
\hline Burlington & $\begin{array}{l}\text { City-managed naturalization projects are currently decided on an ad hoc basis by the Naturalization Sub-Committee of the } \\
\text { Environmental Management Team (cross-departmental). However, the Sub-Committee is working towards development of } \\
\text { an overall naturalization plan. Current efforts include a city-wide inventory of existing initiatives and their participants. } \\
\text { Physical and biological parameters as assessed in watershed studies form the initial basis for naturalization projects managed } \\
\text { by the Conservation Authority. However, given the areas of greatest need, projects are undertaken on an opportunistic basis } \\
\text { where the biggest "bang-for-buck" and landowner cooperation can be achieved. }\end{array}$ \\
\hline Mississauga & $\begin{array}{l}\text { - Beginning with a review of maintenance needs, the City of Mississauga tries to implement at least one naturalization project } \\
\text { on each of its watersheds every year. Projects only take priority if they are politically driven or voluntarily adopted by an } \\
\text { interest group. Data for site selection is from the Natural Areas Survey (2000) BNAI and its updates. } \\
\text { Naturalization projects of the Conservation Authority are based on the "ABC" approach - an evaluation of abiotic, biotic and } \\
\text { community factors. Data for the evaluation is derived from studies conducted by the CA or the NAS (2000) BNAI. These } \\
\text { criteria are essentially used to narrow the scope of a project down from the watershed, to the river, river segment and finally } \\
\text { the project site. Habitat type and the biggest "bang-for-buck" are also considered here. } \\
\text { Additional criteria are set out in its Credit Valley Conservation Stewardship Strategy (2000) for the prioritization of } \\
\text { 'Stewardship' projects (often restoration). In evaluating criteria for a particular project, an importance of high, medium or } \\
\text { low is assigned to project elements that will contribute to specific environmental, social or economic benefits, and projects } \\
\text { are ranked accordingly. Project implementation feasibility is also considered as part of this assessment. }\end{array}$ \\
\hline
\end{tabular}




\begin{tabular}{|c|c|}
\hline$\left(\operatorname{Con}^{\prime} t\right)$ & Description of Prioritization Methodology/Criteris \\
\hline Waterloo & $\begin{array}{l}\text { - Under the Environmental Lands Acquisition and Maintenance Strategy (1999), the acquisition of each site is considered on } \\
\text { the basis of: size, social importance, natural heritage features, uniqueness, ecological functions, availability (for acquisition), } \\
\text { development pressures, and open space linkage opportunity. For each site, criteria are ranked on a scale of } 1-3 \text { and the } \\
\text { scored to determine their rating as being either high, medium or low priority. } \\
\text { On other naturalization projects, the Laurel Creek Watershed Study (1993) forms the basis of information used to set } \\
\text { priorities. Prioritization based primarily on a gci, } \\
\text { suitable sites for naturalization over } 10 \text {-year period (starting in } 2002 \text { ). } \\
\text { Other factors considered include political will, visibility, safety and available funding. Projects motivated primarily by } \\
\text { political will tend to have lower success rate as the site location and/or design features selected may not be viable. }\end{array}$ \\
\hline London & $\begin{array}{l}\text { The City of London uses the Natural Features Restoration Program Evaluation and Implementation Manual (Flegel and } \\
\text { Jacob, 1996) to prioritize projects for naturalization in terms of feasibility and benefits. For evaluation, sites are first } \\
\text { classified as either (A) natural space in need of enhancement, (B) unused open space in need of restoration, (C) sites which } \\
\text { contain natural features but are not in need of naturalization, or (D) sites that have no natural features and no space available } \\
\text { for naturalization. Only Category A and B sites are evaluated with the Natural Features Restoration Criteria. Each criterion } \\
\text { is weighted equally with a maximum score of } 6 \text {. The sites are then ranked and rated based on their final score - sites with the } \\
\text { highest score in their classification become the highest priority. The criteria are: } \\
\text { Social Criteria - Proximity to Schools; Volunteer Stewardship; Visibility/Aesthetics; Proximity to Privately Owned Space; } \\
\text { Potential for Damage (to site) } \\
\text { Ecological Criteria - Association with Natural Corridors; Biological Communities in Existing Natural Area(s); Physical } \\
\text { Features and Problems (per project type); Size and Shape of Site; Suitability for Planting; Proximity to Water for } \\
\text { Wildlife; Proximity to Buildings; Proximity to Other Woodlots } \\
\text { Economic Criteria - Maintenance Concerns or Problems; Long Term Maintenance Savings; Project Costs; Short Term } \\
\text { Maintenance Costs } \\
\text { A complete site evaluation requires a site inspection, reference to previous studies, and a consultation with City staff. } \\
\text { Evaluation does not include a biological inventory of the area - considered to have been completed under previous studies. } \\
\text { While the Upper Thames River Conservation Authority (UTRCA) works closely for naturalization with the City, projects are } \\
\text { also undertaken independently. Prioritization decisions of the UTRCA are based on research conducted for subwatershed } \\
\text { 'report cards' using the "ABC" approach - an evaluation of abiotic, biotic and community factors (combined with mapping). } \\
\text { Projects may be opportunistic depending on resources or land owner and voluateer interest. }\end{array}$ \\
\hline
\end{tabular}


As can be seen from Table 11, while only implemented by three municipalities, the need for naturalization criteria has been recognized by all six selected municipalities. The City of Burlington currently has a committee working towards the development of an overall naturalization plan. Similarly, the City of Hamilton is working on setting targets for natural habitat cover that will be mapped against information from the Nature Counts! (2002) BNAI to determine priorities for naturalization. In addition, as the City of Guelph's Naturalization in the City of Guelph Parks Policy (1993) has now expired, commitments were made in the City's most recent Environmental Action Plan (2003b) to update the strategy, as well as other naturalization policies and programs in place throughout the City.

From Table 11, it can also be seen that there are several similarities among those municipalities that have developed and applied naturalization criteria. One common theme is the consideration of not only ecological, but also social and economic factors. This is because selecting restoration sites based on community support is often as critical to the success of naturalization projects as is the ability to map and measure biological and physical parameters (Schauman and Salisbury, 1998; Hands and Brown, 2002).

The City of London learned the importance of this balance in criteria through municipal experiences. Many of the City of London's early naturalization projects failed due to a lack of public consultation. In its worst case scenario, a natural retrofit that was undertaken in the Gainsborough Park area without a community engagement process resulted in so much resistance and negative community feedback that land managers were forced to change the design. Approximately three years of discussions with residents were required in order to reach an agreement on how to 'retrofit the retrofit', resulting in a considerable expenditure of resources. As a result, the City has fundamentally changed the way in which it plans for naturalization (see Section 6.5.1). In addition, the selection and prioritization criteria for naturalization projects in the City of London are now the most stringent of any of the municipalities examined.

According to respondents, concerns for safety and a dislike of (transition stage) aesthetics are now the two most common community complaints associated with naturalization projects. In some cases, community support for naturalization was also found to falter following the introduction of particular nuisance species; primarily deer, coyotes, fox, predatory birds or waterfowl, mice and other rodents, snakes, and 'weeds'. However, research found that none of the six selected municipalities consider the potential influx of nuisances as a possible criteria when planning naturalization projects.

\subsection{COMMUNITY INVOLVEMENT IN NATURALIZATION}

In practice, naturalization has been met with a mixed reaction from residential communities (Arquilla, 1994; Schauman and Salisbury, 1998; Alario, 2000; Gobster, 2001). Community concerns include aesthetics, safety, lack of certainty about project benefits, lost opportunities for alternate land uses, decreased property value on adjacent lands, health problems (e.g. allergies) and floral and faunal pest infestation. As a municipality's most important decision-making factor should be the concerns of the community, these issues must be addressed. 
As seen in Table 11, naturalization sites are often ranked according to degree of public interest. ${ }^{20}$ Broad-based citizen involvement in planning and implementation is critical to the naturalization process as it empowers stakeholders and helps ensure that the restored landscape will be maintained over the long-term (Gobster, 2001). Having recognized this, there are many ways by which municipalities seek to involve the community in naturalization. Developed based on the testimony of respondents, Table 12 outlines how the community is involved in naturalization projects for the six selected municipalities at each phase of project development.

Table 12: Community Involvement in Naturalization per Project Phase, Selected Municipalities

\begin{tabular}{|c|c|c|c|}
\hline \multirow{2}{*}{ City } & \multicolumn{3}{|c|}{ Description of Citizen Involvement } \\
\hline & Planning Phase & Implementation Phsse & Maintenance Phase \\
\hline Hamilton & $\begin{array}{l}\text { Community input during } \\
\text { Master Plan process; staff } \\
\text { are encouraged but not } \\
\text { required to hold information } \\
\text { sessions for specific projects. }\end{array}$ & $\begin{array}{l}\text { High community involvement } \\
\text { of volunteers; volunteer } \\
\text { groups will often contact CA } \\
\text { to initiate projects. }\end{array}$ & $\begin{array}{l}\text { Community interest is low } \\
\text { unless groups take ownership. }\end{array}$ \\
\hline Guelph & $\begin{array}{l}\text { Community consultation } \\
\text { undertaken during Parks } \\
\text { master planning and for } \\
\text { Official Plan. }\end{array}$ & $\begin{array}{l}\text { High community involvement } \\
\text { of volunteer groups. }\end{array}$ & $\begin{array}{l}\text { Community interest is low } \\
\text { unless groups take ownership. }\end{array}$ \\
\hline Burlington & $\begin{array}{l}\text { Open house held prior to } \\
\text { projects; volunteers often } \\
\text { used to collect data for } \\
\text { background studies. }\end{array}$ & $\begin{array}{l}\text { Moderate community } \\
\text { involvement in on-ground } \\
\text { implementation (volunteers). }\end{array}$ & $\begin{array}{l}\text { Community interest is low } \\
\text { unless groups take ownership. }\end{array}$ \\
\hline Mississauga & $\begin{array}{l}\text { Open houses and/or other } \\
\text { public forum held prior to } \\
\text { projects; workshops for } \\
\text { master plan development. }\end{array}$ & $\begin{array}{l}\text { High community involvement } \\
\text { of volunteer groups; low } \\
\text { involvement of general } \\
\text { community. }\end{array}$ & $\begin{array}{l}\text { Community interest is low } \\
\text { unless groups take ownership. }\end{array}$ \\
\hline Waterloo & $\begin{array}{l}\text { Open house held for most } \\
\text { projects; projects that are } \\
\text { likely to be controversial or } \\
\text { high impact require an open } \\
\text { house and council approval. }\end{array}$ & $\begin{array}{l}\text { High community involvement } \\
\text { through Partners in Parks (see } \\
\text { Table } 10 \text { for details). }\end{array}$ & $\begin{array}{l}\text { Community interest is low } \\
\text { unless groups take ownership. }\end{array}$ \\
\hline London & $\begin{array}{l}\text { Community input meeting } \\
\text { required for all projects. }\end{array}$ & $\begin{array}{l}\text { On-ground involvement of } \\
\text { volunteer groups; additional } \\
\text { volunteers identified during } \\
\text { community input sessions. }\end{array}$ & $\begin{array}{l}\text { Community interest is low } \\
\text { unless groups take ownership; } \\
\text { community updates provided } \\
\text { by City. }\end{array}$ \\
\hline
\end{tabular}

${ }^{20}$ None of the six selected municipalities presented any methodology by means of which this level of interest could be quantitatively or qualitatively determined. 
Most respondents agreed that naturalization projects should be initiated with some form of education for the local community. Arquilla (1994) outlines the broad range of media that can be used for this purpose. Similar to other public education efforts, methods include signage, letters to community residents, letters to City council, information pamphlets or brochures, public discussion meetings/presentations, contact with local advocacy groups, and publication/release of planned maintenance prescriptions.

As outlined in Table 12, four of the six selected municipalities regularly conduct an open house and/or public input meeting during the planning of naturalization projects. These are considered to be opportunities for residents to learn about proposed plans for the landscape and to suggest changes based on community concerns. However, a small number of respondents criticized this open house process as being little more than a public relations tool, stating that the public meetings do not attract a wide enough audience to be representative of the community. In addition, it was suggested that the comments from residents that do attend the meetings rarely have an impact on changing the design of projects.

Public safety and the perception of project aesthetics are the most commonly discussed issues of concern during public forums. There is little evidence from the testimony of respondents or municipal documentation that issues related to nuisance wildlife are frequently raised, either by residents or by project planning staff. However, while enhanced biodiversity is viewed as an ecological benefit of naturalization and is a measure of project success, respondents from each of the six selected municipalities also recognized that the potential establishment of nuisance species should be an important project consideration. The reason that this is not raised at public meetings is unknown, but was suggested by one respondent as one of the many concerns that can be overlooked when contact between planning staff and residents is limited.

While initial public interest in a project that is adjacent to a residential area may be high, municipal experience has found that community interest and involvement in naturalization tends to decrease as it moves through the various phases of project development. The high interest in the on-ground implementation of naturalization projects that is demonstrated by volunteer groups is generally not shared by the community as a whole. Without the ongoing interest of volunteers, most municipalities cannot afford to provide for the long-term monitoring or maintenance of naturalization projects. As a result, the success of naturalization projects is generally not tracked past the implementation phase (typically the first $2-10$ years).

As a result, municipal siaff may remain unaware of any negative ecological or social impacts generated as a result of a particular naturalization project until the problem has reached crisis levels. Respondents were able to cite several instances where naturalization projects have later resulted in community complaints regarding wildlife nuisances. For example, while considered an ecological success, concerned residents of the City of Mississauga objected to the presence of coyotes which appeared around Lake Aquitaine following its naturalization. This situation was eventually diffused through the provision of public education. 


\subsection{Proposed BMPs: Nuisances and Naturalization}

Public education is just one of several best management practices (BMP) proposed by respondents to help municipalities reduce the frequency and/or severity of human-wildlife conflicts experienced as a result of naturalization or residential development. All of the following BMP are proposed as proactive solutions, though many may be implemented as a reaction to an existing problem.

\subsubsection{Undertake a Strong Community Environmental Planning Approach}

Respondents from two of the six selected municipalities suggested that the best way to manage urban wildlife is to undertake a strong community environmental planning approach. This could mean (1) planning natural areas such that wildlife is no longer attracted to the urban matrix and/or (2) planning naturalization projects in order to mitigate their impact on adjacent residential areas. Both approaches demonstrate proactive problem solving on the part of the municipality.

As outlined by Middleton (1994), "[a] key to understanding biodiversity in cities is to consider them at a landscape scale, as a mosaic of different types of habitats". The configuration of this mosaic is thought to be of critical importance. For example, as urban areas expand, remnant natural habitats become increasingly fragmented and isolated, as do the floral and faunal species therein. As a consequence, if an isolated species wants to expand its range it has no option but to pass through the relatively inhospitable urban core. This brings the species into potential conflict with humans (see Design A, Figure 6).

Figure 6: Comparison of Urban Configurations for Wildlife Migration

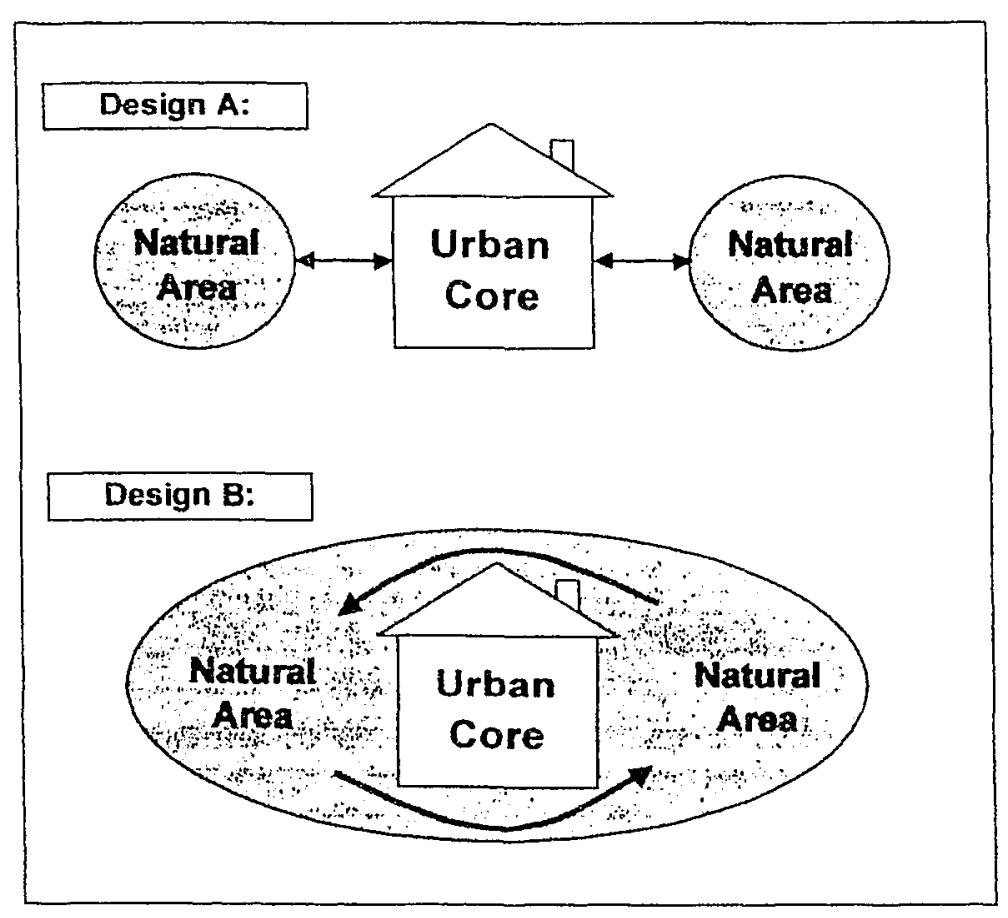


Studies have shown that the frequency of wildlife damage complaints varies among geographic areas and have suggested that this variation is related to local habitat conditions being either favourable or unfavourable for individual species (Hadidian, 1991). As an alternative, an urban configuration that maintains large patches of natural area and ample linkages between habitat patches provides opportunities for wildlife to migrate within the city without being forced to enter the urban core (see Design B, Figure 6).

As outlined in one study, Guelph is seen to have an amount of public, nature-oriented open space that is above the norm for a mid-sized city (Guelph, 1997). The study also applauded the linked nature of a good deal of this public open space network. According to respondents from the Parks and Planning Departments in the City of Guelph, it is by maintaining this urban configuration that the City has been able to avoid most of the common problems associated with urban nuisance wildlife. ${ }^{21}$

However, while the natural preference for more hospitable natural areas and wildlife corridors may keep timid species (e.g. coyotes and fox) from entering the urban core, the same may not necessarily be said of other opportunistic species such as raccoons and rodents that are now well adapted to the urban environment in most areas. If a free meal is available, they will find it. In addition, it has been found that the more that biologically rich areas of a city are connected to each other and to larger expanses of wild habitat, the more species are likcly to survive and thrive (Middleton, 1994). The more species that survive and thrive, the greater the potential for human-wildlife interaction and/or conflict (O'Donnell and VanDruff, 1983). This is why it is important that even cities with urban configurations that are sensitive to the ecological needs of wildlife continue to plan naturalization projects such as to mitigate their potential impact on adjacent residential areas.

There are many ways in which this can be accomplished. First and foremost, naturalization projects should be planned with consultation and participation of the community. Taking this one step further, the City of London has now directly integrated community concerns into its selection criteria for naturalization projects. The priority for a naturalization project is now automatically decreased if there are residential lots within 100 metres of a proposed site (Flegel and Jacob, 1996). In addition, when naturalization must take place in proximity to developments, the City of London now tries to buffer projects by restricting its retrofit activity to the side of the open space that is the furthest from residential properties. These practices are said to be in place to take into consideration possible property owner objections to natural landscaping techniques and the potential for damage to the natural area due to encroachment or vandalism.

\subsubsection{Enhance Technical Considerations for Wildlife During Naturalization}

In addition to strong environmental planning in the community, specific sites selected for naturalization must also be planned for the proactive mitigation of potential human-wildlife conflicts. As outlined by Belant (1997), the architectural design of existing or new facilities and

\footnotetext{
${ }^{21}$ As was discussed in Section 4.2, this perception that nuisance wildlife is not an issue in the City of Guelph is not shared by staff of the Grand River Conservation Authority with responsibility for that area.
} 
the characteristics of adjacent habitat should be considered during the planning stages where nuisance species are likely.

This type of planning requires that the municipality have some prior knowledge of the species that are present in the natural area, the species that are likely to (re)colonize the area following naturalization, and the species which surrounding residents may find undesirable. Regardless of nuisance species presence, it is still recommended that a pre-naturalization inventory of all natural areas be conducted (1) to determine the suitability of the site for restoration, and (2) to set targets for focal species in the habitat and adjust landscape design accordingly (Pedroli et al., 2002). For example, the determination of coyotes as a desired focal species for Toronto's Tommy Thompson Park has led naturalization managers to include constructed den sites in the project design (TRCA, 2000).

Similarly, assuming that potential nuisance species can be identified, naturalization planners can design projects given the active controls that will be required for each specific site. For example, while constructed coyote dens may be appropriate for a relatively remote urban park, they may not be so for a natural area directly adjacent to a residential development. Controls can be designed to either deter or accommodate for species colonization and can include a wide variety of habitat management techniques and exclusionary devices.

To some extent, respondents from all of the six selected municipalities stated that they understood the importance of this type of mitigative landscape design. Most municipalities in southern Ontario have now modified the landscape in at least one site to deter the overabundance of nuisance geese. In addition, it is now common practice for a municipality to discourage the creation of wet components (i.e. mosquito habitat) during natural stormwater management system design.

However, only the City of Mississauga demonstrated evidence that nuisances are regularly considered when planning for naturalization. While the City of London has attempted to create buffers between residents and naturalization projects, this is not done for the specific purpose of discouraging nuisance species. By contrast, the use of mowed buffers by the Parks Department in the City of Mississauga was explained as an active attempt to reduce the backyard migration of species and increase resident comfort level faced with naturalization. During riparian naturalization projects, the City has also been proactive in the construction of extra large culverts designed to accommodate beavers without having their dams become a flooding nuisance.

Unfortunately, though a regular consideration during naturalization, nuisance species potentials are still not mandatory planning criteria for the City of Mississauga. This means that the City's mitigative nuisance design protocols are implemented on an ad hoc basis, and are often limited to major nuisances; e.g. deer, beavers, waterfowl, and mosquitoes. Staff of the City of Mississauga Animal Services Department with a responsibility for monitoring residential nuisance complaints have never been contacted to provide input on proposed projects.

In all municipalities, this ad hoc implementation of mitigative nuisance measures during naturalization can undermine the effectiveness of any mitigative protocols that are in place. It has 
been shown that, "[a]lthough control activities can be effective at the site where the [nuisance] problem occurs, uncoordinated management efforts may cause relocation of the problems to surrounding areas" (Belant, 1997). Therefore, it is recommended that an integrated, landscapelevel management approach be implemented to ensure an overall reduction in the conflict between wildlife and people in urban environments (Bhat et al., 1996; Belant, 1997). This will be further discussed in Section 7.3.

\subsubsection{Enhance Technical Considerations for Wildlife During Development}

With respect to the way that urban development proceeds in a city, municipalities have recognized that there is now a need to enhance technical considerations for the environment in planning and urban design (Kanter, 1990; Waterloo, 2002). This means that methods need to be established to not only balance development with the natural environment, but also to accommodate growth in such a way that negative impacts on both the environment and the community are minimized.

In the case of human-wildlife conflicts, revised technical considerations could include the implementation of construction guidelines that require developers to integrate natural area connections into new subdivision design (see Section 6.5.1). Through various policy documents and strategic decisions, all of the six selected municipalities now have measures in place to connect natural areas via the development of greenways and other wildlife migration corridors. As was seen in the example of the naturalization initiatives of the City of Waterloo (Table 10), it is now common that a municipality require new developments to meet a mandatory designation of park or open space; typically 5\% per land to be developed (Guelph, 1997). Taking this one step further, studies such as Options for a Greater Toronto Area Greenlands Strategy (Kanter, 1990) and the City of Guelph State of Sustainability Report (2003) have recommended that urban municipalities also require developers to link the open space between built up areas. Policies such as these could help to mitigate nuisances by creating more hospitable paths among natural areas.

One respondent also recommended that technical considerations for the mitigation of humanwildlife conflicts be applied to the development of new housing guidelines and/or changes to building codes that would force developers to take a universal approach to common nuisance problems at the time of construction. The following list of simple, low-cost preventative measures is derived from advice provided by the City of Mississauga (n.d.) and the Canadian Federation of Humane Societies (2004). To be effective, these measures should be applied to all new houses, garages and other associated outbuildings.

- Chimneys should be capped with a 16 gauge steel cap;

- All exterior vents (roof, bathroom, kitchen, and dryer) should be screened from the inside with a 16 gauge steel mesh beyond the vent hole;

- Window wells should be screened with a 16 gauge steel mesh or screened with plexiglass;

- Any soffit should be secured with screws and any gaps between soffit and roof should be screened with 16 gauge mesh;

- $\quad$ Decks of $3^{\prime}$ and higher should be completely open around the bottom (i.e. no lattice);

- Decks of 3' and lower need to be properly screened to prevent wildlife invasions;

- Tree should be trimmed at least 15 feet back from the house; 
- Heavy vines and trellis' on the home should be avoided;

- Access to ornamental exterior architecture can be prevented by covering with netting;

- $\quad$ Proper sealing should be used around pipes and other openings;

- Motion-sensor activated exterior lighting should be installed to deter nocturnal species.

The relative simplicity and low-cost of such measures means that their implementation would require only a minimal input of additional time and resources into the construction of a new home. These technical considerations could also proactively mitigate problems experienced by subsequent purchasers who, unlike the initial purchaser, do not receive the educational material on living next to natural areas that is distributed under subdivision agreements.

Despite their benefits, it may be difficult to amend housing guidelines and/or building codes to make the inclusion of such design considerations mandatory. In addition, not all measures to protect the home can be implemented pre-sale. As a house settles, small gaps may appear. Over time, weather and use will cause the exterior of a house to age; roofs rot, concrete cracks and chimneys may become damaged. Eaves troughs need to be regularly cleaned. Preventative screens that are in place can come loose with time. Responsibility will remain with the homeowner to conduct periodic inspections for all of the above problems and remedy situations that place the home in danger of nuisance invasions.

\subsubsection{Enhance Legislation and Encourage Environmental Compliance}

Enhanced technical considerations cannot account for nuisance attractants created by humans that may be unrelated to the design of the urban development or the natural area. Several respondents stated that the largest threats to the success of a naturalization project are residential encroachment and dumping. These activities occur primarily due to a lack of awareness of the appropriate uses of natural areas on the part of adjacent landowners (Mississauga, 2003a). Many residents falsely believe that they are improving the natural area by plariting additional vegetative species, mowing or otherwise maintaining the natural area beyond their property line. Natural areas can also be damaged by residents who attempt to similarly justify the dumping of compost or other biodegradable materials. In certain cases, the behaviours create an additional risk of attracting nuisance wildlife out of natural areas and onto residential property.

In response to this, the enforcement of environmental by-laws has been recognized as a tool that could influence resident behaviour to discourage practices that have a negative impact on the environment (Waterloo, 2002). Most municipalities now have by-laws that prohibit encroachment onto natural areas or any form of illegal dumping of wastes. However, only the City of London was found to have included anti-dumping and anti-encroachment measures into its strategy for the maintenance of naturalization projects (Arquilla, 1994). This strategy suggests that the by-laws be applied to protect naturalization projects through active site monitoring, followed by cautionary notices (i.e. prepared form letters) and possible disciplinary action to be decided on the individual basis of each offender. Stronger enforcement of existing environmental by-laws such as these may also be useful in discouraging negative practices that attract nuisance species. 
This idea can be further expanded by the proposed creation of new environmental by-laws designed to discourage human behaviour that is responsible for the local presence and/or overabundance of nuisance species populations. Section 128 of the Ontario Municipal Act enables a municipality to pass by-laws which prohibit and regulate real or potential public nuisances (Ontario, 2001). For example, the City of Mississauga has passed a by-law to prescribe standards for nuisance weeds and tall grasses on private lands (By-Law 0267-2003). Among issues of heaith and safety, this by-law was created over concerns for all private landscaping that "may create habitats for mosquitos, rodents and otíler insects and animals" (Mississauga, 2003b). Similarly, under the City of Mississauga Farks By-Law (277-96), it is prohibited for any person to feed waterfowl in a park "except in a designated area" (Mississauga, 1996). Additional by-laws could be passed by municipalities which would prohibit the feeding of wildlife in any form. If the use of bird feeders is allowed, the by-law could also stipulate schedules for their appropriate use and maintenance. Where existing, municipal by-laws that govern the proper disposal of curbside wastes and compost should also be reviewed.

However, there are limits to what can be done to prevent nuisances that are encouraged by landowners. As Section 15.1(3) of the Ontario Building Code Act (1992) enables a municipality to pass by laws prescribing the standards for maintenance of property within a municipality and Section 127(a) of the Municipal Act (2001) enables by-laws requiring the owners of land to clean and clear the land, many municipalities already have by-laws in place to regulate lot and/or property maintenance standards. However, public opposition to the infringement of residents" property rights can still restrict the ability of municipalities to pass a by-law on many nuisance attractants. This can include, but is not limited to: the composition of species in flower and vegetable gardens; specific schedules for the maintenance of lawns, fruit trees, decorative ponds and barbeques; the repair of garage doors, decks, roofs and other problems with the house exterior (see Section 6.5.3); and other practices that intentionally or unintentionally provide wildlife with food and shelter (Mississauga, n.d; CFHS, 2004). Even if by-laws governing such actions could be passed, the wide dispersion of such attractants throughout a municipality would make their active monitoring and enforcement extremely difficult.

\subsubsection{Encourage Education on Naturalization}

Public information is considered to be a critical step in the naturalization process (Arquilla, 1994). At present, public education may be the best available tool to increase tolerance towards naturalization and raise awareness over potential conflicts. This is currently most commonly accomplished by means of public open houses, naturalization information notices, and signage. As the most cost-effective long term measure, signage is now a requirement of naturalization projects in both the City Mississauga and the City of Guelph. As outlined in Section 4.4.3, the information that signs provide may be highly valuable in discouraging encroachment and raising public perceptions of naturalization projects, particularly during the juvenile, transitional phase when they appear the most unkept. Municipalities with informative and well-positioned signs anticipate more public maintenance and less vandalism to sites (Gueiph, 1993; Arquilla, 1994).

Enhanced education should also be considered for municipal staff. In 1994, an informal survey ố naturalization site managers in the City of London found that managers believed park staff to be among the worst offenders of site degradation (Arquilla, 1994). In response, site managers 
recommended that quality, informative training programs regarding naturalization are needed for all park staff. Respondents from other municipalities also noted that a lack of internal communication and coordination has sometimes resulted in the inadvertent destruction of a naturalization project by staff in other municipal departments.

However, it is not just municipal staff that could benefit from enhanced training and education on naturalization. In its Environmental Strategic Plan (2002), the City of Waterloo found that while "a great deal of information exists about proactive environmental practices that can be applied when managing new growth... [c] urrently it is difficult to access and share this information with all stakeholders". In order to increase this capacity, the Strategic Plan proposes that an annual or bi-annual information-sharing 'Development Forum' be held. The desired outcomes of these forums were outlined as follows (Waterloo, 2002):

- Increased stakeholder communication and awareness;

- Informed and efficient decision-making process;

- Better understanding of the need for different forms of development;

- Better understanding between stakeholders; and

- Recognized divergent views between business and the environment.

These forums could be used to encourage the utilization of more informed landscape design management in the development of naturalization sites. Municipal staff might also have a lot to add to a forum discussion on the topic of naturalization and urban development. The survey of naturalization site managers in the City of London (1994), staff expressed their frustration at not being allowed to have more input into issues such as land management, appropriate equipment and public reaction. The insights of municipal staff involved in naturalization are critical to the planning process as they "are the people on the front lines, receiving the complaints and the compliments" (Arquilla, 1994). To this end, the municipality must make itself available for feedback and respond in the best interest of the community.

In the case of nuisance species, this reactive response must be supplemented by some proactive educational measures. Developers and municipalities are already contributing to community environmental planning by marketing new subdivisions adjacent to natural areas to more environmentally-minded citizens. Through subdivision agreements, these citizens are also provided upon entry with resources that will facilitate their living next to natural areas.

Municipalities must also have the capacity to react in advance to provide enhanced public education when changes in land use are likely to result in increased human-wildlife conflicts. This means knowing where naturalization is likely to result in the presence of nuisance species and providing advarice information on, for example, the ecology and behaviour of coyotes. This could also relate to other changes in municipal policy with a potential impact on wildlife behaviour. One respondent stressed the importance of informing residents when changes to municipal garbage policy result in new crurbside practices that could attract wildlife nuisances. 


\section{6}

ReCOMMENDATIONS fOR NATURALIZATION ANd CONFLICT Mitigation

During this analysis, it was found that each of the six selected municipalities could significantly improve their capacity to plan for naturalization. The development of a formalized naturalization policy or program is a good step in this direction, particularly if these policies include a plan or process to locate and rank potential restoration sites. Criteria for prioritization should be clear, and be based on the best available science for site selection and landscape design. These should be reviewed periodically as municipal experiences reveal more about the impacts of naturalization.

Municipalities should also develop a system to improve their understanding of how restoration designs will be accepted, and therefore, maintained by nearby residents. As outlined by Schauman and Salisbury (1998), "[d]eveloping a strategy for locating restoration is a planning problem, understanding people's responses to and behaviour toward urban green restoration is a design issue". This understanding is fundamental to the success of naturalization. Restoration that is not valued by citizens in a community will not be maintained.

At a minimum, the public must be notified and meaningfully involved in the planning of local naturalization projects. Communities that are not engaged in the process of planning and implementing naturalization may not understand or accept the results. Residents concerns for safety, aesthetics and human-wildlife conflict must be integrated into naturalization landscape design.

Fnhanced education on naturalization is required for the affected public, as well as for developers, naturalization managers and other municipal staff. Depending on the situation of a particular city, it is further recommended that municipalities consider implementing some combination of the proactive best management practices outlined in Section 6.5. 


\subsection{CONCLUSIONS AND RECOMMENDATIONS TO MUNICIPALITIES}

Through improvement of habitat conditions and the creation of important migration corridors, many urban environments are now inhabited by a much larger wildlife population than they were several decades ago. However, urban growth also means that the space available to wildlife in the city is increasingly restricted. While most urban residents generally enjoy seeing wildlife, augmented exposure and negative experiences associated with locally overabundant wildlife populations are increasing public concerns over these species. A media analysis conducted over the Summer 2003 has revealed the extent of some of the major human-wildlife conflicts that exist across Canada. These tensions are predicted to intensify as urban habitats improve or new wildlife populations adjust to living in the urban environment (Hadidian, 1991).

As a result, human-wildlife conflict management has recently emerged as a major concern for both urban planners and the sustainability of urban biodiversity. As traditional techniques for the control of nuisance species are not well suited to the urban environment, recent research has focused on the developmient of new tools that would be adapted to the complexities of urban human-wildlife cohabitatic n (Messmer, 2000; Le Lay and Hubert-Moy, 2001; Fall and Jackson, 2002). However, issues surrounding choice of methods often remain controversial and politically charged.

Using selected municipalities in southern Ontario as an example, this research has explored the development and application of principles for human-wildlife conflict management in urban areas. Throughout this thesis report, three basic actions have been advocated as measures that any municipality can take to better manage human-wildlife conflicts. These are:

1. Increase their knowledge of the magnitude and public perception of conflicts;

2. Increase their knowledge of urban biodiversity to address the ecology of conflicts; and

3. Use the information gained to better plan the location and landscape of urban natural areas and to enhance residents' willingness to tolerate real or perceived conflicts.

The extent to which the six selected municipaities have recognized the need for and/or have begun to implement these activities has been the focus of this study.

\subsection{Municipal Capacity for Human-Wildlife Conflict Management}

The objectives of the research conducted for this thesis include the identification of best management practices through the examination of municipal successes, failures and lessons learned on human-wildlife conflict. Through literature reviews and interviews with municipal stakeholders, research for this thesis has revealed that the current municipal capacity for humanwildlife conflict is generally insufficient to deal with growing problems.

While most municipalities now realize that nuisance wildlife problems exist, they have not yet recognized the importance of mitigating the negative wildlife interactions that may result from expanded naturalization or residential development. In many cases, they are still largely divided on the need to manage urban wildlife nuisances. For most respondents, the presence of any native wildlife in urban areas is seen as a benefit to urban ecosystems. 
Municipalities that have taken mitigative action against human-wildlife conflicts commonly rely on two approaches - public education to increase residential tolerance for wildlife and the creation of landscape buffers between natural areas and developments. For major nuisances, various habitat management techniques or exclusionary devices have also been used to deter the colonization of unwanted species in natural areas. However, weak municipal performance monitoring means that the effectiveness of these measures is still in question.

\subsubsection{Public Perceptions of Nuisance Conflicts}

Understanding the public's perceptions, interest, values and knowledge of urban wildlife is key not only to effective public education programs but also the selection of viable damage control options. However, there have yet been few attempts on the part of selected municipalities to assess public perceptions of wildlife. Of the six municipalities examined, only the City of Mississauga was found to have a formalized sysiem for the regular monitoring of residents' concerns regarding wildlife. This system represents a best management practice as it allows the municipality to use readily available information to understand public perceptions and react to community concerns before they can evolve into crisis situations. By contrast, community surveys conducted on an ad hoc basis after a major nuisance problem has been identified can only be used to avert similar crises if the lessons learned can be applied to future conflict situations.

Municipal experience has found that negative perceptions of wildlife held by individuals bein $g$ adversely affected by nuisances can frequently be improved through the provision of basic information on the ecological value of wildlife in the urban environment. In addition to ecological education, respondents identified a need to raise awareness among residents about how human behaviour can influence human-wildlife conflicts. Despite this, there are few public education programs conducted by the selected municipalities that are directly targeted at issues related to human-wildlife conflict mitigation or resolution. Though education in the form of print and online resources, public media, and signage have been used to some extent by each of the selected municipalities, only the City of Mississauga places a high reliance on public education as the primary human-wildlife conflict resolution tool. From the assessment in Section 4, it is clear that public education programs need to become more targeted and accessible if they are to be effective, long-term solutions.

\subsubsection{Biodiversity Science and Information}

Knowing where conflicts are likely to arise and which species are likely to be involved is key to allowing municipalities to target public education efforts to where they are needed most. Better scientific information on species distribution, abundance and the ecology of human-wildlife conflicts is also critical to other management decisions related to wildlife damage control. Unfortunately, it was found that most municipalities either have no information or have only anecdotal information related to the presence and distribution of nuisance species. Without this data, options for nuisance species control are limited to reactive meas.sres. Decisions taken at crisis points are extreme, confrontational and not designes to allow for adaptive management.

Experts have also suggested that in order to preserve its biodiversity, at a minimum, a city must inventory its open spaces and ecological resources (Andrews and Cranmer-Byng, 1981; Platt et 
al., 1994; Inoguchi et al., 1999; WHC, 2001). However, it was found that only two of the selected municipalities had completed a BNAI, while two were still in the planring or early implementation phase. Despite having completed a wide range of biodiversity related study initiatives, the lack of a comprehensive, integrated municipal biodiversity inventory means that the r rioritization, implementation and review of important planning initiatives may not be possible (see Section 7.3).

\subsubsection{Nuisances and Naturalization}

As naturalization is in many ways still an experimental science, municipalities must recognize the need for adaptive management. There should be flexibility in project design and implementation, and each project should be subject to some form of monitoring, review and debate. In addition to applicable science, the restoration of urban open spaces requires two complementary efforts; (1) a plan or process to locate and rank potential restoration sites and (2) an understanding of how restoration will be accepted and maintained by residents (Schauman and Salisbury, 1998; Gobster, 2001).

However, research revealed that only four of the selected municipalities could demonstrate evidence of having developed a coordinated municipal naturalization policy and/or specific prioritization criteria for their naturalization projects. Though the community is often involved in the planning, implementation and maintenance of naturalization projects, it has been suggested that the current means of residential input into site-specific pioject decisions is too limited for their concerns to have a meaningful influence on project design. As a result, negative ecological or social impacts that result from a particular natura'iration project (such as a residential influx of nuisance species) may go unrecognized until the problem has reached crisis levels.

\subsection{Best Management Principles for future ACtion}

New solutions for human-wildlife conflict management are needed. However, while it is the objective of this research to develop principles for best management practices, it is not the objective of this thesis to prescribe specific human-wildlife conflict measures. The selection of human-wildlife conflict measures should be done at the discretion of the municipality, taking into consideration local conditions, conflicts and the needs of residents.

The selected course of action taken depends largely on the goal of human-wildlife conflict management (KWS, n.d.). As seen in Figure 7, conflict management options can essentially be divided into four categories - avoidance, prevention, reduction and elimination. 
Figure 7: Human-Wildlife Conflict Management Spectrum, Options and Effects

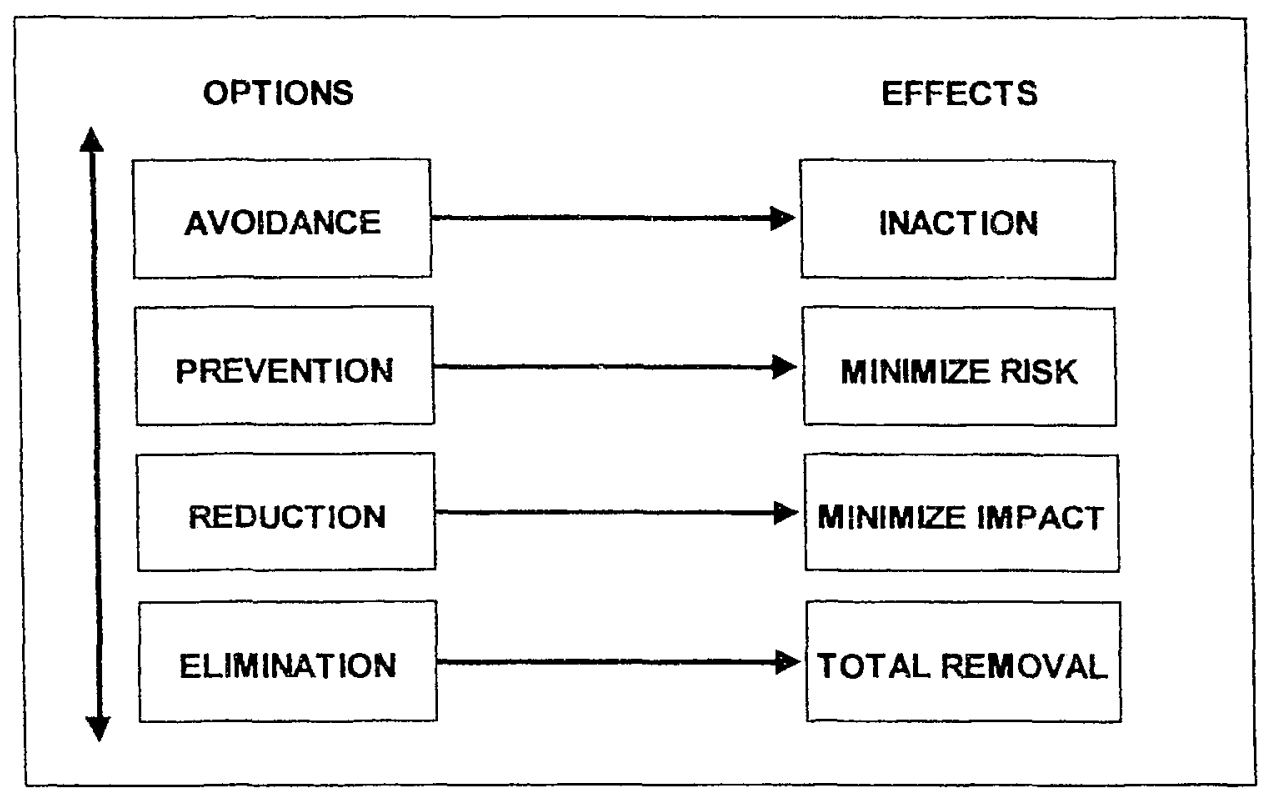

Source: Adapted from KWS, n.d.

As a strategy, avoidance involves a failure to act or attempts to avoid responsibility. Often the result of a failure to identify nuisance problems, avoidance is equivalent to ignoring a problem that creates real conflicts or risks. This places the burden of action on individual residents; effectively reducing tolerance for the nuisance and resulting in the implementation of site-specific management techniques. This rarely achieves more than the simple displacement of the nuisance to surrounding areas (Bhat et al., 1996; Belant, 1997). Therefore, while avoidance is currently the most common approach to municipal nuisance wildlife management in southern Ontario, it is not recommended as a an appropriate management strategy.

Elimination falls at the other end of the management spectrum. This option implies the total removal of conflict, likely through the lethal control of nuisance wildlife species or the removal of urban habitat. However, the removal of habitat would have a negative impact on the urban environment that extends far beyond nuisances. In addition. the use of lethal controls can create concerns for public safety and is unlikely to be tolerated by residents (Fall and Jackson, 2002). As a result, elimination is also not recommended as an appropriate nanagement strategy.

Between extremes, prevention and reduction are more feasible and optimal goals. These two management options can be used separately, but are likely more effective if used in combination (KWS, n.d.). Conflict prevention measures are designed to reduce the risk associated with urban wildlife before it impacts residents, such as through the use of exclusionary devices or proactive habitat modifications. Similarly, assuming that risks associated with nuisance wildlife are inevitable, conflict reduction measures should be established to help minimize the impact of real or perceived wildlife-related damage. For example, public education and awareness initiatives can reduce the impact of conflicts by increasing residential tolerance to nuisances. Therefore, the first principle for urban human-wildlife conflict management is for municipal agencies to focus on the prevention and reduction of risks. 
Secondly, municipalities need to be proactive in implementing measures for prevention and reduction of human-wildlife conflict. In a study of urban residents' attitudes towards wildlife, O'Donnell and VanDruff (1983) found that an individual's tolerance for wildlife was lowered by the existence of a previous problem with a nuisance species. Early identification and mitigation of real or potential problems is therefore critical to the maintenance of positive public attitudes towards urban wildlife.

Thirdly, effective municipal decisions regarding both nuisances and naturalization management need to be based on the best available information. More than just the development and use of scientific and socio-economic information, this process involves communication. The numerous facets of human-wildlife conflict management make it relevant to a wide range of municipal departments, including those that deal with planning, parks and recreation, public works, environmental services, public health and economic development. Consequently, communication among these municipal departments and other relevant municipal agencies should be improved such that they are each involved in the decision-making process. As "wildlife movement is governed by habitat limits and not municipal limits..." such communication must also take place among municipalities to not only assess regional conflicts but also to help ensure a more coordinated approach to management (Kanter, 1990).

Lastly, measures for human-wildlife conflict management need to respond to the needs of the community. Communities that are not engaged in the decision-making process may not understand or accept the results. Municipalities must have an appreciation of the many ways in which urban wildlife either positively or negatively impacts residents' quality of life.

\subsection{RECOMMENDATIONS FOR INTEgRATED MANAGEMENT}

As stated by Le Lay and Hubert-Moy (2001), "there are still no tools sufficiently adapted to the complexities of human wildlife cohabitation in cities". If this is true, then how can the above principles be turned into practice? The answer is perhaps that municipalities do not require the development of just one tool, but rather an integrated approach that considers all available management options.

Based in part on the findings of other researchers, the following three recommendations suggest complementary measures that can be implemented to help improve municipal capacity for humanwildlife conflict. Each of the recommendations integrates the four best management principles outlined above. Numerous additional management options (i.e. 'tools') for the prevention and reduction of conflicts have been recommended throughout this report.

\section{Recommendation 1: Create a Nuisance Management Working Group}

Issues surrounding choice of methods for human-wildlife conflict management remain controversial and politically charged. As there is not one single agency with a lead role in wildlife management, many municipalities remain largely divided not only on how to manage, but also on what to manage. Furthermore, as naturalization and urban wildlife management are still in an experimental phase, there is no guarantee that methods selected will have wide-scale effectiveness. In addition, the migratory and opportunistic nature of nuisance wildlife populations 
means that control activities that are effective at one site will rarely solve a nuisance problem across a larger management area.

Due to the controversial nature of human-wildlife conflict management and the problems commonly associated with site-specific nuisance control, researchers have recommended that an integrated, landscape-level approach to management be used to reduce the frequency and severity of conflicts in the urban environment (Bhat et al., 1996; Belant, 1997; WHC, 2001). Under this scenario, a centralized working group comprised of relevant government and non-government stakeholders, the development industry, private citizens, wildlife experts and other interested stakeholders would be formed to provide overall direction for nuisance species management (Belant, 1997). As suggested by Belant (1997), the primary functions of such a working group would be:

1. Assessing the nature and extent of nuisance problems;

2. Defining relevant aspects of the ecology and interactions of nuisance species;

3. Developing an integrated management plan to address the problem(s); and

4. Periodically evaluating the efficiency and effectiveness of the management program.

While one landowner is unlikely to exercise sufficient control, coordinated management across the municipality or the watershed can result in cooperative solutions to common problems.

Facilitating public input into this process will require more time and resources. However, public participation will enhance the credibility of the working group. It will also benefit the municipality by providing stakeholders with increased opportunity to become more knowledgeable about management options and will ultimately result in more public ownership of the outcome (Messmer, 2000).

\section{Recommendation 2: Develop Integrated Nuisance Management (INM) Plans}

In keeping with the primary functions of the centralized working group, it is further recommended that urban municipalities develop integrated nuisance management (INM) plans to systematically and proactively address human-wildlife conflicts that arise in the city.

Similar to the concept of integrated pest management (IPM) ${ }^{22}$, the INM would be a decisionmaking model used to prevent and manage nuisance problems that are of concern to residents. The goal of the INM would not be to eliminate nuisance wildlife, but rather to keep nuisances at acceptable levels as determined by ecological and socio-economic study. Developed through the input of the centralized working group and other community consultations, the INM would apply to all municipal departments and contractors who directly or indire atly manage wildlife. This includes those who plan, design, renovate or construct landscapes and facilities.

\footnotetext{
${ }^{22}$ As integrated pest management is most frequently used to minimize the use of potentially harmful pest control products (e.g. pesticides), most programs for IPM define a 'pest' as an organism that can be treated with such products (London, 2003a). This is not the case for many urban 'nuisance' organisms.
} 
Procedures for the development of appropriate urban nuisance management techniques have been established through the IPM of various Canadian municipalities (Calgary, 1998; London, 2003a). These procedures include the following four steps ${ }^{23}$ :

1. Identify, monitor and assess the nature and extent of nuisance problem(s).

In order to effectively manage human-wildlife conflicts, the conflicts must first be understood. As a result, identification is the first and most crucial step in integrated nuisance management. Problem identification may also be more effective if supplemented by a process of problem visualization such as the computerized map of risk for humanwildlife conflict that will be outlined in Recommendation 3 .

Some major nuisances (e.g. deer, waterfowl and other overabundant species) have already been identified. However, in most cases this first step will require municipalities to begin monitoring residential experiences with nuisance species to determine the types of real or perceived conflicts, the locations where problems occur, and the type and approximate number of species involved. This monitoring can also be used to estimate residential, municipal or ecological risk or loss as a result of problems. Additional information on the ecology of nuisance species (for example, time of the year when present or most active) will aid in determining when and where control management activities need to be conducted.

2. Use this assessment to determine the appropriate level and timing of action(s).

The general goal of most naturalization projects is to establish an ecologically balanced landscape, and thus project objectives often include increasing species diversity and abundance in a given area. As a result, the recolonization of natural areas by native 'nuisance' species is generally not a concern for wildlife and open space managers and should not require any action. However, this 'do nothing' approach to management should not to be confused with 'avoidance'. Once monitoring reveals conflict with the surrounding area, the 'do nothing' option may no longer be feasible.

Appropriate timing and levels of action for the management of a particular nuisance species should be determined on the basis of real and/or perceived risks to residents and urban ecology. Tolerance to pests is a subjective concept that will also require further municipal study. Past studies have found that residential tolerance levels for nuisances are likely to vary with the type of species and the area of the city where the species is found (O'Donnell and VanDruff, 1983; Hadidian, 1991). Residential tolerance will also vary on a site-by-site basis; whether the species is in the home, on the property, or in an adjacent natural area (London, 2003a).

23 The principles for IPM are often divided into five steps rather than four, with pest identification and pest monitoring outlined as separate procedures (London, 2003a). 
The scientific methods required to determine ecological tolerance levels are not the subject of this report. However, according to the testimony of respondents, it is important to note that there may be considerable difference in residential tolerance levels and the ecological carrying capacity for a particular species. For example, as an introduced species, the Mute swan can pose a significant threat to the ecology of a natural area. Despite this, public preference for swans means that their population is often maintained while other native species (e.g. Canada goose) are removed (Hindman, n.d.). In addition, a lack of basic ecological information on the value of species means that other species that are beneficial to the ecology of a natural area (e.g. pollinators and top predators) may also not be tolerated by residents.

In such cases, tolerance levels need not be reached in order for action to be taken. Many treatments for human-wildlife conflict management that are considered environmentally benign - for example, public education and mitigative landscape design - can and should be implemented on a proactive basis.

\section{Review all possible treatment techniques and select the most appropriate.}

Once the need for action has been determined, steps to deal with the nuisance should be taken. As outlined in Section 3.4.2, there is a wide range of wildlife damage management techniques that exist and can be used in different situations with varying effectiveness. The most frequently cited techniques include: habitat management; food source management; averse conditioning; exclusion; repellents; capture, removal and relocation; nest/egg disturbance; anti-fertility programs; introduction of natural predators; and lethal methods. Again, landscape-level management techniques are preferred to site-specific management as this helps reduce the possibility that the nuisance problem will be displaced or dispersed in the municipality.

Screening criteria should be established to evaluate the suitability of each action with respect to the particular problem and desired nuisance management objectives. The ultimate decision as to which nuisance management strategy to follow should include the consideration of many practical factors: conflict distribution, species ecology, human and financial resources, the costs and benefits of nuisance management techniques and public opinion. One example of this suggested screening criteria process is outlined in Table 13. 
Table 13: Screening Criteria for Strategic INM Actions

\begin{tabular}{|l|l|l|l|}
\hline \multicolumn{1}{|c|}{ Regulatory } & \multicolumn{1}{|c|}{ Social } & \multicolumn{1}{c|}{ Economic } & \multicolumn{1}{c|}{ Technical } \\
\hline $\begin{array}{l}\text { Is the action compliant } \\
\text { with environmental } \\
\text { laws? }\end{array}$ & $\begin{array}{l}\text { Would the action be } \\
\text { widely acceptable? }\end{array}$ & $\begin{array}{l}\text { Are the costs } \\
\text { reasonable? }\end{array}$ & $\begin{array}{l}\text { Can existing technology } \\
\text { adequately support the } \\
\text { action? }\end{array}$ \\
\hline $\begin{array}{l}\text { Does the action comply } \\
\text { with applicable } \\
\text { regulatory guidelines? }\end{array}$ & $\begin{array}{l}\text { Would multi- } \\
\text { stakeholder } \\
\text { participation be likely? }\end{array}$ & $\begin{array}{l}\text { Could the action be } \\
\text { delivered with } \\
\text { existing resources? }\end{array}$ & $\begin{array}{l}\text { Is alternative technology } \\
\text { available? }\end{array}$ \\
\hline $\begin{array}{l}\text { Does the action require } \\
\text { new legislation? }\end{array}$ & $\begin{array}{l}\text { Would stakeholder } \\
\text { support for the action } \\
\text { continue? }\end{array}$ & $\begin{array}{l}\text { Would unrealistic tax } \\
\text { increases likely result } \\
\text { from the initiative? }\end{array}$ & $\begin{array}{l}\text { Is the technology proven } \\
\text { to be effective? }\end{array}$ \\
\hline $\begin{array}{l}\text { Will greater } \\
\text { enforcement be } \\
\text { necessary? }\end{array}$ & Is the action ethical? & $\begin{array}{l}\text { Would costs remain } \\
\text { stable? }\end{array}$ & $\begin{array}{l}\text { Are non-technological } \\
\text { alternatives possible? }\end{array}$ \\
\hline
\end{tabular}

Source: Waterloo, 2002

In many cases, human-wildlife management conflicts are better resolved by managing the behaviour of residents than the behaviour of species. Several researchers have found that enhancing tolerance is not only a highly effective strategy, but is also more readily accepted by residents than active population controls (Messmer, 2000; Fall and Jackson, 2002). As a result, the selection of treatment techniques should consider options for both species management and human behaviour/perception management.

It is also important to note that not all treatment strategies are reactive (see Figure 8). According to the City of Calgary IPM (1998), site management, rehabilitation and longterm management are the three most essential elements in a successful IPM program. In addition, higher levels of program effectiveness are achieved by placing a greater emphasis on problem assessment, problem prevention through improved site design, and the establishment of greater levels of nuisance tolerance. Though untested, the same can likely be said for INM.

Figure 8 demonstrates how the development of an INM Plan can allow a municipality to casily integrate the different treatment strategies for the management of current and probable pest problems that have been proposed throughout this report. 


\section{Figure 8: Integrated Nuisance Management Programs, Design of Treatment Strategies}

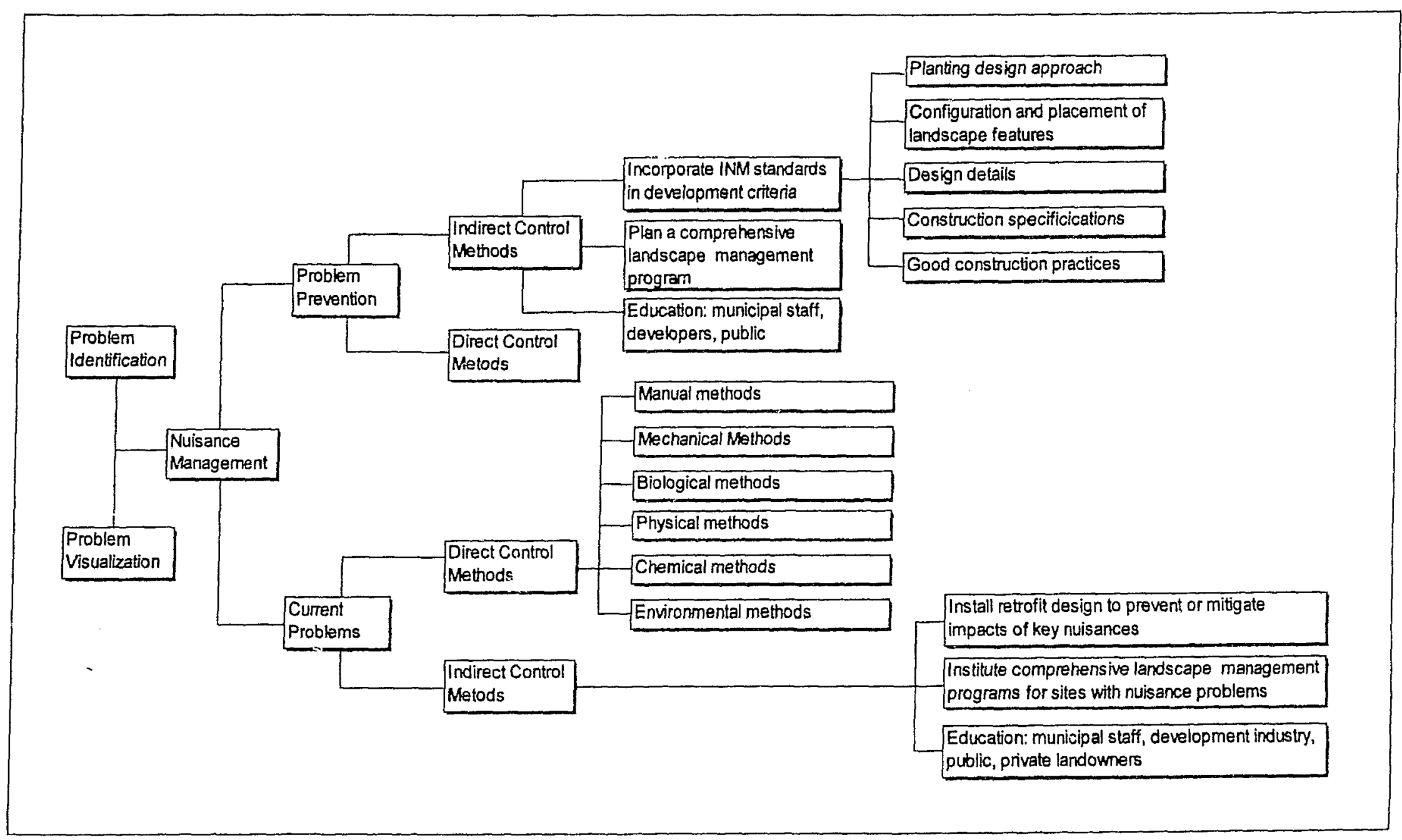

Source: Adapted from Calgary, 1998 
4. Periodically evaluate the effectiveness of the selected course of actions, and revise as necessary.

As with any good management system, INM requires that monitoring continue following the implementation of human-wildlife interface control measures. This will allow staff responsible for the INM to evaluate the effectiveness and make any necessary program adjustments. This review can also serve as a source of information on best management practices, with the lessons learned applied to improve practices elsewhere in the city and to help reduce the chance of similar nuisance problems in the future.

The feasibility of this recommendation is demonstrated by the fact that each of the six selected municipalities has now implemented some form of integrated pest management system for the maintenance of public lands. However, while four municipalities have integrated the principles of IPM into a plant health care (PHC) program, only Guelph and London have established an actual Integrated Pest Management Plan.

For increased efficiency, the NNM could also be integrated into a larger municipal initiative for integrated pest management. For example, following the lead of other Canadian cities, the City of Calgary began implementation of its Integrated Pest Management Plan in 1998. ${ }^{24}$ Though initiated by a desire to reduce its reliance on pesticides, the City of Calgary IPM is innovative as it is designed to help manage every kind of natural "pest". This includes not only injurious plants, insects and rodents, but also larger vertebrate wildlife such as beavers and Richardson ground squirrels.

\section{Recomme* dai $3:$ Computerized Maps of Risk for Human-Wildlife Conflict}

Urban planners in other jurisdictions that have already attempted to implement an integrated approsch to nuisance management have found the process hindered by a lack of problem visualization (Le lay and Hubert-Moy, 2001). Therefore, to help facilitate the implementation of municipal INM Plans it is recommended that "[a] cartographic approach is needed to integrate all the different components of human wildlife interactions, to analyze their connections and spatial distribution in the city, to increase urban knowledge, and to identify courses of action" (Le Lay and Hubert-Moy, 2001).

Geographical Information Systems (GIS) can be used to help urban planners and other municipal decision-makers complete a wide variety of tasks including preliminary data processing, data storage and retrieval, spatial searches and analysis, and spatial interaction modeling (Jones, 1997). By combining analytical and mapping capacities, the use of GIS can assist in not only the visualization of urban problems, but also their comprehension, communication and resolution.

${ }^{24}$ Calgary IPM (1998) is viewable on-line: www.calgary.ca/DocGallery/BU/parks_operations/ipm.pdf 
As a result, the popularity of GIS among urban planners has now grown significantly (Jones, 1997; Le Lay and Hubert-Moy, 2001). In fact, the majority of the municipalities selected for study already use GIS for the conduct of programs related to general environmental maintenance, such as ecological land classification, environmental impact assessment, natural heritage mapping and street tree inventories. Other municipalities, such as the City of Guelph, have made commitments to create and maintain GIS layers for monitoring natural areas within the next four years (Guelph, 2003a). Therefore, the shift from current uses of GIS to human-wildlife conflict management is simplified as urban planners have the software, expert knowledge and some of the critical georeferenced, digital data already in hand.

Researchers have demonstrated how the applications of GIS can help urban planners resolve specific human-wildlife conflicts, by using individual problem species as a case study (see Le Lay and Hubert-Moy, 2001). According to Le Lay and Hubert-Moy (2001), methods used to map risks for human-wildlife conflict management in an urban area can be divided into three main steps:

1. Identification of wildlife problem components and factors affecting them.

Wildlife problem components can be separated into five categories of risk - (1) physical risks, such as wildlife attacks; (2) epidemiological risk, such as the spread of disease and allergens; (3) ecological risk, such as competition or predation; (4) property damage risks; and (5) economic pressures. In order to develop a computerized map of risk, it is essential to first identify which components are linked to the presence of a particular nuisance wildlife species in the urban area. Second, it is important to identify the severity of those risks. Each facet of risk can be discussed and ranked on the basis of scientific and/or urban expert and community input. As problems between wildlife and people are generally brought about by the accumulation of smaller problems, it is essential to identify not only the problem components but also the links among various factors.

2. Collection of multi-disciplinary data on wildlife problem components.

Le Lay and Hubert-Moy (2001) have divided data needs into two categories - 'wildlife potentials' and 'urban vulnerability'. 'Wildlife potentials' refer to the risk in relation to the presence of a species in the urban area, expressed by the species' capacity for conflict by coming into contact with the community, their property, or other wildlife species. To show how this may vary in time, space or intensity, data collected under this category will require the study of the size, spatial distribution, and urban movement patterns of the given species population. The temporal analysis of these factors should include not only diurnal and seasonal fluctuations, but also information on species colonization where available. ${ }^{25}$ Existing data on species habitat and resource availability may be a good starting point for where species data is unknown or incomplete, but the use of these variables alone as a proxy for species data will severely limit the accuracy of results.

\footnotetext{
${ }^{25}$ Unfortunately, this temporal analysis will be limited by the availability of historical species data.
} 
'Urban vulnerability' refers to the risk related to the social, economic, and epidemiological response of the urban centre to the presence of a given wildlife species. A sound comprehension of the public perception of risk is then essential as it determines the classification of different factors involved in urban vulnerability, and thus the success of the resulting analysis. Other input data could include the physical distribution of buildings and vegetated patches at risk of property damage, the sociodemographic distribution of vulnerable segments of the human population, political vulnerability of different jurisdictions, or administrative vulnerability associated with varying land use restrictions.

3. Drawing of different map layers and of final map of risk by using GIS.

One limitation or consideration for the data that is collected is that it must be georeferenced. Georeferenced data can then be input into GIS soft ware selected at the discretion of the municipality, and maps can be created to express different aspects of wildlife potentials and urban vulnerability. After these initial mar; are created, an overall map of risk can be drawn up by overlaying different risk compone ${ }_{2}$ ts (see Figure 9).

Figure 9: GIS Configuration for Computerized Map of Risk for Human-Wildlife Conflict

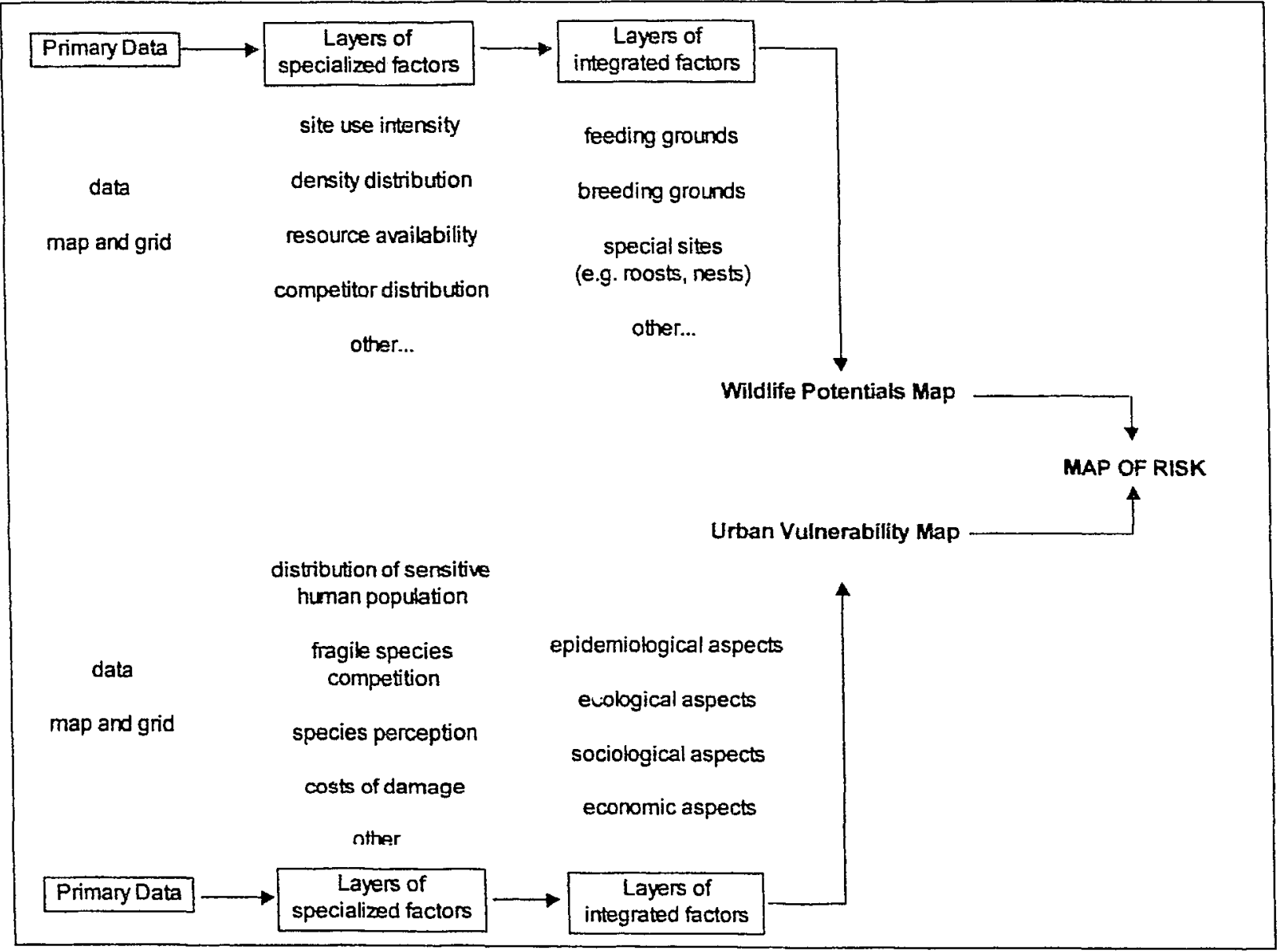

Source: Adapted from Le Lay and Hubert-Moy, 2001 
The map of risk is created and analysed based on the expectation that:

Risk of Human-Wildlife Conflict $=$ Wildlife Potentials $\mathrm{x}$ Urban Vulnerability

At the end of the process, decision-makers will evaluate the current situation or even future alternatives based on the use of best available data. If developed and used correctly, computerized maps of risk can be important tools not just for the comprehension and visualization of the problem situation by urban planners and wildlife managers, but also by the public affected by a species. A well-developed risk mapping process can also reduce the costs of actions carried out by the city, as it allows decision-makers to anticipate conflicts and take early action in heavy risk areas as well as increase efficiency by summing the effects of various actions made in several places at the same time (Le Lay and Hubert-Moy, 2001).

Unfortunately, the existing lack of comprehensive, integrated information on the public perception or ecology and dynamic nature of urban nuisance species means that it will be difficult for municipalities in southern Ontario to achieve the efficiencies that could be made possible by each of the e three recommendations. As with any decision model, a lack of good input data will likely result in a lack of good results. However, this should not discourage municipalities from working toward a goal of enhanced human-wildlife conflict management - one step at a time. 


\section{REFERENCES}

AAA (2003) Wildlife Education: Animal Quick FAC Sections. Fact sheets. AAA Wildlife Control. Accessed on-line: www.aaawildlife.com/edu.html, March 2004.

Alario, M. (2000) "Urban and ecological planning in Chicago: Science, policy and dissent" in Journal of Environmental Planning \& Management. Vol. 43, Issue 4, pp. 489-505.

Andrews, W. and J. Cranmer-Byng (1981) Urban Natural Areas: Ecology and Preservation. Environment Monograph No. 2. Institute for Environmental Studies, University of Toronto, Toronto.

Arquilla, B. (1994) Naturalization Area Maintenance Manual. Parks and Recreation Department, City of London, Ontario.

Beatley, T. (2000) Green Urbanism: Learning from European Cities. Island Press, Washington D.C.

Belant, J. (1997) "Gulls in urban environments: landscape-level management to reduce conflict" in Landscape and Urban Planning. Vol. 38, pp. 245-258.

Bhat, M. et al. (1996) "Controlling transboundary wildlife damage: Modeling under alternative management scenarios" in Ecological Modeling. Vol. 92, pp. 215-224.

Blackwell, T. (2003) "Large-scale cull' of Canada Geese possible: Ottawa orders study to probe risk to airplanes as fowl population explodes" in National Post. 2003.07.16, pp. A5.

Bourdages, J.-L. and C. Labelle (2000) Protecting Wild Species at Risk in Canada. Science and Technology Division, Parliumentary Research Branch. Government of Canada, Ottawa.

Burlington (1997) City of Burlington Official Plan. City of Burlington, Region of Halton, Ontario.

Burlington (1998) A State of the Environment Report for the City of Burlington. Burlington Sustainable Development Committee, City of Burlington, Ontario.

Burlington (2002) Bird Flocking and Roosting in urban Areas Information Package. Roads and Parks Maintenance Department, City of Burlington, Ontario.

Burlington (2004) City of Burlington Statistical Data. City of Burlington, Ontario. Accessed on-line: www.city.burlington.on.ca/Planning/statsdata.htm, June 2004.

Caldecott, J. (1996) "Good Governance in Model and Real Countries" in Decentralization and Biodiversity Conservation. Lutz, E. and J. Caldecott (Eds.). World Bank, Washington D.C. pp. 139-144. 
Calgary (1998) City of Calgary Integrated Pest Management Plan. City of Calgary, Alberta. Accessed on-line: www.calgary.ca/DocGallery/BU/parks_operations/ipm.pdf, March 2004.

Canada (1994) Migratory Birds Convention Act. Legislation, Government of Canada. Accessed on-line: laws.justice.gc.ca/en/M-7.01/text.html, March 2004.

Canada (2002) Pest Control Products Act. Legislation, Government of Canada. Accessed on-line: http://laws.justice.gc.ca/en/P-9/, April 2004.

CBI (2001) The Great Canadian Bio-Blitz. Canadian Biodiversity Institute, Ottawa, Ontario. Accessed on-line, May 2004: www.biodiversityonline.ca/BioBlitz/intro.htm.

CFHS (2004) Living with Urban Wildlife. Fact sheets, series. Canadian Federation of Humane Societies. Accessed on-line: www.cfhs.ca/Store/index.htm, March 2004.

Conover, M. et al. (1998) Review of Data on Human Injuries, Illnesses, and Economic Losses Caused by Wildlife in the United States. Abstract. Proceedings of the Wildlife Society Symposium on the Complexities of Addressing Human-Wildlife Conflicts. Accessed online: wildlifedamage.unl.edu/proceedingList.shtml?List=TWS_Arnual_Meeting_Synnposia_on_Wildlife_Damage, March 2004.

CO (2000a) Conservation Ontario Corporate Profile. Conservation Ontario, Ontario. Accessed on-line: www.conservation-ontario.ca/profile/profile.htm, May 2004.

CO (2000b) Conservation Ontario: Education. Conservation Ontario, Ontario. Accessed on-line: www.conservation-ontario.ca/education/education.htm, May 2004.

CVC (n.d.) Be a Good Neighbour: Give Nature a Helping Hand. [Brochure] Credit Valley Conservation Authority, Ontario.

CVC (2000) Credit Valley Conservation Stewardship Strategy. Credit Valley Conservation Authority, Ontario.

CVC (2002) Integrated Watershed Monitoring Program, 2002 Summary Report. Credit Valley Conservation Authority, Ontario.

CVC (2003) CVC Reflections 2003. Credit Valley Conservation Authority, Ontario.

D'Eon, R. et al. (1995) The Beaver Handbook: A Guide to Understanding and Coping with Beaver Activity. Ontario Ministry of Natural Resources, Northeast Science and Technology, Government of Ontario.

Dwyer, J. (2002) Nature Counts!: Hamilton Natural Areas Inventory Summary Report. City of Hamilton, Ontario. 
EC (1995) Narrative Descriptions of Terrestrial Ecozones and Ecoregions of Canada. Environment Canada, Government of Canada.

EC (2003) Hinterland Who's Who. Fact sheet series. Canadian Wildlife Service, Environment Canada, Government of Canada.

EMAN (2003) Improving Local Decision-Making Through Community Based Monitoring: Toward a Canadian Monitoring Network. Ecological Monitoring and Assessment Network, Environment Canada. Government of Canada, Ottawa.

Fall, M. and W. Jackson (2002) "The tools and techniques of wildlife damage management changing needs: an introduction" in International Biodeterioration \& Biodegradation. Vol. 49, pp. 87-91.

Feinsinger, P. (2001) Designing Field Studies for Biodiversity Conservation. Island Press, Washington, D.C.

Flegel, C. and B. Jacob (1996) Natural Features Restoration Program: An Evaluation and Implementation Manual. Department of Planning and Development, City of London, Ontario.

Fleury, A. and R. Brown (1997) "A framework for the design of wildlife conservation corridors: With specific application to southwestern Ontario" in Landscape and Urban Planning. Vol. 37, pp. 163-186.

Gibbs, Z. (2001) Coyotes in Calgary: Public Perceptions and Opportunities for Outreach. Master's Thesis. Faculty of Environmental Design, University of Calgary.

Gobster, P. (2001) "Visions of nature: Conflict and compatibility in urban park restoration" in Landscape and Urban Planning. Vol. 56, pp. 35-51.

Gompper, M. (2002) "Top camivores in the suburbs? Ecological and conservation issues raised by colonization of north-eastern North America by coyotes" in Biosciences. Vol. 52, Issue 2, pp. 185-191.

GRCA (1993) Laurel Creek Watershed Study. Grand River Conservation Authority, Ontario.

Groffman, P. et al. (2003) "Down by the riverside: Urban riparian ecology" in Frontiers in Ecology. Vol. 1, Issue 6, pp. 315-321.

Guelph (1993) Naturalization in the City of Guelph Parks - Policy. Recreation and Parks Department, City of Guelph, Ontario.

Guelph (1995) City of Guelph Official Plan. City of Guelph, Ontario. 
Guelph (2000) Guelph Residents' Environmental Handbook: Partners in Stewardship of Our Natural Environment. City of Guelph, Ontario.

Guelph (2003a) City of Guelph State of Sustainability Report, 1998-2001. $2^{\text {nd }}$ Ed. Green Plan Steering Committee, City of Guelph, Ontario.

Guelph (2003b) Environmental Action Plan. Planning, Environment and Transportation Department, City of Guelph, Ontario.

Guelph (2003c) City of Guelph Fact Sheet - Population Growth. City of Guelph, Ontario.

Hadidian, J. (1991) Interactions Between People and Wildlife in Urbanizing Landscapes. Proceedings from the $5^{\text {th }}$ Eastem Wildlife Damage Control Conference. Ithaca, New York.

Hamilton (2001) City of Hamilton's Sustainability Indicators Report, 2000-2001. City of Hamilton, Ontario.

Hamilton (2002) City of Hamilton Parks, Culture and Recreation Public Survey. City of Hamilton, Ontario.

Hamilton (2003) City of Hamilton - Facts and Figures, 2003. City of Hamilton, Ontario.

Hands, D. and R. Brown (2002) "Enhancing visual preference of ecological rehabilitation sites" in Landscape and Urban Planning. Vol. 58, pp. 57-70.

HCA (2002) Watershed Wildlife. Fact sheet, Hamilton Conservation Authority. Accessed online: www.conservationhamilton.ca/environment/watersheds/wildlife.asp, Oct. 2003.

HCA (2003) Hamilton Conservation Authority Conservation Strategy: Healthy Streams... Healthy Communities. Hamilton Conservation Authority, Ontario.

Heaton, M. et al. (2002) Ontario's Stream Rehabilitation Manual. Ontario Streams, Belfountain, Ontario.

Henshaw, B. (1997) A Strategy for the Management of the Canada Goose in the Greater Toronto Bioregion. Prepared for the Greater Toronto Region Canada Goose Project Steering Committee by Garner Lee Limited, Ontario.

Hindman, L. (n.d.) Mute swans: Beautiful but controversial birds. Wildlife and Heritage Division, Maryland Department of Natural Resources, Maryland. Accessed on-line: www.dnr.state.md.us/wildlife/muteswans.html, May 2004.

HRCA (2003a) Halton Natural Areas Inventory. [Slideshow - not published]. Halton Region Conservation Authority, Halton, Ontario. 
HRCA (2003b) Halton Natural Areas Iriventory: Brochure to Landowners. Halton Region Conservation Authority, Halton, Ontario.

Hudson, M. (2000) Groundwork: Invesigating the Need for Nature in the City. Evergreen, Toronto. Accessed on-line: www.evergreen.ca/en/cg/toolshed/gw2000/index.html, March 2004.

Ingram, J. et al. (2001) Urban Naturalization in Canada: A Policy and Program Guidebook. Evergreen, Toronto.

Inoguchi, T. et al. (1999) Cities and the Environment: New Approaches for Eco-Societies. United Nations University Press, New York.

Johnson, C. (1995) "Planning a designing for the multiple use role of habitats in urban/suburban landscapes in the Great Basin" in Landscape and Urban Planning. Vol. 32, pp. 219-225.

Johnson, K. (2003) "Counting Central Park wildlife: Birds, bats, insects, fish being tallied for first ever spot check on animal residents" in National Post. 2003.06.28, pp. A22.

Jones, C. (1997) Geographical Information Systems and Computer Cartography. Addison Wesley Longman Limited, Singapore.

Kanter, R. (1990) Options for a Greater Toronto Area Greenlands Strategy. [Overview] Government of Ontario, Toronto.

KWS (n.d.) Conflict Management. Kenya Wildlife Service, Government of Kenya. Accessed on-line: www.safariweb.com/kwild/conflict.htm, January 2004.

Le Lay, G. and L. Hubert-Moy (2001) "Environmental Auditing: Computerized map of risk to manage wildlife species in urban areas" in Environmental Management. Vol. 27, No. 3, pp. 451-461.

London (2003a) Community Plant Health Care - Integrated Pest Management (PHC-IPM) Plan. Steering Committee on Pesticide Management, London, Ontario.

London (2003b) City of London Parks \& Recreation Strategic Master Plan. City of London, Ontario.

London (2003c) Sifton Bog White-tailed Deer: Final Report of the Community Steering Committee. Sifton Bog White-tailed Deer Community Steering Committee, City of London, Ontario.

MacLeod, M. (2003) "What's up, Doc? Wabbits. Lots of 'em; Revenge of the herbivores: a cool, damp spring means lots to eat from lush city gardens, and critters flourish" in The Hamilton Spectator. 2003.08.09, pp. A01. 
Marshall, I. and P. Schutt (1999) A National Ecological Framework for Canada. Environment Canada and Agriculture and Agri-Food Canada, Government of Canada.

McIntyre, N. et al. (2000) "Urban ecology as an interdisciplinary field: differences in the use of "urban" between the social and natural sciences" in Urban Ecosystems. Vol. 4, pp. 5-24.

McGuckin, C. and R. Brown (1995) "A landscape ecological model for wildlife enhancement of stormwater management practices in urban greenways" in Landscape and Urban Planning. Vol. 33, pp. 227-246.

MDNR, (2002) Maryland Task Force on Non-Lethal Wildlife Management: Findings and Recommendations. Maryland Task Forse on Non-Lethal Wildlife Management, Maryland Department of Natural Resources. Government of Maryland. Accessed on-line: dnrweb.dnr.state.md.us/download/wildlife/nltfreport.pdf, March 2004.

Messmer, T. (2001) "The emergence of human-wildlife conflict management: turning challenges into opportunities" in International Biodeterioration \& Biodegradation. Vol. 5, pp. 97102.

Middleton, J. (1994) "Effects of urbanization on biodiversity in Canada" (Ch.6) in Biodiversity in Canada: A Science Assessment. Biodiversity Science Assessment Team, Environment Canada, Ottawa. pp. 116-120

Mississauga (n.d.) Wildlife Proofing Your Community/Your Home. [Brochure] Animal Services Department, City of Mississauga, Ontario.

Mississauga (1995) Mississauga Animal Control Wildlife Trouble Shooting Guide. Animal Services Department, City of Mississauga, Ontario.

Mississauga (1996) Parks By-Law (277-96). City of Mississauga, Ontario.

Mississauga (2000) Natural Areas Survey. [Fact Sheets]. City of Mississauga, Ontario.

Mississauga (2001) Credit Valley Wildlife Study. Community Services Department, City of Mississauga, Ontario.

Mississauga (2002) Mississauga's Natural Areas: What Everyone Should Know About Our Protected Areas. Recreation \& Farks Division, Community Services Department, City of Mississauga, Ontario.

Mississauga (2003a) Neighbours of Mississauga's Natural Areas: A Comprehensive Information Booklet for Property Owners Living Near Natural Areas. Recreation \& Parks Division, Community Services Department, City of Mississauga, Ontario. 
Mississauga (2003b) Nuisance Weed and Tall Grass Control By-Law (0267-2003). City of Mississauga, Ontario.

Mississauga (2004) Statistics for Animal Services Call-Backs and General Interest, 1994-2002. [Unpublished] Animal Services Department, City of Mississauga, Ontario.

Morris, R. Et al. (2002) Credit Valley Conservation Terrestrial Monitoring Program. [Draft] Credit Valley Conservation Authority, Ontario.

O'Donnell, M. and L. VanDruff (1983) Wildlife Conflicts in an Urban Area: Occurrence of Problems and Human Attitudes Towards Wildlife. Proceedings of the $1^{\text {st }}$ Eastern Wildlife Damage Control Conference, Ithaca, New York.

Oliviera, M. (2003) "Activists fume after county gases Canada geese" in Winnipeg Free Press. 2003.07.10, pp. A7

OMAF (2001) Southern Ontario Rural Profile: A Presentation on Rural Ontario's Demographic and Socio-economic Characteristics Based on Statistics Canada Data. Rural Development Unit, Ontario Ministry of Agriculture and Food, Government of Ontario.

OMNR (2003) Nuisance Wildlife. Fact Sheet, Ontario Ministry of Natural Resources. Government of Ontario.

Ontario (1990a) Conservation Authorities Act. Legislation, Government of Ontario. Accessed on-line: www.e-laws.gov.on.ca/tocBrowseCL_E.asp?lang=en, March 2004.

Ontario (1990b) Endangered Species Act. Legislation, Government of Ontario. Accessed on-line: www.e-laws.gov.on.ca/tocBrowseCL_E.asp?lang=en, March 2004.

Ontario (1992) Building Code Act. Legislation, Government of Ontario. Accessed on-line: www.e-laws.gov.on.ca/tocBrowseCL_E.asp?lang=en, March 2004.

Ontario (1997) Fish and Wildlife Conservation Act. Legislation, Government of Ontario. Accessed on-line: www.e-laws.gov.on.ca/tocBrowseCL E.asp?lang=en, March 2004.

Ontario (2001) Municipal Act. Legislation, Government of Ontario. Accessed on-line: www.e-laws.gov.on.ca/tocBrowseCL_E.asp?lang=en, March 2004.

Ottawa (1999) Natural Areas. [Brochure] City of Ottawa Sustainability Report Bulletin, Vol. 2, No.1. City of Ottawa, Ontario.

Ottawa (2003a) Natural Space in Urban Places. [Bulletin, March 2003] City of Ottawa, Ontario.

Ottawa (2003b) Urban Natural Areas Environmental Evaluation Study (UNAEES): Open House. [Panels from Open House, May 2003 - unpublished]. City of Ottawa, Ontario. 
Ottawa (2004) Urban Natural Areas Environmental Evaluation Study (UNAEES): Open House. [Panels from Open House, March 2004 - unpublished]. City of Ottawa, Ontario.

Parsons, R. (1995) "Conflic hetween ecological sustainability and environmental aesthetics: Conundrum, canärd or curiosity" in Landscape and Urban Planning. Vol. 32, pp. 227 244.

Pearman, M. (2004) "Nature by design: How to NatureScape your yard into an urban eden" in Nature Canada. Canadian Nature Federation, Vol. 33, No. 1 (Spring 2004).

Pedroli, B. et al. (2002) "Setting targets in strategies for river restoration" in Landscape Ecology. Vol. 17 (Suppl. 1), pp. 5-18.

PEIL (2003) Hanlon Creek State-of-the-Watershed Study. Planning \& Engineering Initiatives Ltd. for the City of Guelph, Ontario.

Platt, R. et al. (1994) The Ecological City: Preserving and Restoring Urban Biodiversity. The University of Massachusetts Press, Amherst, Mass.

Poole, R. (2003) "Call of the urban wild: Meet the neighbours: They're really wild, and there are lots of them" in National Post. Toronto, 2003.06.14. pp. TO1/Front.

Sabloff, A. (2001) Reordering the Natural World: Humans and Animals in the City. University of Toronto Press, Toronto.

Savard, J-P. et al. (2000) "Biodiversity concepts and urban ecosystems" in Landscape and Urban Planning. Vol. 48, pp. 131-142.

Schauman, S. and S. Salisbury (1998) "Restoring nature in the city: Puget Sound experience" in Landscape and Urban Planning. Vol. 42, pp. 287-295.

Sopuck, R. (2003) "Wildlife management maintains balance" in Winnipeg Free Press. Winnipeg, 2003.07.05. pp. E6/Travel.

Statscan (2001) Community Profiles. Statistics Canada, Government of Canada. Accessed on-line: [url], March 2004.

Statscan (2002) A Profile of the Canadian Population: Where We Live. Statistics Canada, Government of Canada. Accessed on-line: geodepot.statcan.ca/Diss/Highlights/Highlights_e.cfm, August 2003.

Theobald, D. et al. (2000) "Incorporating biological information in local land-use decision making: designing a system for conservation planning" in Landscape Ecology. Vol. 15, pp. $35-45$. 
Toronto (2001) Forest Health Care: Beavers. Fact sheet. Urban Forestry Services, Parks \& Recreation Department, City of Toronto, Ontario. Accessed on-line: www.city.toronto.on.ca/trees/pdfs/BVRfs.pdf, March 2004.

TRCA (2000) Tommy Thompson Park Public Urban Wilderness: Habitat Creation and Enhancement Projects, 1995-2000. Toronto Region Conservation Authority, Toronto.

UTRCA (n.d.) Living with Natural Areas: A Guide for Citizens of London. [Brochure] Upper Thames River Conservation Authority, London, Ontario.

UTRCA (2001) The Upper Thames River Watershed Report Cards, 2001. Upper Thames River Conservation Authority, Ontario.

Vuorisalo, T. (2001) "Urban biodiversity in local newspapers: a historical perspective" in Biodiversity and Conservation. Vol. 10, pp. 1739-1756.

Waterloo (n.d.) Laurel Creek Watershed Monitoring Program: Discussion Paper for Program Rationale. [not published] City of Waterloo, Ontario.

Waterloo (1998a) Living with Nature in West Side Waterloo: A Good Neighbour's Guide. City of Waterloo, Ontario.

Waterloo (1998b) Wildlife in the City - Facts You Should Know. Fact sheet. Parks and Works Department, City of Waterloo, Ontario.

Waterloo (1999) Environmental Lands Acquisition and Maintenance Strategy. [Response Paper] Development Services Department, City of Waterloo, Ontario.

Waterloo (2001) Laurel Creek Watershed Monitoring Program Progress, 1996-2001. City of Waterloo, Ontario.

Waterloo (2002) Environmental Strategic Plan. City of Waterloo, Ontario.

Waterloo (2003) Environmental Initiatives. City of Waterloo, Ontario.

Waterloo (2004) Community Profile. City of Waterloo, Ontario.

WHC (2001) "The Status of Wildlife Habitats in Canada's Urban Landscapes" (Ch. 7) in The Status of Wildlife Habitat in Canada, 2001. Wildlife Habitat Canada, Ottawa.

Whitelaw, G. et al. (2003) "Establishing the Canadian Community Monitoring Network" in Environmental Monitoring and Assessment. Vol. 88, pp. 409-418.

Young, C. and P. Jarvis (2001) "A simple method for predicting the consequences of land management in urban habitats" in Environmental Management. Vol. 28, No. 3, pp. 375387. 


\section{APPENDIX A \\ URBAN WiLdLIFE MANAGEMENT STUDY - INTERVIEW QUESTIONS}

Please Note: The exact order and the precise wording of the open-ended questions will be molded to suit the interview - the number and type of questions asked will be directly related to the role that you play in your municipality. You will not be asked to elaborate on questions for which documentation is available.

\section{A. Background Information}

I will begin by collecting some basic background information about the role that you and your department or division play in the City of XX. The information collected here will allow me to build some context around the answers that you give during the rest of the interview.

1. Briefly describe the position that you hold in the City of XX.

2. Do you believe that there are any aspects of your job as XX that relate to the management of wildlife and/or nuisance species? If so, please describe.

\section{B. Public Perceptions of Nuisance Species}

The focus of this thesis research is on understanding the issues surrounding human-wildlife conflicts caused by 'nuisance' species of wildlife. Nuisance species are those that are involved in any real or perceived negative interactions with humans. Some examples of wildlife that are commonly considered an urban nuisance can include, but are in no way limited to coyotes, deer, raccoons, beavers, skunks, geese, and seagulls. In addition to posing potential health and safety problems, the management of such species can also translate into significant financial costs for both the municipality and private citizens.

1. In your opinion, how is wildlife generally viewed by residents of the City of XX? Is wildlife viewed as a nuisance, a benefit to society, or a combination of both?

2. Please describe how urban wildlife is commonly dealt with in the City of XX. If the City of XX has a public policy (or published guidelines) on the control of nuisance species in the municipality, please describe and/or provide documentation if available.

3. To your knowledge, are there any initiatives to monitor wildlife complaints or evaluate public perceptions of wildlife in the City of XX? If yes, please describe. Provide documentation if available. If the initiative is conducted by an organization outside the municipal government, please specify.

4. Are you aware of any initiatives, such as public education campaigns, that might affect public perceptions of wildlife in the City of XX? If yes, please describe. Provide documentation if available. If the initiative is conducted by an organization outside the municipal government, please specify. 


\section{Biodiversity Science and Information}

In order to effectively manage human-wildlife conflicts, the conflicts must first be understood. Planning for conservation is a process that uses scientific data. For effective management, ecological data and analysis must be available to and be understood by those who will be affected by the decisions being made. Much recent attention has been given to biological diversity in Canadian cities. However, while there is much encouraging progress at the level of policy, studies have found that relevant biological data and the ability to use this data to predict changes to the environment as a result of land use decisions are still in short supply.

1. A natural or open space can include many types of urban habitat - parks, conservation areas, unused or abandoned lands, stream corridors, wetlands, forests, wildflower meadows, etc. What type of information on natural and open spaces is currently available for use by the municipality in planning and operations? If this information includes an inventory of natural and open spaces, please describe the inventory process and results and/or provide documentation if available.

2. What type of information on urban wildlife is currently available for use by the municipality in planning and operations? If this information includes an inventory of wildlife in the city (that is separate from the natural and open spaces inventory), please describe the inventory process and results and/or provide documentation if available.

\section{Planning for Naturalization Projects}

To enhance opportunities for urban biodiversity, there has been a recent trend towards the integration of unused open space resources into the municipal land use system. This is most often accomplished through naturalization and green space restoration projects, where open spaces are either left untouched to allow for natural regrowth or are purposefully landscaped to reestablish some of their pre-development character. This process also requires scientific data, not only to understand and improve the natural landscape design but also to predict the impacts that this landscape change might have on the natural environment and the surrounding community. To be effective, interventions to restore natural areas must ensure that the outcome is improvement, and not further impoverishment.

1. In the past ten years, have there been any naturalization projects undertaken in the City of $X X$ ? Please describe and/or provide documentation if available - focus on project successes, failures and lessons learned. If the projects were conducted by an organization outside the municipal government, please specify.

2. What type of information or criteria - physical, biological and/or demographic - are used when planning naturalization projects? Please describe how this information is used. 
3. Community support can have a large influence on the long-term success of a naturalization project. Among other factors, community attitudes toward ecological restoration are related to their knowledge about the project and their perceptions of the outcomes. What is the level of community involvement in planning, implementing or maintaining naturalization projects?

4. The restoration of urban green spaces has been demonstrated to attract a wide variety of 'nuisance' species. Do planners consider this in naturalization project design? If any human-wildlife conflicts have arisen as a result of naturalization projects, please describe the nature of the conflict and the reaction of the community.

\section{Municipal Partnerships for Naturalization}

Please note that the following question is targeted to subjects that work for organizations outside the municipal government, such as Conservation Authorities, who play an important role in open space restoration.

1. Do you work in partnership with the City of XX to design and/or implement your naturalization projects? If yes, please describe the nature of this partnership. 
APPENDIX B

Key Characteristics of the Six Municipalities Selected for Study

\begin{tabular}{|c|c|c|c|c|c|c|}
\hline \multirow{2}{*}{ Characteristic } & \multicolumn{6}{|c|}{ City } \\
\hline & Hamilton & Grelph & Burlington & Mississaug: & Waterioo & London \\
\hline Population " & 490,268 & 106,170 & 150,836 & 612,925 & 86,534 & 336,539 \\
\hline Area $\left(\mathrm{km}^{2}\right)^{\prime}$ & $1,117.11$ & 86.66 & 185.71 & 288.42 & 64.09 & 421.77 \\
\hline $\begin{array}{l}\text { Population } \\
\text { Density }\end{array}$ & 438.90 & $1,225.10$ & 812.20 & $2,125.10$ & $1,350.30$ & 797.90 \\
\hline $\begin{array}{l}\text { \# of Private } \\
\text { Dwellings }{ }^{\text {a }}\end{array}$ & 194,154 & 42,479 & 59,020 & 198,235 & 35,437 & 146,976 \\
\hline $\begin{array}{l}\text { Private Dwelling } \\
\text { Density " }\end{array}$ & 173.80 & 490.18 & 317.81 & 687.31 & 525.93 & 384.47 \\
\hline $\begin{array}{l}\text { \% Urban Pop. } \\
\text { (per county) }^{b}\end{array}$ & $60-80 \%$ & $60-80 \%$ & $60-80 \%$ & $80-99 \%$ & $60-80 \%$ & $80-99 \%$ \\
\hline$\%$ Foreign Born " & $24.46 \%$ & $21.23 \%$ & $21.26 \%$ & $47.63 \%$ & $22.73 \%$ & $21.69 \%$ \\
\hline $\begin{array}{l}\text { Open Space } \\
\text { Allocations } \\
\text { (per 1000 pop.) }^{c} \\
\end{array}$ & no data & $3.3 \mathrm{ha} / 1000$ & $3.58 \mathrm{ha} / 1000^{\circ}$ & $3.2 \mathrm{ha} / 1000$ & $1.3 \mathrm{ha} / 1000$ & no set ratio \\
\hline $\begin{array}{l}\text { Residential } \\
\text { Parkland } \\
\text { Dedication }\end{array}$ & no data & $\begin{array}{c}5 \% \text { on all lands to } \\
\text { be developed } \\
(1.0 \text { ha/ } 300 \text { units })\end{array}$ & no data & $\begin{array}{c}5 \% \text { on developable } \\
\text { lands } \\
(1.0 \text { ha/ } 300 \text { units })\end{array}$ & $\begin{array}{l}5 \% \text { on all lands to } \\
\text { be developed } \\
(0.5 \mathrm{ha} / 300 \text { units })\end{array}$ & $\begin{array}{c}5 \% \text { on all lands to } \\
\text { be developed } \\
(1.0 \text { ha } 300 \text { units })\end{array}$ \\
\hline $\begin{array}{l}\text { Conservation } \\
\text { Authority }{ }^{\circ}\end{array}$ & Hamilton CA & Grand River CA & Halton CA & Credit Valley CA & Grand River CA & Upper Thames CA \\
\hline Amalgamation? & 2001 & No & No & No & No & No \\
\hline
\end{tabular}

Sources: a - Statscan, 2001; b - OMAF, 2001; c - Guelph, 1997; d - CO, 2000a; e - Burlington, 1998 
This Appendix is designed to supplement understanding of the six municipalities selected for study with contextual background information. The following municipal profiles are provided to add some description to the above Table.

\section{City of Hamilton}

In January 2001, the Towns of Ancaster, Dundas and Flamborough, the Township of Glanbrook, the City of Hamilton and City of Stoney Creek were amalgamated to form the new City of Hamilton.

By population, the City of Hamilton is currently the $9^{\text {th }}$ largest urban municipality in Canada and the $4^{\text {th }}$ largest in Ontario. According to the 2001 Census, Hamilton's population is 490,270 - after adjusting for the Census undercount, Hamilton's population is estimated to be over 503,000 . Hamilton's population growth rate between 1996 and 2001 is estimated at $4.8 \%$ (Hamilton, 2003). While $97 \%$ of residents live in urban areas, the City's large area means that only $20.15 \%$ of the municipal land use is considered urban (Dwyer et al, 2002).

The Parks Division of the City of Hamilton Public Works Department is responsible for the maintenance of an "extensive inventory" of municipal parks and open spaces. At present, the City maintains 1,078 ha of parkland at 310 locations, in addition to 549 ha of natural area at 32 locations and $137 \mathrm{~km}$ of recreational trails. However, due in part to its location on the Niagara Escarpment and in the biological transition zone between two major forest regions, approximately $20 \%$ of the City (23,000 ha) has been identified as environmentally significant (Hamilton, 2001; Dwyer et al, 2002).

The present distribution of natural areas in Hamilton has been determined largely by geographic factors. Natural areas in Hamilton include both undeveloped lands - areas that are either protected or have been found unsuitable to development - and previously disturbed lands that are reverting to a more natural state either spontaneously (post-abandonment) or deliberately (Dwyer et al., 2002).

\section{City of Guelph}

As a separated City, Guelph does not form part of the County system of government.

By the end of 2003, it is estimated that the total population of the City of Guelph reached 113,00 people. The City of Guelph has experienced an average annual growth rate of approximately $2 \%$ over the past ten years. Due to a decline in the average household size, the number of households in Guelph is increasing at a faster rate than the population. As a result, Guelph has recognized a need to accommodate that population through the development of more dwelling units on the 1160 ha of land that is currently designated for residential use (Guelph, 2003c).

While the Official Plan for the City of Guelph allocates 11.5 ha of open space per 1000 population, the City is required to supply only $3.3 \mathrm{ha} / 1000$. The City of Guelph Parks Department is the steward of approximately 565 ha of parkland in over 100 parks across the City, of which only 251 ha is maintained by exterisive horticultural techniques. In addition, respondents 
from the City of Guelph suggested that the relative lack of urban nuisances in the municipal core could be attributed to the City's urban configuration and linkages. The following is a general description of this configuration:

"The Guelph open space system is dominated by the presence of the Speed and Eramosa Rivers that, together, form the shape of a wishbone as they meander through the heart of the City. A good deal of the corridor that contains the rivers is in public ownership, and has been shaped and tied together into a variety of types of parks... and natural river shoreline and wetlands" (Guelph, 1997).

Located near the northern extreme of the Carolinian forest ecosystem, Guelph is home to Canada's first Canadian Heritage River to be designated in a highly settled area (Guelph, 2000). In 1993, the City of Guelph developed a Green Plan as the first step in a strategic planning process designed to move Guelph towards a vision of environmental sustainability (Guelph, 1997). In 2001, the City adopted an updated "green" Official Plan. In 2003, the approval of a Environmental Action Plan furthered the effective implementation of these policies (Guelph, 2003b).

\section{City of Burlington}

The City of Burlington is the largest of four municipalities in the Regional Municipality of Halton. It was incorporated as a City in 1974.

Part of a highly urbanized corridor, the City of Burlington is located between Hamilton and Toronto. Similar to Hamilton, there is a clear geographical division between its urban and agricultural areas. While the majority of residents live in urban areas, the City's large area means that only $43.32 \%$ of the municipal land use is considered urban (Burlington, 2004).

Burlington contains 1,148 ha of parkland, of which 490 ha is maintained by the City.

Environmentally significant areas include parts of the Niagara Escarpment and the shoreline for Lake Ontario (Burlington, 1998). According to its Official Plan (1997), Burlington was declared a "sustainable city" in 1989.

\section{City of Mississauga}

The City of Mississauga is the largest municipality in the Region of Peel. It was incorporated as a City in 1974.

With its population estimated at 624,000 , Mississauga is currently the $6^{\text {th }}$ largest and fastest growing City in Canada (Statscan, 2002). It is also one of the most multicultural, with close to $50 \%$ of residents born outside of Canada (Statscan, 2001).

The City of Mississauga maintains 481 parks and 25 major trail systems. However, the City's Natural Areas Survey (2000) has identified 144 additional remnant natural areas under both private and public ownership. These comprise $7 \%$ of the City land base. Since the late 1980s, the City of Mississauga has been involved in the naturalization of over 200 sites and more than 303 ha 
of public land. Located at the intersection of two major forest regions, Mississauga maintains a great diversity of species (Mississauga, 2002).

Approximately $80 \%$ of the natural areas in Mississauga are associated with watershed valley systems (Mississauga, 2002). The majority of the City lies within the southern extreme of the Credit Valley watershed. The Credit Valley Conservation (CVC) Authority is viewed as being highly progressive in terms of watershed management. For example, the CVC was selected as the pilot-test watershed for the Ontario Ecological Land Classification (ELC) System, now in standard use across the province.

\section{City of Waterloo}

The City of Waterloo is the largest municipality in the Regional Municipality of Waterloo. The Region of Waterloo was created as a new upper tier of municipal government in 1973.

The Laurel Creek Watershed drains most of the lands within the City of Waterloo. Approximately half of this area is currently under urban development, with the majority of this being concentrated in the lower half of the watershed (GRCA, 1993). Between 1996 and 2001, the population of the City of Waterloo grew by approximately $11 \%$ (Statscan, 2001). The current population for the City is estimated at 102,300 people (Waterloo, 2004).

The City of Waterloo adopted an 'Environment First' Policy in 1989. As a result, environmental considerations have since been strategically integrated into all City business units (Waterloo, 1999). For example, the City has now developed an interdepartmental Environmental Coordination Team and has engaged a variety of stakeholders in a Mayor's Environmental Task Force. Over the past 15 years, the City has designed the West Side of Waterloo so that the natural environment can be preserved. Among other things, this means that all wetlands, woodlands and creeks in West Side Waterloo are protected from development by surrounding naturalized buffer areas and living fence property lines (Waterloo, 1998a).

The City of Waterloo now maintains 757 ha of public parks and green spaces which include more than $100 \mathrm{~km}$ of community trails. As of 1999, the City's woodlands totaled 688 ha of which 317.4 ha was under public ownership. This is the equivalent of $46.1 \%$ of the City's remaining woodland cover (Waterloo, 1999).

Of the six selected municipalities, the City of Waterloo was found to have the only public policy on wildlife in the City. This policy states that:

"When general nuisance incidents are caused by wildlife on private property, the City of Waterloo will provide the homeowner with assistance in the form of information about animal control procedures and a list of companies that can respond to their needs. When animal populations have become a general nuisance as defined by the city, or are contributing to a watershed area problem by impeding water flows or destroying habitat, the City of Waterloo will take appropriate action to remove, relocate or reduce the population of wildlife" (Waterloo, 1998b). 


\section{City of London}

The City of London was incorporated as a City in 1855. The last major annexation of the City occurred in 1961.

Currently the largest City in Middlesex County, London's population was estimated at 336,539 people in 2001. This represents a population increase of 3.3\% since 1996 (Statscan, 2001). The population is not only becoming increasingly ethnically diverse, but is also rapidly aging (London, 2003b).

The City of London currently maintains over 280 parks, open spaces and environmentally significant areas, with more than $60 \mathrm{~km}$ of community trails. These 2,038 ha of municipal open space result in an actual supply of 6 ha per 1000 population. However, this open space is not equitably distributed as older, more developed parts of the City fall considerably short of this standard (London, 2003b). Often referred to as the "Forest City", the City currently maintains 155,640 trees (approx. 120 species) of which 32,101 are in managed parks. This total does not include those in unmanaged natural areas.

At present, the purported overabundance of White-tailed deer in London's Sifton Bog is likely its most controversial environmental planning issues. Sifton Bog is an Environmentally Significant Area and Provincially Significant Wetland located in west London, virtually surrounded by residential neighbourhoods. Using the OMNR standard for White-tailed deer carrying capacity of .05 deer per hectare, the Bog would be expected to be able to support a resident population of 3 deer. However, more than 45 deer have been observed in the Bog (London, 2003c).

\section{Note on Conservation Authorities}

The jurisdiction of Ontario's Conservation Authorities is organized on a watershed basis. As natural watersheds do not respect political boundaries, a given Conservation Authority will generally have jurisdiction in several municipalities. Similarly, the political boundary of many municipalities is not contained by just one watershed. For the purposes of this research, a municipality is considered to be part of a particular Conservation Authority's jurisdiction if the majority of the municipal land base falls within the Authority's planning area. During interviews, respondents for Conservation Authorities with jurisdiction over several municipalities were asked to target their response to activities conducted in the selected municipality in question. 


\section{APPENDIX C}

Annotated Bibliography of Articles Included in Media Analysis, Summer 2003

\begin{tabular}{|c|c|}
\hline Date & Reference Information \\
\hline 2003.05 .01 & $\begin{array}{l}\text { AP, "Washington state officials worry about grizzly move" in The Daily News (Kamloops). } \\
\text { move of } 25+\text { bears from B.C. to Washington border raises protest; fear for public safety and the rural } \\
\text { economy across that border. } \\
\text { story also covered by Montreal Gazette (same date) and Prince George Citizen (same date). }\end{array}$ \\
\hline 2003.05 .02 & $\begin{array}{l}\text { CanWest News Service, "Derby targets pesky gophers" in Calgary Herald. A2. } \\
\text { - } \quad \text { gopher-derby to be held between May } 1 \text { and August 31, 2003; gophers tails to be sent to the Saskatchewan } \\
\text { Wildlife Federation as proof of the kill; gophers considered a nuisance to rural livelihoods. } \\
\text { story also covered by Vancouver Sun (same date) and Prince George Citizen (same date). } \\
\text { - } \\
\text { Langerak, J., "Woodpeckers damaging inn: Northern Flickers drilling holes where starlings nest" in The Daily } \\
\text { Courrier (Kelswna). A5. } \\
\text { - Northern Flickers are a protected species, but there proximity to people often creates nuisixise challenges. }\end{array}$ \\
\hline 2003.05 .03 & $\begin{array}{l}\text { Anon., "Hungry bear snooping around Bentinck home" in The Record (Waterloo Region). H3. } \\
\text { bears are infringing on urban domain in Ontario; article endorses reestablishing the spring bear hunt in } \\
\text { Ontario for fear of attacks on humans. } \\
\text { Thompson, W.-A., "Deer on horns of dilemma" in Calgary Herald. B2. } \\
\text { - } \\
\text { growth of deer herd in the City of Calgary as a result of a lack of predators has resulted in overcrowding; } \\
\text { overcrowding has increased the risk of deer-vehicle collisions. }\end{array}$ \\
\hline
\end{tabular}




\begin{tabular}{|c|c|}
\hline Date & Reference Information \\
\hline 2003.05 .04 & $\begin{array}{l}\text { McCooey, P., "Seized animals set free: Ministry releases raccoons, skunks taken in armed raid" in The Ottawa } \\
\text { Citizen. A8. } \\
\text { animals seized from wildlife rehabilitation centre; OMNR introduced new release restrictions in Summer } 2002 \\
\text { to limit use of rehabilitation centres due to risk of rabies. Centre may remain open as educational facility. } \\
\text { Egan, M.-J., "Bring home some bats: Having the eco-friendly mosquito killers around may help protect against West } \\
\text { Nile Virus" in The London Free Press. p. } 5 \text {. } \\
\text { - } \\
\text { bats being considered as an alternative to pesticides for mosquito control; people must overcome their fear of } \\
\text { bats and place bat boxes in their backyards to attract the species. } \\
\text { article outlines distribution of rabies cases in Ontario - fox ( } 67 \%) \text {, skunk (30\%), bats (<3\%), with remaining } \\
\text { cases by coyotes and 'other' (Source: Brad Glasman, Upper Thames River Conservation Authority). }\end{array}$ \\
\hline 2003.05 .05 & $\begin{array}{l}\text { MacKay, B.K., "Help raise a FLAP over migratory birds" in Toronto Star, B07. } \\
\text { - } \quad \text { CD ROM has been designed to educate people against the dangers to migratory birds of night-lit city } \\
\text { buildings; estimates }+2,000 \text { birds injured/night by hazard. See www.flap.org for details. }\end{array}$ \\
\hline 2003.05 .06 & $\begin{array}{l}\text { Dodge, G., "Hunts opponents do not understand bear problems" in The Sudbury Star. A7. } \\
\text { - } \quad \text { letter to the editor endorses a return to the spring bear hunt in Ontario for fear of personal and property } \\
\text { security following increase in Ontario bear population. }\end{array}$ \\
\hline 2003.05 .07 & -.-- \\
\hline
\end{tabular}




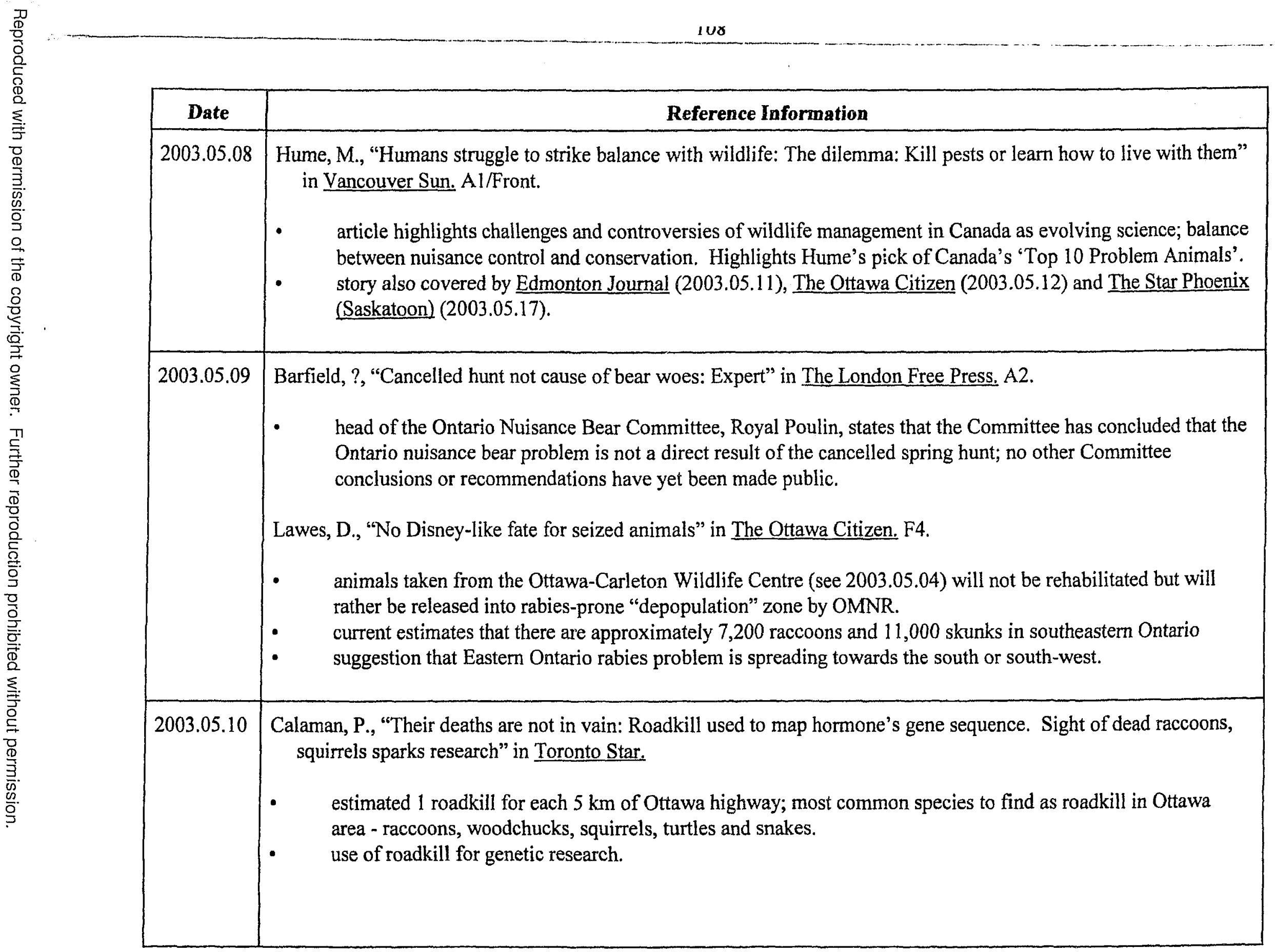




\begin{tabular}{|c|c|}
\hline Date & Reference Information \\
\hline $\begin{array}{l}2003.05 .10 \\
\text { (con't.) }\end{array}$ & $\begin{array}{l}\text { Anon., "Beware the bears" in The Sault Star. A2. } \\
\text { - } \quad \text { OPP response to three bear sightings near Heyden, Ontario; OPP state that bears are not a threat but worried } \\
\text { that bears will continue to approach residential areas in search of food. } \\
\text { warning to residents to mitigate conflicts by use of best bear-aware practices. }\end{array}$ \\
\hline 2003.05 .11 & -.--. \\
\hline 2003.05 .12 & $\begin{array}{l}\text { Elliot, I., "Police probe claims of coyote bite" in The Kingston Whig-Standard. p.3. } \\
\text { - fear of coyotes and other caged wildlife at Bergeron's Exotic Animal Sanctuary (Picton, Ontario) prompt } \\
\text { county complaints of zoning; county goal is closure of Sanctuary. } \\
\text { fear of coyotes more important than real threat, as boy never actually bitten. } \\
\text { Anon., "Answer on bears urgent" in The Sault Star. A4/Opinion. } \\
\text { - complaints re: delays in Ontario Nuisance Bear Committee decisions on the spring bear hurt as urban bear } \\
\text { nuisance reports increase in Sudbury (note: original story source is The North Bay Nugget). }\end{array}$ \\
\hline 2003.05 .13 & --.-- \\
\hline 2003.05 .14 & $\begin{array}{l}\text { Pynn, L. "Conservation service statistics rise: The government has closed regional offices, redirecting complaints to a } \\
\text { call centre in Victoria" in Vancouver Sun. } \\
\text { - } \quad \text { of calls received by B.C. Wildlife Service in September } 2002-2,289 \text { related problem wildlife, } 345 \text { related to } \\
\text { environmental violations, and 2,229 were general inquiries. }\end{array}$ \\
\hline
\end{tabular}




\begin{tabular}{|c|c|}
\hline Date & Reference Information \\
\hline $\begin{array}{l}2003.05 .14 \\
\text { (con't.) }\end{array}$ & $\begin{array}{l}\text { Casey, D., "Wildlife death sentence: Don't drop off animals, humane society warns" in The Ottawa Sun. p. } 7 . \\
\text { - } \\
\text { Ottawa is a high-risk zone for raccoon rabies and is closed to the rehabilitation of all species; as a result, all } \\
\text { orphaned wildlife dropped at the Humane Society must be euthanized. In first two weeks of May, Society } \\
\text { euthanized } 77 \text { raccoons, skunks and squirrels. } \\
\text { By contrast, the U.S. still permits licensed rehabilitators to take orphaned animals even in high-risk rabies } \\
\text { zones. }\end{array}$ \\
\hline 2003.05 .15 & $\begin{array}{l}\text { Anon., "Wildlife call centre logs plenty of calls" in The Daily Courrier (Kelowna). A3. } \\
\text { - } \quad \text { estimated 5\% of B.C. residents have placed calls to the B.C. Wildlife Call Centre. Of } 24,000 \text { calls, approx, } \\
\text { 1,400 reported aggressive cougars or sightings of bears in urban areas, } 13,000 \text { requested information on } \\
\text { common nuisances, and 5,000 were non-emergency related. 1-800-663-WILD. } \\
\text { Fekete, J. and A. Poulton, "Animal lover worries sick squirrel will die if no one steps in to help: The closing of the } \\
\text { wildlife centre has left people struggling to find help for wild animals" in The Ottawa Citizen. C3. } \\
\text { - } \quad \text { due to rabies high-risk, all 'vector' species (i.e. raccoons, fox, skunks) must be euthanized by law. } \\
\text { - OMNR advises that it is currently better for the species to leave wildlife alone than try to help. } \\
\text { See www.wildlifeproblems.ncf.ca. } \\
\text { Casey, D., "Rabies free, thanks to MNR" in The Ottawa Sun. p.20. } \\
\text { - }\end{array}$ \\
\hline
\end{tabular}




\begin{tabular}{|c|c|}
\hline Date & Reference Information \\
\hline 2003.05 .16 & $\begin{array}{l}\text { Seymour, R., "Nuisance geese get filled with lead" in The Daily Courier (Kelowna). A3. } \\
\text { - goose population in Okanagan Valley considered to cause environmental, aesthetic and human health } \\
\text { problems; one municipality (Peachland) continues to use lethal methods to remove geese from its waterfront. } \\
\text { suggested that the Canada goose population rehabilitation program that the Canadian Wildlife Service (CWS) } \\
\text { established in the early } 1970 \text { 's has been too successful; geese are now over-adapted to urban life. Only if all } \\
\text { other methods fail does CWS now issue a permit to kill geese - the permit lists the \#/day and annual maximum } \\
\text { allowable kill. } \\
\text { Scammell, B., "Art of trapping beavers" in Red Deer Advocate. C3. } \\
\text { - residents are concerned about the humane and ecological treatment of the nuisance beaver population in } \\
\text { downtown Calgary; beavers (in Calgary and Canada as a whole) now demonstrate aggressive behaviour that is } \\
\text { characteristic of overcrowding. } \\
\text { beaver control is required for many natural area rehabilitation projects; trapping for fur is no longer } \\
\text { considered an economically viable alternative. }\end{array}$ \\
\hline 2003.05 .17 & $\begin{array}{l}\text { Van Dusen, T., "Fight for deer life looms: Lanark Group planning illegal cull" in The Ottawa Sun. E1. } \\
\text { overabundant deer are creating a nuisance for crops, fencing, timber and increase risk of auto collisions; } \\
\text { OMNR still refuse to classify deer as a nuisance. } \\
\text { residents also protest the reintroduction of other species that would help control the deer population. } \\
\text { Bird, D., "Throwing out birds with the bath: With the arrival of West Nile Virus, birdbaths have been targeted as a } \\
\text { source of mosquitoes. But these places can provide an important source of water for birds" in Montreal Gazette. } \\
\text { H9. } \\
\text { conflict is growing between WNV and urban bird habitat; article encourages other measures (e.g. regular } \\
\text { cleaning) to help manage both issues }\end{array}$ \\
\hline
\end{tabular}




\begin{tabular}{|c|c|}
\hline Date & Reference Information \\
\hline 2003.05 .18 & $\begin{array}{l}\text { Pukay, B., "Even house-bound cats can get rabies" in Times Colonist (Victoria). C3. } \\
\text { - } \quad \text { spread of rabies from other urban wildlife to domestic pets is possible if pets are not properly vaccinated. }\end{array}$ \\
\hline 2003.05 .19 & 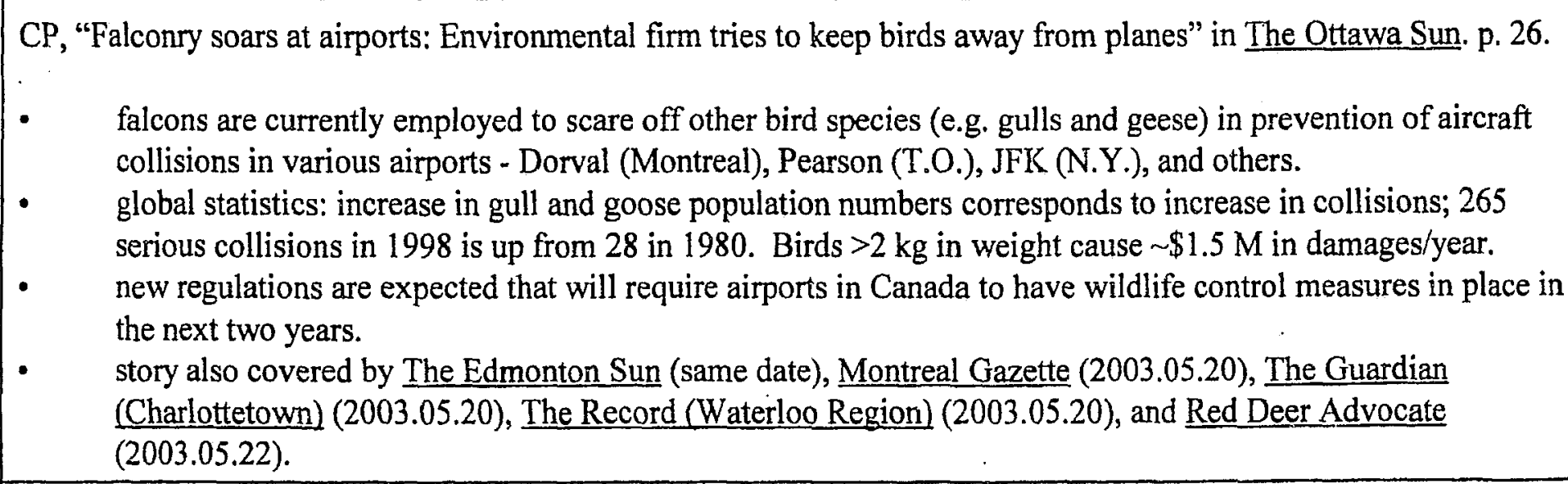 \\
\hline 2003.05 .20 & -.--- \\
\hline 2003.05 .21 & $\begin{array}{l}\text { Corcoran, T., "Toronto's chance to save us from pests" in National Post. Editorial. } \\
\text { - City of Toronto expected to vote on a by-law that would ban the cosmetic use of pesticides against weeds and } \\
\text { other (native) invasive species; Toronto has already stopped cosmetic spraying of public property. } \\
\text { article's terminology describes native species (e.g. wildflowers) as environmental "pests". }\end{array}$ \\
\hline 2003.05 .22 & $\begin{array}{l}\text { Worthington, P., "Coyotes seized from animal sanctuary" in The Toronto Sun. p. } 16 . \\
\text { - } \quad \text { public fear of the spread of rabies from Bergeron's Exotic Animal Sanctuary, Prince Edward County. } \\
\text { began as a political business where the city/county wanted to close Sanctuary for zoning reasons; news spread } \\
\text { to the public with fear of "nuisance" wildlife created. }\end{array}$ \\
\hline
\end{tabular}




\begin{tabular}{|c|c|}
\hline Date & Reference Information \\
\hline $\begin{array}{l}2003.05 .22 \\
\text { (con't.) }\end{array}$ & $\begin{array}{l}\text { Ramaniuk, R., "Canker worm fight begins" in The Winnipeg Sun. p.14. } \\
\text { city spraying trees in parks to prevent infestation; worm is a nuisance to humans that use parks and poses an } \\
\text { ecological threat of deforestation. } \\
\text { Anon., "Wandering cougar tranquilized"in Edmonton Journal. B6. } \\
\text { - } \quad \text { cougar found wandering in Calgary; was tranquilized, given medical assistance and then re-released. } \\
\text { story also covered in Montreal Gazette (same date), Calgary Herald (2003.05.23), and Red Deer Advocate } \\
\text { (2003.05.23). } \\
\text { Major, E., "Peregrine falcons don't belong in the city" in The Daily Courier (Kelowna). A11/Opinion. } \\
\text { resident against encouraging birds of prey to nest in urban areas. }\end{array}$ \\
\hline 2003.05 .23 & 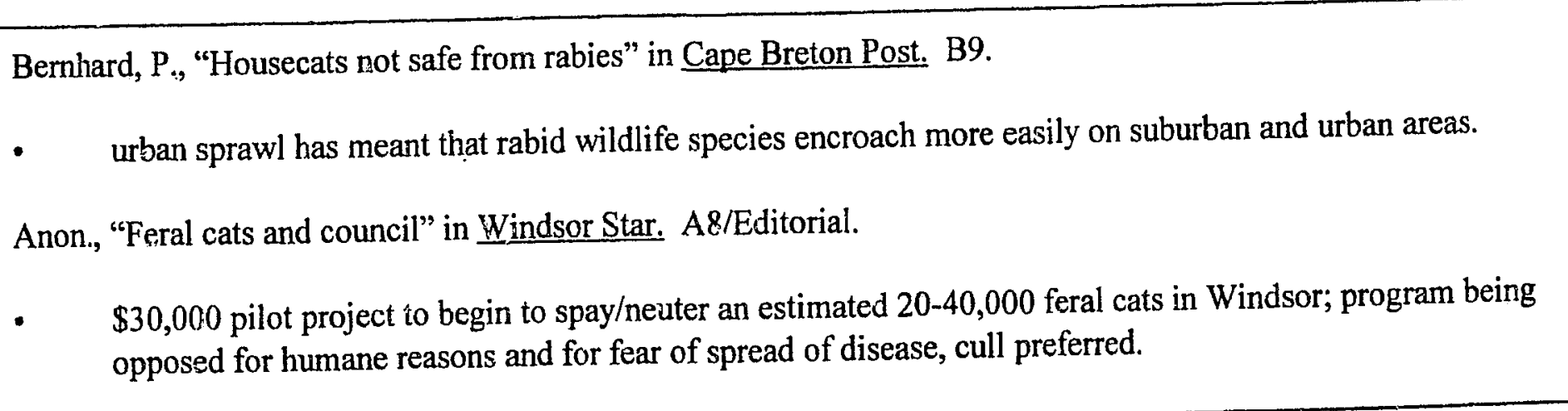 \\
\hline 2003.05 .24 & --.--- \\
\hline
\end{tabular}




\begin{tabular}{|c|c|}
\hline Date & Reference Information \\
\hline 2003.05 .25 & 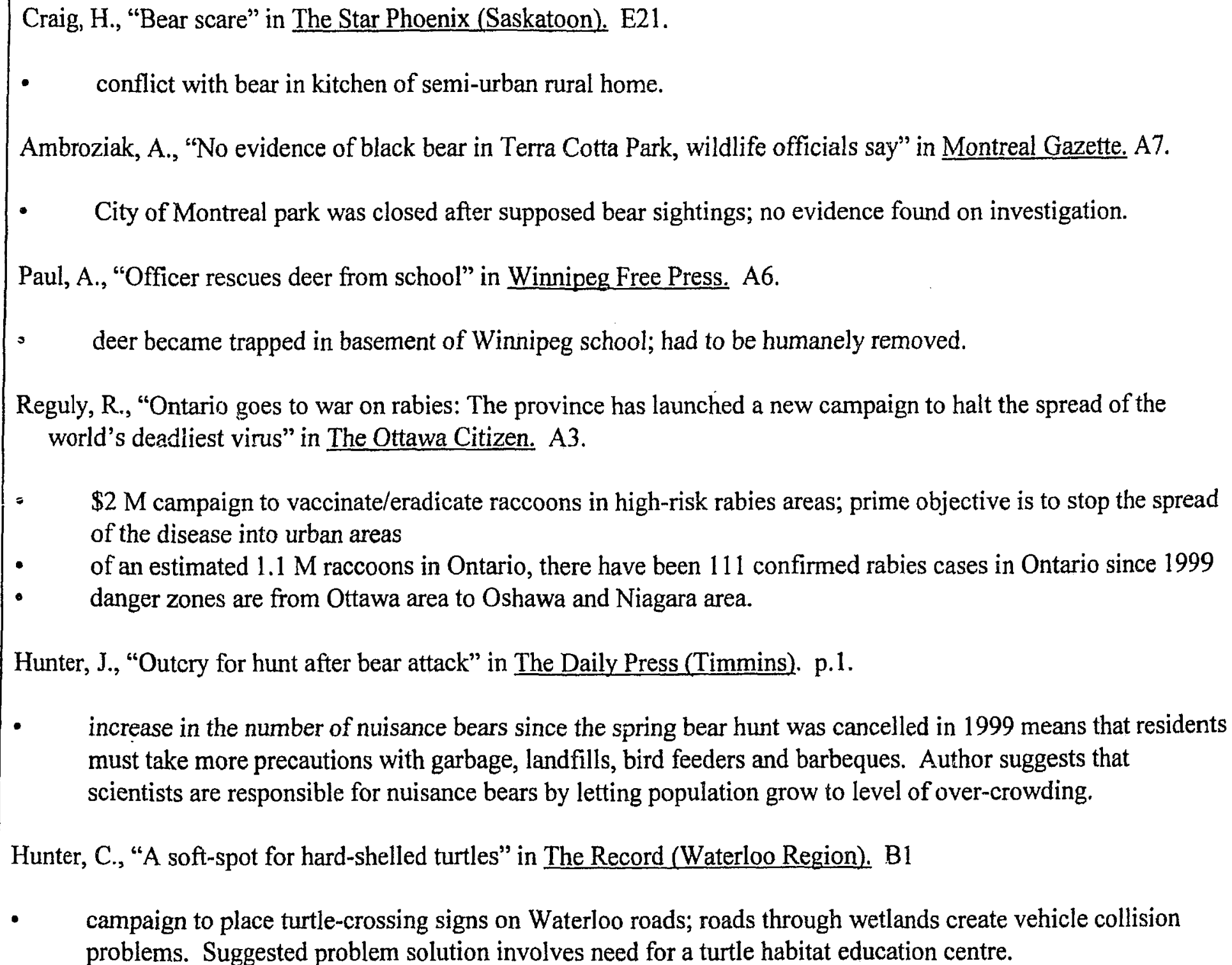 \\
\hline
\end{tabular}




\begin{tabular}{|c|c|}
\hline Date & Reference Information \\
\hline 2003.05 .27 & $\begin{array}{l}\text { Edgar, P., "Wascawwy wabbits! Gardeners declare war on ravaging cottontails" in Winnipeg Free Press. B1 } \\
\text { - } \quad \text { conflict between rabbits and gardeners in Winnipeg; rabbits that are captured are relocated outside the city. } \\
\text { article also suggests methods to discourage rabbits on residential property. }\end{array}$ \\
\hline 2003.05 .28 & - \\
\hline 2003.05 .29 & $\begin{array}{l}\text { Inwood, D., "Inventor goes to bats for skeeter-free world: David Hills' bat houses are flying off the shelves" in The } \\
\text { Province (B.C.). A4. } \\
\text { company promoting bat houses to reduce WNV-related mosquito problems and to keep bat pests out of attics. } \\
\text { health officials warn against encouraging bats in urban areas for fear of rabies spread; company protests claim } \\
\text { as unfounded bat fears. }\end{array}$ \\
\hline 2003.05 .30 & $\begin{array}{l}\text { Gibb, J., "Spring bear hunt desperately needed in North" in The Daily Press (Timmins). p.6. } \\
\text { - } \\
\text { concern over human-bear conflict with growing black bear population; author debates whether increased } \\
\text { conflicts are an issue of urban adaptation of bears or human behaviour creating urban attractants. }\end{array}$ \\
\hline 2003.05 .31 & $\begin{array}{l}\text { Cowan, J., "Will wilder Don nurture mosquitoes? Wetlands: Some say that Don would be a West Nile breeding } \\
\text { ground" in National Post. TO4. } \\
\text { article debates the spending of City money for the revitalization of wetlands along the Don River in Toronto } \\
\text { while faced with WNV threats; health impact studies of the revitalization have been requested by Council. }\end{array}$ \\
\hline 2003.06 .01 & $---\cdots$ \\
\hline 2003.06 .02 & $-\ldots$ \\
\hline
\end{tabular}




\begin{tabular}{|c|c|}
\hline Date & Reference Information \\
\hline 2003.06 .03 & $\begin{array}{l}\text { Loan, D., "Greater Toronto does indeed have a bear population" in The Daily Press (Timmins). p.6. } \\
\text { - David Loan, Manager of the International Fund for Animal Welfare responds to editorial of } 2003.05 .30 \text {; } \\
\text { rebuts criticisms of spring bear hunt as an issue solely for northern Ontario by asserting that there are in fact } \\
\text { hundreds of bears present in the York and Durham Regions (i.e. in the Rouge Park system). }\end{array}$ \\
\hline 2003.06 .04 & $\begin{array}{l}\text { Anon., "Banff park wardens drive grizzly bear out of town" in The Leader-Post (Regina). C10. } \\
\text { bear was found in town hunting elk; both the bear and the elk had to be driven out of the town boundary for } \\
\text { resident safety. } \\
\text { story also covered by the Edmonton Journal (same date). } \\
\text { Anon., "Loose moose caught" in Red Deer Advocate. A3. } \\
\text { - } \\
\text { tranquilizers were used to remove two moose from within City of Edmonton. } \\
\text { Anon., "Park roaming coyote could be rabid: cops" in The Toronto Sun. p.26. } \\
\text { - } \\
\text { coyote(s) in North York park system found to have attacked four people within one week; people wamed to } \\
\text { be aware of coyotes but reminded that they are generally a timid species. } \\
\text { concerns to be directed to Toronto Animal Services - (416) 338-7297. }\end{array}$ \\
\hline 2003.06 .05 & $\begin{array}{l}\text { Anon., "Crows creepy for Cranmore residents" in Red Deer Advocate. A5. } \\
\text { - } \quad \text { residents have signed a petition in an attempt to force the City of Cranmore to deal with nuisance crow } \\
\text { population; after }>30 \text { calls, City has started destroying nests (added fear of WNV). } \\
\text { crow population grew in the City when surrounding grain elevators were torn down. } \\
\text { - } \quad \text { story also covered by Prince George Citizen (2003.06.06). }\end{array}$ \\
\hline
\end{tabular}




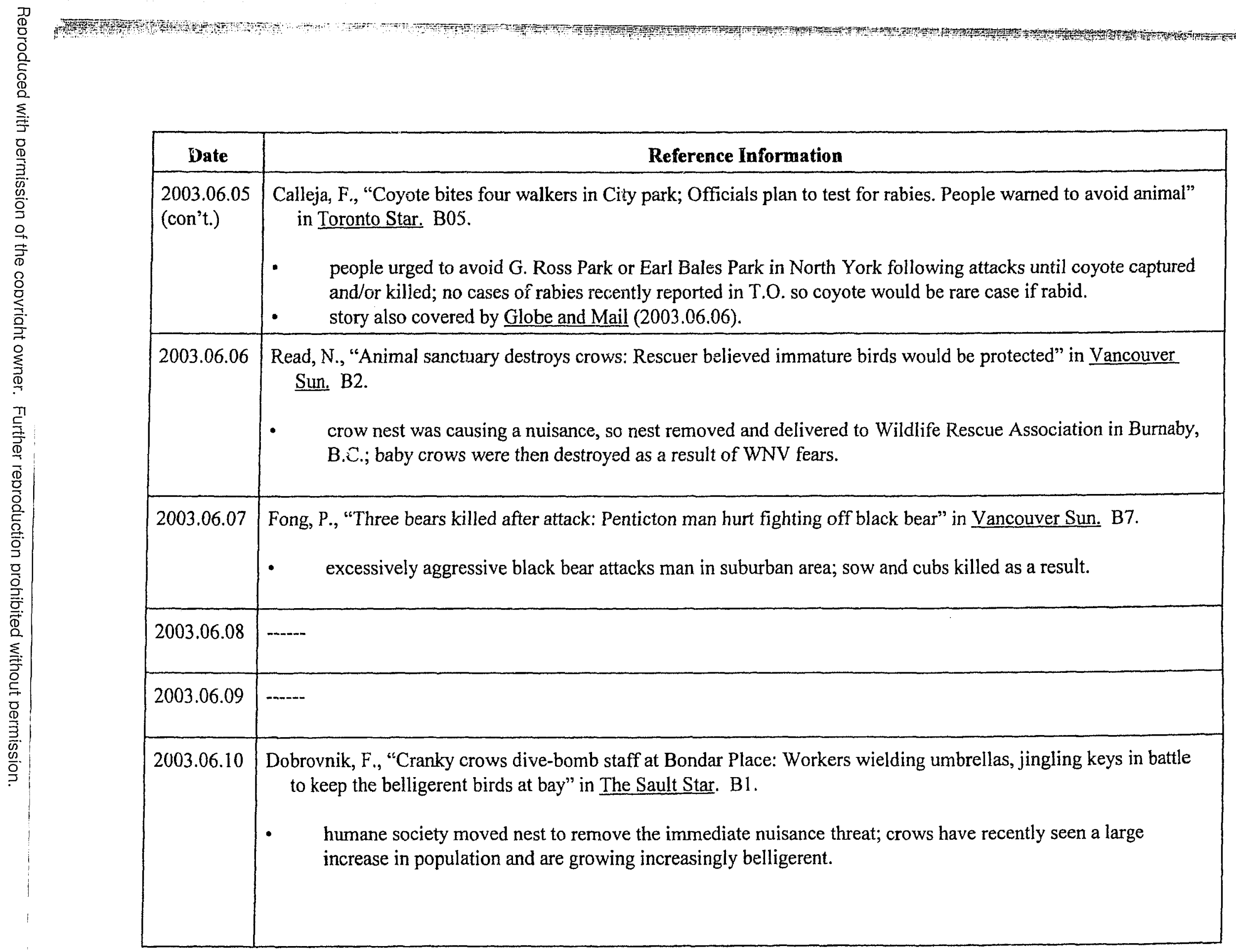




\begin{tabular}{|c|c|}
\hline Date & Reference Information \\
\hline 2003.06 .11 & $\begin{array}{l}\text { Pink, D., "Plan to protect green spaces long overdue, activist says" in The Record (Waterloo Region). B6. } \\
\text { three new areas of Waterloo have been designated as 'environmentally sensitive lands', protected from } \\
\text { development by the Grand River Conservation Authority. }\end{array}$ \\
\hline 2003.06 .12 & $\begin{array}{l}\text { CanWest News Service, "What do a dirty SUV and a deer have in common" in Edmonton Journal. A3. } \\
\text { - Aeer trapped in Regina car wash was released by a provincial conservation officer. } \\
\text { Anon., "Wile E. Coyote visits town" in Toronto Star. P14. } \\
\text { - coyotes in T.O. parks have led to four bites; coyote to be captured for rabies tests for the safety of the coyote } \\
\text { and the safety of residents. } \\
\text { Power, B., "Wildlife folks applaud city's shaggy lawn look; Ban on cosmetic pesticides behind extra weeds on } \\
\text { property" in The Chronicle-Herald (Halifax). A4. } \\
\text { Halifax ban on pesticides began on April 1,2003; allows wildlife habitat to be created in urban areas } \\
\text { (especially native wildflowers). } \\
\text { Canadian Wildlife Federation encourages Canadians to bring wildlife back to communities and backyards - } \\
\text { www.cwf-fcf.org/pages/indexe.htm. } \\
\text { Poole, R., "City denies mulling leg traps for coyote: Attacking joggers: Humane Society launches accusations at } \\
\text { health officials" in National Post. A23. } \\
\text { - T.O. claims that leg traps are not permitted under the Toronto Board of Health's Coyote Response Strategy } \\
\text { (www.city.toronto.on.ca/health/pdf/boh_coyote_response_strategy_report.pdf). } \\
\text { current coyote problem presents the first real threat to the City in terms of rabies, never before experienced. }\end{array}$ \\
\hline
\end{tabular}




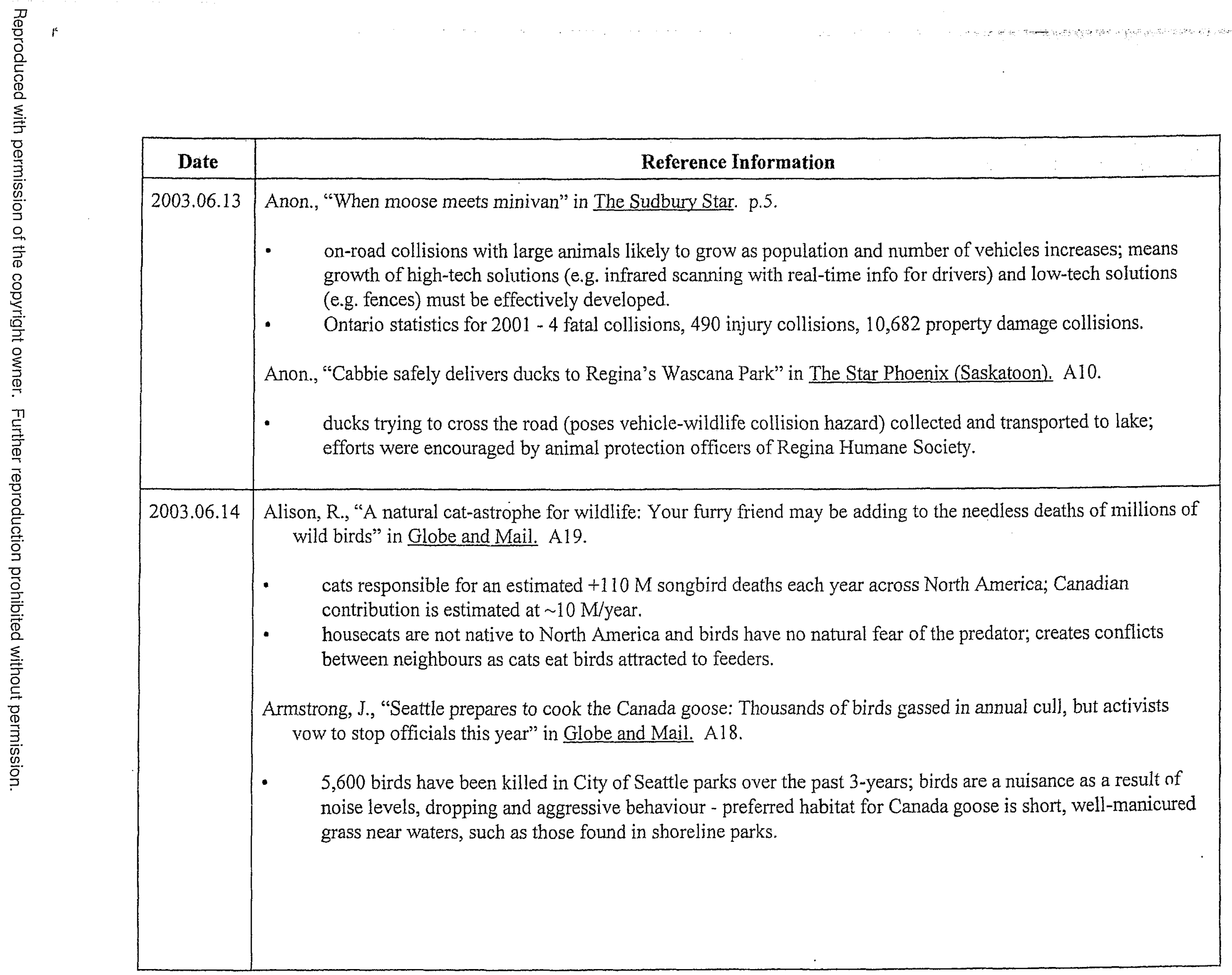




\begin{tabular}{|c|c|}
\hline Date & Reference Information \\
\hline 2003.06 .21 & $\begin{array}{l}\text { Anon., "Bears are moving from rural areas to cities" in Red Deer Advocate. B10. } \\
\text { bears are spreading into urban areas in cities of the northwestern United States; biologists say that they pose } \\
\text { little threat to humans but there are still calls to bring back the bear hunt and protect bear habitat. }\end{array}$ \\
\hline 2003.06 .22 & -..-.- \\
\hline 2003.06 .23 & $\begin{array}{l}\text { Anon., "Wild near the strip malls; Overlooked campground lies in the heart of Scarborough - Nature is within } \\
\text { walking distance" in Toronto Star. B02. } \\
\text { Glen Rouge campground is the largest urban campground in Canada; including in listings of Toronto's parks, } \\
\text { discovery walks and trail map. }\end{array}$ \\
\hline 2003.06 .24 & --.-- \\
\hline 2003.06 .25 & $\begin{array}{l}\text { Bombardier, D., "Un chevreuil entre Triolet" in La Tribune. A2. } \\
\text { deer cornered in city school; deer killed by injuries sustained while trying to escape. } \\
\text { Rockwell, K., "City wants bears killed only as a last resort" in Vancouver Sun. A15. } \\
\text { Port Moody, B.C. had two bears destroyed by the City in June; in general, City states that it prefers public } \\
\text { education to lethal measures. Public education includes: front page coverage of issue in local newspaper, } \\
\text { "focus" newsletter distributed by councillors to all residents, notices sent to homes where nuisance bears are } \\
\text { known to be in proximity, and trails closed when bears are present. }\end{array}$ \\
\hline 2003.06 .26 & -...-.. \\
\hline
\end{tabular}




\begin{tabular}{|c|c|}
\hline Date & Reference Information \\
\hline 2003.06 .27 & $\begin{array}{l}\text { Ennis, H., "Deer cull proposal up for debate at city hall" in The London Free Press. A3. } \\
\text { Thames River Conservation Authority wants to cull deer as they fear that the overabundant deer population } \\
\text { will damage the environmentally sensitive Sifton Bog; others suggest that there is no need for a cull as there is } \\
\text { no proof that damage has actually occurred and that most of the problem is "social". } \\
\text { Coolican, L., "Coyote run-in sparks alarm: Signs posted at south-side ravine after dog-walker startled" in The } \\
\text { Edmonton Sun. p. } 24 \text {. } \\
\text { coyotes have inhabited the area for several years and no longer appear to be timid of people; community } \\
\text { groups concerned about the issue have posted a sign to warn other residents. So far, no incidents have } \\
\text { occurred and group hopes that awareness raising can keep it that way. }\end{array}$ \\
\hline 2003.06 .28 & $\begin{array}{l}\text { Anon., "A howling good site" in Montreal Gazette. H11. } \\
\text { - } \\
\text { peview of Washington State organization website debunking the myths about wolves as a nuisance species; } \\
\text { promotes understanding of ecological functions of predators - www.wolfhaven.org. } \\
\text { Mittelstaedt, M., "Canada's national pest: Beavers are industrious. Maybe too industrious" in Globe and Mail. F8. } \\
\text { - } \quad \text { beaver is valued by society of one of Canada's inational symbols but is also an ecological pest as a result of its } \\
\text { industriousness; main problem is that natural predators of beavers are not viable in urban areas and thus lethal } \\
\text { measures must be taken to manage population levels. } \\
\text { beaver is listed in Calgary as a "problem animal" (along with Norway rats, moles, magpies and raccoons), and } \\
\text { info for their control is posted on the City of Calgary website. Estimated 1,500-3,000 beavers in City result in } \\
\text { destruction of urban forest. } \\
\text { Toronto has beavers in Don, Rouge and Humber rivers that create concerns similar to those in Calgary; } \\
\text { however, T.O. beavers are being welcomed as natural part of urban fauna and protective measures rather than } \\
\text { lethal measure are taken (e.g. Toronto's more valuable/vulnerable trees are protected by metal wraps). }\end{array}$ \\
\hline
\end{tabular}




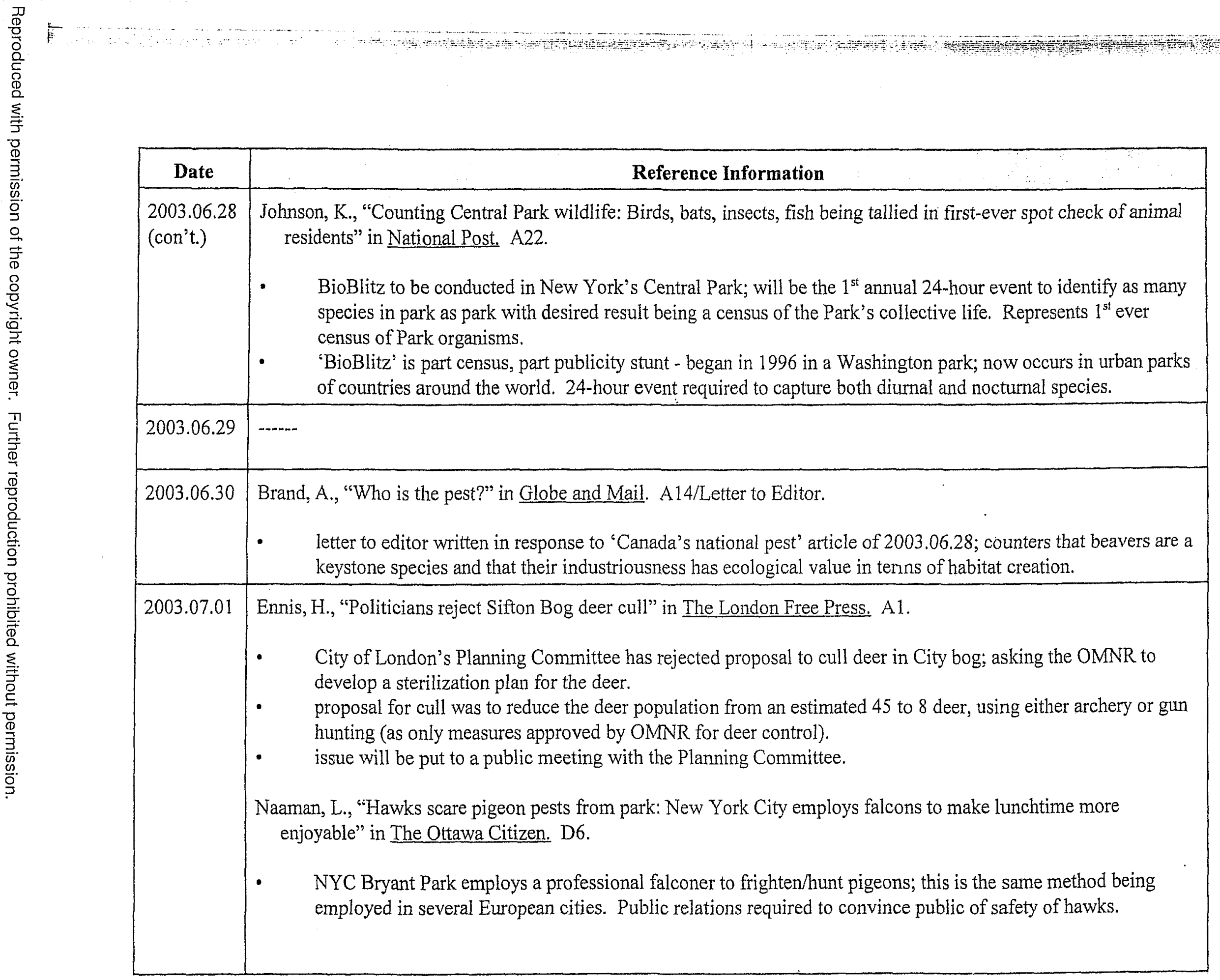




\begin{tabular}{|c|c|}
\hline Date: & Reference Information \\
\hline 2003.07 .02 & -.--- \\
\hline 2003.07 .03 & $\begin{array}{l}\text { Waite, A., "Don't cry uncle about ants" in Calgary Herald. S9. } \\
\text { tips about how to prevent home/garden ant infestations; also highlights ecological value of ants. }\end{array}$ \\
\hline 2003.07 .04 & $\begin{array}{l}\text { CP, "Province issues bear warning" in The Sudbury Star. A6. } \\
\text { OMNR issues warning to residents of eastern Ontario about potential entry of black bears into populated } \\
\text { areas; say bears may enter in search of food due to berry shortage. } \\
\text { draft report of Ontario Nuisance Bear Committee expected in Summer } 2003 \text {. } \\
\text { story also covered by The Ottawa Citizen (same date). } \\
\text { Portman, T., "When wildlife hits the highway: Roadkill a major cause of mortality in some animals" in Winnipeg } \\
\text { Free Press. A8. } \\
\text { - } \\
\text { insurance records show that there were some } 8,400 \text { large mammal collisions in Manitoba in 2002; no record is } \\
\text { kept of small mammal collisions. } \\
\text { collisions are likely to contribute to the decline of the local wildlife population, especially those that migrate } \\
\text { in large groups. Habitat fragmentation is the main reason animals are forced to cross roads. }\end{array}$ \\
\hline 2003.07 .05 & $\begin{array}{l}\text { CP, "Health officials warn Hamilton bats rabid" in The Sault Star. B7. } \\
\text { two rabid bats found in Hamilton; endangers the lives of residents and their pets. } 1^{\text {st }} \text { case of bat rabies since } \\
2001 \text {. } \\
\text { - } \quad \text { story also covered by Toronto Sun (same date). }\end{array}$ \\
\hline
\end{tabular}




\begin{tabular}{|c|c|}
\hline Date & Reference Information \\
\hline $\begin{array}{l}2003.07 .05 \\
\text { (con't.) }\end{array}$ & $\begin{array}{l}\text { Sopuck, R., "Wildlife management maintains balance" in Winnipeg Free Press. E6. } \\
\text { suggests that economic and public safety costs of urban wildlife necessitate management responses; article } \\
\text { calls for sound, science-based wildlife management; lethal measures and improved land stewardship } \\
\text { considered as solutions. } \\
\text { Cowan, P., "Farewell dear Farley, have a good life" in The Leader-Post (Regina). B1. } \\
\text { - } \\
\text { ofnual Canada goose round-up and transport from Regina parks to wildlife centre to reduce superabundance } \\
\text { Canada geese create conflict for use of park space and vehicle collisions. } \\
\text { Legge, L., "Something to crow about; Forget birdbrain" in The Chronicle-Herald (Halifax). E1. } \\
\text { conflicts growing between humans and crows; some issues are result of crow instincts and some are the result } \\
\text { of habits learned from human behaviour. } \\
\text { Fragomeni, C., "Take care around bats; warning issued after rabid bats found in downtown" in The Hamilton } \\
\text { Spectator. A03. } \\
\text { - } \\
\text { two rabid bats found in Hamilton; warning to residents issued by public health ( } 905-540-5019 \text { ). } \\
\text { article also lists preventative and emergency measures for dealing with bats and other rabid species. }\end{array}$ \\
\hline 2003.07 .06 & $\begin{array}{l}\text { Engstrom, K., "City wildlife not confined to clubs: Animals abundant inside perimeter" in The Winnipeg Sun. A10. } \\
\text { article about urban wildlife viewing; provides tips, techniques and cautions. }\end{array}$ \\
\hline
\end{tabular}




\begin{tabular}{|c|c|}
\hline Date & Reference Information \\
\hline $\begin{array}{l}2003.07 .06 \\
\text { (con't.) }\end{array}$ & $\begin{array}{l}\text { MacKinnon, B., "Nuisance bear problems spark outrage in North" in The Daily Press (Timmins). p.1. } \\
\text { - } \\
\text { response to OMNR nuisance bear warning issued for southeastern Ontario; suggests that nuisances are a direct } \\
\text { result of bear overpopulation due to lack of spring bear hunt rather than temporary food shortage. }\end{array}$ \\
\hline 2003.07 .07 & $-\cdots$ \\
\hline 2003.07 .08 & $\begin{array}{l}\text { Egan, M., "Sifton Bog deer cull rejected: Councillors want to examine the use of chemical sterilization to cut deer } \\
\text { numbers" in The London Free Press. B1. } \\
\text { - } \\
\text { sterilization to become selected option rather than archery hunt; deer present fears not only for ecology of the } \\
\text { bog but also human nuisances (i.e. browsing, vehicle collisions, etc.), but not all residents are convinced that a } \\
\text { deer problem actually exists. Suggestion that deer may have to be accepted as a natural factor in London. }\end{array}$ \\
\hline 2003.07 .09 & $-\cdots---$ \\
\hline 2003.07 .10 & $\begin{array}{l}\text { Bohn, G. and N. Reed, "Cougar captured in Burnaby: Three-year old male may have been driven into residential area } \\
\text { by rising local cougar population" in Vancouver Sun. A3. } \\
\text { cougar in backyard of suburban Burnaby, B.C.; tranquilized, tested for disease and released. } \\
\text { story also covered by Edmonton Journal (same date), The Province (same date), and Montreal Gazette (same } \\
\text { date). } \\
\text { Oliviera, M., "Activists fume after county grasses Canada geese" in Winnipeg Free Press. A7. } \\
\text { - } 700 \text { geese were gassed in New Jersey; considered flying vermin after causing thousands of dollars in damage } \\
\text { to parks as a result of droppings and Foraging. } \\
\text { Coalition to Prevent the Destruction of Canada Geese (based in New York - www.canadageese.org) urging the } \\
\text { U.S. Government to develop an official plan for the birds. }\end{array}$ \\
\hline
\end{tabular}




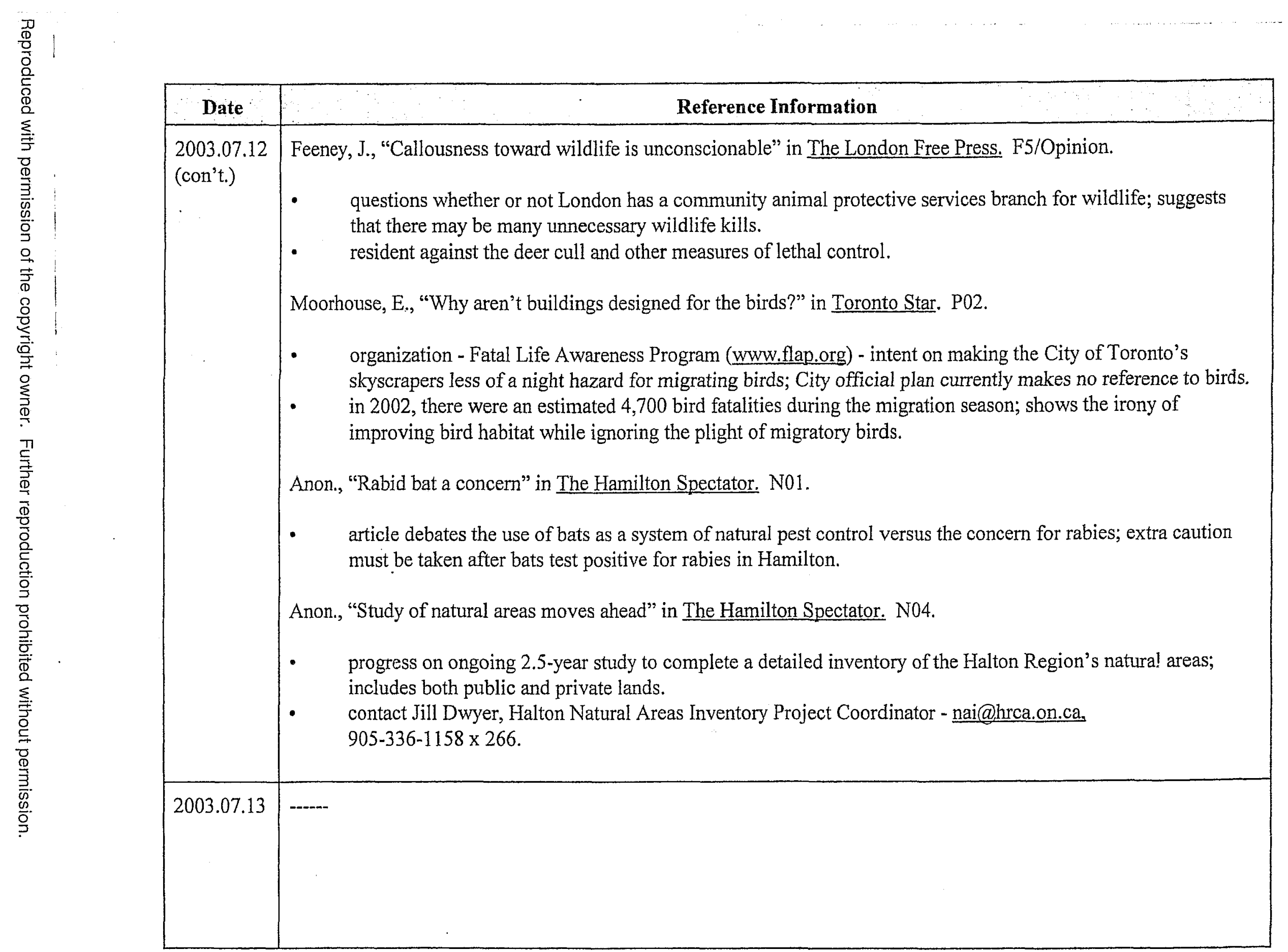




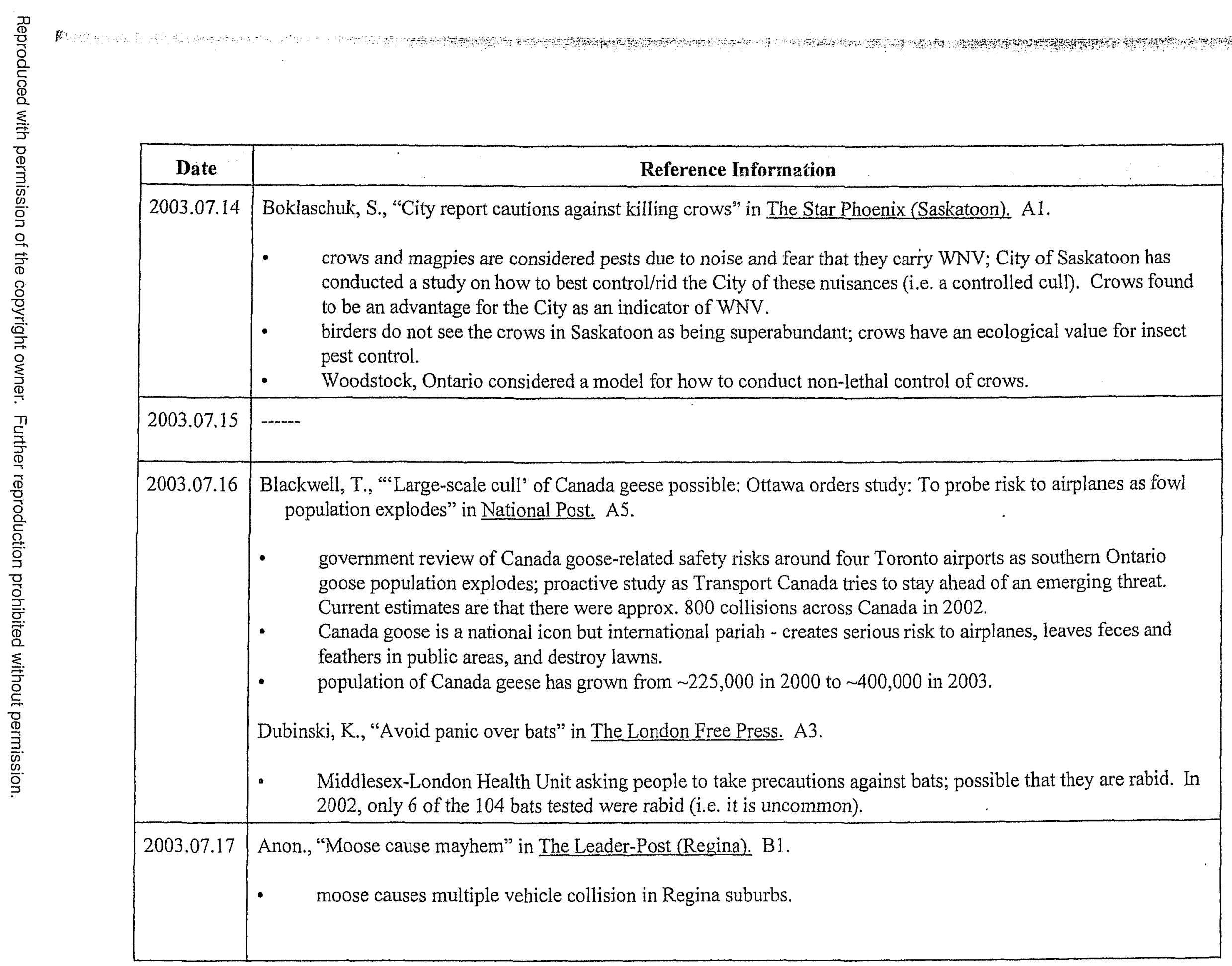




\begin{tabular}{|c|c|}
\hline Date & Reference Information \\
\hline $\begin{array}{l}2003.07 .17 \\
\text { (con't.) }\end{array}$ & $\begin{array}{l}\text { Josey, S., "Airport study takes aim at geese; seeks to reduce risk to planes. Activists oppose killing birds" in Toronto } \\
\text { Star. D04. } \\
\text { - } \\
\text { study will cover four airports - Pearson, City Centre, Buttonville and Oshawa. } \\
\text { estimated +95 collisions between birds and airplanes in GTA in } 2002 \text {. } \\
\text { Animal Alliance of Canada (www.animalalliance.ca) oppose the study; claims that govermment is just trying } \\
\text { to find the justification to fit pre-conceived conclusions. }\end{array}$ \\
\hline 2003.07 .18 & -..-- \\
\hline 2003.07 .19 & $\begin{array}{l}\text { Czekaj, L., "Cougar report claws for concern" in The Ottawa Sun. p.5. } \\
\text { - } \quad \text { possible sighting of a cougar in a remote part of Ottawa; authorities issue official warning to residents. Last } \\
\text { confirmed Ontario cougar sighting was in } 1884 \text {. }\end{array}$ \\
\hline 2003.07 .20 & ----- \\
\hline 2003.07 .21 & -.--- \\
\hline 2003.07 .22 & $\begin{array}{l}\text { Greer, P., "If we kill cattle, why not deer?" in The London Free Press. A6/Opinion. } \\
\text { - } \quad \text { comparison of morality between beef and deer cull; resident lends support to Sifton Bog cull for ecological } \\
\text { reasons (i.e. habitat destruction). } \\
\text { Chorney, M., "Crow eradication foolish move likely to upset nature's balance" in The Star Phoenix (Saskatoon). A6. } \\
\text { - City of Saskatoon proposal to cull nuisance crows being opposed; suggested that better control would be } \\
\text { changes to human behaviour (e.g. covered garbage, bird feeder controls, etc.). } \\
\text { cites the ecological value of crows as WNV indicators and scavengers of harmful insects and roadkill. }\end{array}$ \\
\hline
\end{tabular}




\begin{tabular}{|c|c|}
\hline Date & Reference Information \\
\hline 2003.07 .23 & -...- \\
\hline 2003.07 .24 & --.-- \\
\hline 2003.07 .25 & -..- \\
\hline 2003.07 .26 & -..-- \\
\hline 2003.07 .27 & $\begin{array}{l}\text { Daniels, A., "Think before you swat" in The Ottawa Citizen. C8/Book Review. } \\
\text { - humans consider bugs nuisances, but could not exist without their ecosystem services (e.g. pollination, } \\
\text { vegetation control, decomposition, etc.). } \\
\text { book by Gilbert Waldbauer, What Good Are Bugs? (Harvard University Press). } \\
\text { Beech, M., "Invading deer bother "burbs" in The London Free Press. p.2. } \\
\text { - provides examples of conflict between white-tailed deer and people in London's Sifton Bog } \\
\text { OMNR does not recognize sterilization as a deer population control method. }\end{array}$ \\
\hline 2003.07 .28 & $\begin{array}{l}\text { Anon., "Release bear study now" in The Sault Star. A4. } \\
\text { - City residents in northern Ontario want report on cancelled spring bear hunt released; believe that hunting ban } \\
\text { is political rather than scientific while the nuisance threat is real. }\end{array}$ \\
\hline 2003.07 .29 & -..- \\
\hline 2003.07 .30 & ---- \\
\hline
\end{tabular}




\begin{tabular}{|c|c|}
\hline Date & Reference Information \\
\hline 2003.07 .31 & $\begin{array}{l}\text { Wilson, J., "Rimbey hires crow killer: Birds have attacked some residents, mayor says" in Red Deer Advocate. B1. } \\
\text { - } \\
\text { town of Rimbey, Alberta to cull crows; crows are considered a nuisance (noise, WNV, etc.) and are not } \\
\text { protected under the Migratory Birds Act. } \\
\text { alternate argument is that food sources and forested areas are attracting crows; people can reduce the crow } \\
\text { population by increasing level of cleanliness (i.e. not contributing to food source). } \\
\text { story also covered by The Chronicle-Herald (Halifax) (same date), National Post (same date), The Record } \\
\text { (Waterloo Region) (same date) and Edmonton Journal (same date). }\end{array}$ \\
\hline 2003.08 .01 & $-\cdots-\ldots$ \\
\hline 2003.08 .02 & -...... \\
\hline 2003.08 .03 & ----- \\
\hline 2003.08 .04 & $\cdots$ \\
\hline 2003.08 .05 & $\begin{array}{l}\text { Caron, R., "New program helps citizens to become bear aware" in The Daily Press (Timmins). p.3. } \\
\text { - Timmins bear awareness program to reduce the nuisances felt by problem bears; provides information about } \\
\text { the habits of bears and precautions to be taken to prevent/eliminate conflicts. }\end{array}$ \\
\hline 2003.08 .06 & -..-- \\
\hline 2003.08 .07 & …-. \\
\hline 2003.08 .08 & ----- \\
\hline
\end{tabular}




\begin{tabular}{|c|c|}
\hline Date & Reference Information \\
\hline 2003.08 .09 & $\begin{array}{l}\text { MacLeod, M., "What's up, Doc? Wabbits. Lots of 'em; Revenge of the herbivores: a cool, damp spring means lots } \\
\text { to eat from lush city gardens, and critters flourish" in The Hamilton Spectator. A01. } \\
\text { - } \quad \text { no formal rabbit census has been taken, but rabbit population appears to be in boom cycle (AAA Wildlife } \\
\text { Control in Hamilton claims this to be one of their busiest seasons ever); OMNR does not actively monitor } \\
\text { urban wildlife like rabbits, despite the fact that more rabbits may lead to more coyotes. } \\
\text { urban property often considered a 'cafeteria for wildlife' with garbage and gardens supplementing diets. }\end{array}$ \\
\hline 2003.08 .10 & $-\cdots$ \\
\hline 2003.08 .11 & $\begin{array}{l}\text { Sankar, C., "The bears in the North aren't shy anymore: They feel free to come and go as they please" in The } \\
\text { Sudbury Star. A3. } \\
\text { states that bears have moved into urban Sudbury; debates the need for a spring bear hunt versus the right of } \\
\text { bears to use this territory. }\end{array}$ \\
\hline 2003.08 .12 & $\begin{array}{l}\text { Koopmans, R., "Homeless man hurt in attack by 'predatory' black bear" in Vancouver Sun. A2. } \\
\text { - } \quad \text { aggressive black bear attacked a man in Kamloops; authorities caution locals of potential danger as the bear } \\
\text { has not yet been found. This is unusual activity for a black bear. } \\
\text { Flannigan, T., "Bat story should have waited" in The Daily Courier (Kelowna). A9. } \\
\text { previous story of dead bats never clarified that the bats were not rabid; this is a case of poor wildlife reporting } \\
\text { that lost business for wildlife outfits. }\end{array}$ \\
\hline 2003.08 .13 & $\begin{array}{l}\text { Strickland, P. "Bear necessities: Conservation officers have been busy so far this year" in Prince George Citizen. p13. } \\
\text { - Northern Bear Awareness Team has had numerous nuisance complaints since January, and } 5 \text { bears have been } \\
\text { destroyed. Garbage is the \#1 attractant and public education and awareness is the \#1 solution. }\end{array}$ \\
\hline
\end{tabular}




\begin{tabular}{|c|c|}
\hline Date & Reference Information \\
\hline $\begin{array}{l}2003.08 .13 \\
\text { (con't.) }\end{array}$ & $\begin{array}{l}\text { Anon., "Bear believed responsible for attack trapped and shot" in The Daily News (Kamloops). A1. } \\
\text { - follow-up to previous story of homeless man attacked; use of lethal methods of bear control. } \\
\text { Chevalier, P., "Officials should read Bechtel Park master plan" in The Record (Waterloo Region). A10. } \\
\text { - } \quad \text { natural area of parkland being destroyed for development of an extended playing field without the } \\
\text { consultation of the Bechtel Park Master Plan; Plan has set conservation priority for area. }\end{array}$ \\
\hline 2003.08 .14 & $\begin{array}{l}\text { Chiarelli, N., "Province set to launch its anti-rabies program; No cases have been reported since last year" in } \underline{\text { The }} \\
\text { New Brunswick Telegraph Journal. A5. } \\
\text { - } \begin{array}{l}\text { anti-rabies program designed for raccoons and skunks in southern New Brunswick communities; cost expected } \\
\text { to have been } \$ 225,000 \text { in } 2002 \text {. }\end{array}\end{array}$ \\
\hline 2003.08 .15 & $\begin{array}{l}\text { Anon., "Ratting out city's rodents" in Montreal Gazette. A18. } \\
\text { - } \\
\text { an excessive population of rats has been at a construction site in the City of Montreal; City 'vermin patrol'has } \\
\text { been called to deal with crisis - fear as rats carry disease, cause house fires, etc. } \\
\text { no rat 'census' has ever been performed in Montreal, but there is an estimated 3-5 rats per person. } \\
\text { citizen role in rat control is to respect garbage by-laws. }\end{array}$ \\
\hline 2003.08 .16 & -.---. \\
\hline 2003.08 .17 & -..-. \\
\hline 2003.08 .18 & $-\cdots-.-$ \\
\hline 2003.08 .19 & -..... \\
\hline
\end{tabular}




\begin{tabular}{|c|c|}
\hline Date & Reference Information \\
\hline 2003.08 .20 & $\begin{array}{l}\text { Nelson, P., "Bat in toilet bowl startles N.B. family" in The New Brunswick Telegraph Journal. Al. } \\
\text { bat entered the home through a hole; became trapped and frightened family. Tested for rabies despite few } \\
\text { recent cases in New Brunswick. } \\
\text { Anon., "Bats cause fuss" in Montreal Gazette. A9. } \\
\text { +90 people are being vaccinated against rabies after bats were found in a hospital; only a precautionary } \\
\text { measure. }\end{array}$ \\
\hline 2003.08 .21 & -..-.- \\
\hline 2003.08 .22 & $\ldots$ \\
\hline 2003.08 .23 & $\begin{array}{l}\text { Anon., "Set Roxboro's felines free" in Montreal Gazette. A28/Opinion. } \\
\text { residents upset after leash laws put in place for cats; by-law meant to protect against property damage and help } \\
\text { prevent bird casualties. }\end{array}$ \\
\hline 2003.08 .24 & -..... \\
\hline 2003.08 .25 & $\begin{array}{l}\text { Funston, M., "Halton launches wildlife study; Recording flora, fauna in region's undeveloped area. Aim is to protect } \\
\text { environment as building continues" in Toronto Star. B07. } \\
\text { - } \quad \text { study is designed as } \$ 575,000 \text { over 2-years in Halton Region; involves government agencies at various levels } \\
\text { and environmental groups. Jill Dwyer, project coordinator. } \\
\text { comprehensive inventory of natural areas; information is to be used to help evaluate bordering development } \\
\text { plans. Will be similar to a study completed in Hamilton. }\end{array}$ \\
\hline
\end{tabular}




\begin{tabular}{|c|c|}
\hline Date & Reference Information \\
\hline 2003.08 .26 & $\begin{array}{l}\text { Block, S., "Bat dropped by for a snooze" in The Leader-Post (Regina). B1. } \\
\text { - } \quad \text { bat found outside Regina home and removed by animal control as a result of safety concerns. }\end{array}$ \\
\hline 2003.08 .27 & -...- \\
\hline 2003.08 .28 & $\begin{array}{l}\text { Nolan, K., "Kindness to wild animals can be repaid in bites" in Yukon News. p.24. } \\
\text { - Arizona Game \& Fish Department drafting action plan to stop wildlife feeding in the State; wild animals are } \\
\text { becoming more aggressive due to contact with humans and several bite incidents have been reported. } \\
\text { action plan will call for municipal by-law bans on wildlife feeding, increased public education, and wildlife } \\
\text { controls to be built into new development plans; will recognize the difference between intentional feeders of } \\
\text { wildlife and inadvertent feeders. }\end{array}$ \\
\hline 2003.08 .29 & -non.-. \\
\hline 2003.08 .30 & $\ldots$ \\
\hline 2003.08 .31 & End of Analysis. \\
\hline
\end{tabular}

